\title{
Technologies to Remove Selenium from Water and Wastewater
}

\author{
Eric Lichtfouse (D), Nadia Morin-Crini D, Corina Bradu, Youssef- \\ Amine Boussouga, Mehran Aliaskari, Andrea Iris Schäfer, Soumya Das, \\ Lee D. Wilson, Michihiko Ike, Daisuke Inoue, Masashi Kuroda, \\ Sébastien Déon (D), Patrick Fievet (D), and Grégorio Crini 1
}

\begin{abstract}
After major pollution by nitrates and pesticides, soils and groundwater in some parts of the world are now facing the emergence of a third major issue of selenium (Se) contamination. Selenium occurrence in ecosystems results naturally from weathering of Se-containing rocks, and is further aggravated by human activities. Selenium is ubiquitous in the environment, and the two main sources of human exposure by Se are food and water. Se, a metalloid, is an important micronutrient due to Se antioxidant, anti-inflammatory and chemo-preventative properties. At normal dietary doses, selenium is an essential diet element that has nutritional proper-
\end{abstract}

\footnotetext{
E. Lichtfouse ( $\square)$

Aix Marseille University, CNRS, IRD, INRA, Coll France, CEREGE, Aix-en-Provence, France

N. Morin-Crini · G. Crini $(\bowtie)$

Laboratoire Chrono-environnement, UMR 6249, UFR Sciences et Techniques, Université

Bourgogne Franche-Comté, Besançon, France

e-mail: nadia.crini@univ-fcomte.fr; gregorio.crini@univ-fcomte.fr

C. Bradu

Department of Systems Ecology and Sustainability, PROTMED Research Centre,

University of Bucharest, Bucharest, Romania

e-mail: corina.bradu@g.unibuc.ro

Y.-A. Boussouga $\cdot$ M. Aliaskari · A. I. Schäfer

Institute for Advanced Membrane Technologies (IAMT), Karlsruhe Institute of Technology (KIT), Karlsruhe, Eggenstein-Leopoldshafen, Germany

e-mail: youssef-amine.boussouga@kit.edu; aliaskari.mehran@kit.edu; andrea.iris.schaefer@ kit.edu

S. Das

Department of Geological Sciences, University of Saskatchewan, Saskatoon, SK, Canada

e-mail: soumya.das@usask.ca

L. D. Wilson

Department of Chemistry, University of Saskatchewan, Saskatoon, SK, Canada

e-mail: lee.wilson@usask.ca
} 
ties and is necessary to maintain good health in humans and animals. Nonetheless, exposure to high concentrations of selenium is harmful to living beings. In terms of contamination, selenium as an emerging hazardous substance is receiving particular attention in developing countries, where research is focussing on water treatment. Actual remediation techniques are limited because removing Se from complex mixtures of substances is very challenging. Yet, techniques of water decontamination are developing rapidly. Here, we review selenium occurrence, pollution, properties and remediation. Advanced remediation include technologies based on zero-valent iron, iron-oxy-hydroxides, supported materials, nanofiltration, reverse osmosis, enhanced ultrafiltration, electrodialysis, and activated granular sludge.

Keywords Selenium - Water - Wastewater - Removal technologies · Coprecipitation · Reduction techniques · Zero-valent iron · Metal oxides · Activated alumina $\cdot$ Activated carbon $\cdot$ Ion-exchange $\cdot$ Supported materials Membrane filtration $\cdot$ Electrodialysis $\cdot$ Activated granular sludge

\title{
3.1 Introduction
}

Sola dosis facit venenum - All things are poison, and nothing is without poison; only the dose determines what is not a poison. Paracelsus (1493-1541)

Metals and metalloids, and their organometallic derivatives are among the substances that present a recognized danger to humans and the environment. Metals and metalloids are part of our daily lives because they are used in a wide variety of products and applications. Due to their particular physical, chemical and biological properties, they have many industrial applications, e.g. in anti-corrosion coatings, stainless steel composition, electrical industry, pigment manufacturing, fruit fungicide manufacturing, construction, catalytic converters, alloy and semiconductor manufacturing, wood processing, glass manufacturing, catalysis, and cosmetology.

In the field of nutrition, certain metals and metalloids are also useful or even essential at trace levels for our health, contributing to the proper functioning of living organisms (Amiard 2011; Crini 2017; Hejna et al. 2018). However, these

\author{
M. Ike $\cdot$ D. Inoue \\ Division of Sustainable Energy and Environmental Engineering, Graduate School of \\ Engineering, Osaka University, Suita, Osaka, Japan \\ e-mail: ike@see.eng.osaka-u.ac.jp; d.inoue@see.eng.osaka-u.ac.jp \\ M. Kuroda \\ Graduate School of Environmental and Disaster Research, Tokoha University, \\ Suruga-ku, Shizuoka, Japan \\ e-mail: kuroda@sz.tokoha-u.ac.jp \\ S. Déon - P. Fievet \\ Institut UTINAM, UMR CNRS 6213, UFR Sciences et Techniques, Université Bourgogne \\ Franche-Comté, Besançon, France \\ e-mail: sebastien.deon@univ-fcomte.fr; patrick.fievet@univ-fcomte.fr
}


substances can also have negative impacts at individuals, population and ecosystem levels, resulting from their transport, transfer, bioaccumulation and biomagnification along the food chain. For example, metals such as iron, cobalt and zinc, are either essential for human health because they have a physiological role, or toxic in larger amounts or certain forms. Other substances have no biological function and can become toxic if they are absorbed in excess. Other substances such as cadmium, mercury, lead and arsenic are poisonous in their ionic form. This is the paradox of these contaminants, they are both useful and potentially dangerous. For these reasons, many metals and their derivatives are among the most monitored hazardous substances. Toxicity depends not only on concentration but also on speciation. For instance, many elements such as arsenic, chromium, nickel, manganese and vanadium, exist under several different oxidation states. Other elements such as mercury, tin, manganese and arsenic occur under different chemical forms. From a chemical and toxicological point of view, these substances are now well-known (Amiard 2011).

The intensive use of metals and metalloids by humans began with the Industrial Revolution more than 250 years ago (Crini and Lichtfouse 2018). From the beginning, this use began to affect the environment, and therefore our ecosystems. Their presence in different environmental compartments, e.g. water, soil and air, is mainly due to contamination generated by human activities, e.g. soil degradation. Yet there are also natural sources such as earth's crust elements, volcanic activities and natural biological activity. Anthropogenic sources of Se are numerous and varied, for instance: agricultural activities, e.g. fertilizing; industrial activities, e.g. mining and metallurgy; industrial discharges in water, soil and air; combustion by incineration for energy production, and transport activities (Rosenfeld and Beath 1964).

In Europe, in order to improve the quality of the environment and guarantee the health of populations, regulations have been gradually set up since the 1970s, particularly in the field of industrial waste (Crini and Badot 2007, 2010; Fordyce 2013; Crini 2017; Hejna et al. 2018). The objective was to reduce or eliminate emissions of targeted substances according to criteria of toxicity, persistence and bioaccumulation. Metals are now one of the most closely controlled classes of chemicals, classified as hazardous or priority hazardous substances. In Europe, currently, out of forty or so metals in the periodic table, the following twelve metals are subject to special monitoring, particularly for discharges and industrial wastes: aluminum, arsenic, cadmium, chromium, chromium, nickel, copper, tin, iron, manganese, mercury, lead and zinc. Considerable environmental efforts have been made by the industry over the past 30 years, yet metals and metalloids continue to be the subject of constant debate and concern.

Selenium is a subject of particular attention. Se is known as the "double-edged sword element" for its dual beneficial and toxic character to health (FernándezMartínez and Charlet 2009). Indeed, despite Se nutritional benefits, it is one of the most toxic natural elements. Selenium is ubiquitous in the environment and the two main sources of human exposure are food and water. This metalloid is an important micronutrient for living beings and an essential trace element of fundamental importance to health due to its nutritional and biological properties. At normal dietary doses, selenium is necessary to maintain good health in humans and animals. 
Indeed, Se deficiency is a major problem worldwide, with several cases of deficiency reported. However, exposure to high concentrations of selenium is harmful to living beings.

Overexposure and selenium deficiency have been associated with adverse health effects. In 1999, Peter M. Chapman, a world-renowned environmental toxicologist, asked the following question: is selenium a potential time bomb or just another contaminant? This issue highlights "the valuable but risky nature of this chemical element" (Chapman 1999). Over the past two decades, selenium has become a new substance of concern, not only for nutrition and medicine but also for water pollution (Hatfield 2001; Wu 2004; Fernández-Martínez and Charlet 2009; Santos et al. 2015; Vinceti et al. 2017, 2018a, b; Hejna et al. 2018; Ullah et al. 2018, 2019). As a consequence, research on selenium is developing in environmental science to study its presence, behavior, transfer, and bioaccumulation; in toxicology to assess toxicity and impact; and in water engineering to clean waters.

Selenium is naturally present and widespread in the environment. It is released by natural processes, including geological and geothermal activities, and human activities, e.g. mining, industry, and agriculture. Various parts of the world, especially in North America and in Europe, are experiencing issues of selenium contamination, especially in soils, aquifer sediments and groundwater (Wu 2004; Conley et al. 2009; DeForest et al. 2012; Fordyce 2013; Santos et al. 2015; Crini 2017; Di Marzio et al. 2019; Paul and Saha 2019). Living organisms can be exposed to selenium through Se presence in food and drinking water. Exposure to selenium also occurs when living beings come into contact with soil or air that contains selenium. The two main sources of selenium exposure are food, e.g. bread, cereals, nuts, fish, eggs and milk, and tap water (Rosenfeld and Beath 1964; Combs and Combs 1986; Combs 1988; Mayland 1994; Hatfield 2001; Reilly 2002; Fernández-Martínez and Charlet 2009; ANSES 2012; Bañuelos et al. 2014; Health Canada 2014; Santos et al. 2015; Crini 2017; Kieliszek 2019).

After pollution by nitrates and pesticides in some parts of the world like France face the issue of selenium pollution. Unlike most pesticides, selenium is mainly of natural origin (INERIS 2011; INRS 2011; OMS 2011; ANSES 2012; Health Canada 2014; Paul and Saha 2019). There are also anthropogenic sources of selenium in many industries including mining, petroleum refining and metallurgical activities. Other human activities such as the release of sedimentary construction waste rocks, irrigation and fossil fuel combustion also contribute to selenium contamination (Crini 2017). For drinking water, the World Health Organization has set a regulation limit of $40 \mu \mathrm{g} \mathrm{Se} / \mathrm{L}$, most European countries have set the regulation limit at $10 \mu \mathrm{g} / \mathrm{L}$, and the upper limit set by the United States Environmental Protection Agency is $50 \mu \mathrm{g} / \mathrm{L}$. However, the value of $10 \mu \mathrm{g} / \mathrm{L}$ is often exceeded in groundwater (Fordyce 2013; Santos et al. 2015; Crini 2017).

Today, we have reached the Pollutant Removal Age of the anthropocene, and there has been considerable efforts to develop technologies to reduce contaminant emissions (Crini and Lichtfouse 2018). The removal of selenium from water and wastewaters is of great interest in the field of water pollution. However, the problem is not simple because it is difficult to remove trace selenium from complex mixtures 
of substances. In its natural form as an element, selenium cannot be destroyed but it does have the ability to change of form. From a chemical point of view, due to their structure and stability, selenium forms are difficult to treat and often compete with other substances (BRGM 2011; Crini 2017). The removal of selenium from water and wastewater is controlled by Se speciation and the chemical composition of the water from the supply source. Treatment is also costly due to the characteristics of the aqueous solution and due to the strict discharge limits of selenium and its oxyanions such as Se(IV) and Se(VI) (Koren et al. 1992; Kapoor et al. 1995; Crini 2017; Stefaniak et al. 2018; Rene et al. 2019). Speciation of selenium in groundwater or in a raw effluents plays an essential role in the effectiveness of treatment methods used for Se removal, especially because selenium is often present at low concentrations, less than $1 \mathrm{mg} / \mathrm{L}$ (Fernández-Martínez and Charlet 2009; BRGM 2011; Santos et al. 2015). Most of the current research focuses on Se(IV) and Se(VI) removal, and an interesting challenge is the removal of the organic form of selenium. Like other many metalloids, selenium is difficult to remove, especially the oxyanion of $\mathrm{Se}(\mathrm{VI})$ present, for example, in mining effluents (Rene et al. 2019).

Two types of contaminated waters should be distinguished: waters to be treated for drinking, which usually contain less than $0.1 \mathrm{mg} \mathrm{Se} / \mathrm{L}$, and industrial waters that contain more than $1 \mathrm{mg} / \mathrm{L}$. In both cases effluents containing selenium are often associated with other substances and high salinity (Koren et al. 1992; Kapoor et al. 1995). As a consequence, the choice and effectiveness of a treatment process is influenced not only by the oxidation state of selenium, its concentration and the presence of other contaminants, but also by several other factors such as pre-existing treatment facilities and processes, treatment objectives, as well as waste treatment concerns, and costs.

Technologies available for the removal of selenium can be classified in chemical methods, e.g. coprecipitation, reduction-adsorption, oxidation-reduction, electrocoagulation, catalyzed cementation; physical treatments, e.g. adsorption, membrane filtration, ion-exchange; and biological methods such as microbial reduction, bacterial treatment, enzymatic reduction, fluidized bed reactor, algal assimilation and constructed wetlands (Koren et al. 1992; Kapoor et al. 1995; Sandy and DiSante 2010; Santos et al. 2015; Crini 2017; Rene et al. 2019).

For drinking water, local disposal solutions such as sand filtration coupled with ion exchange resins and membrane treatments, e.g. microfiltration and nanofiltration, show removal performances above 95\% (Crini 2017). However, such solutions are often poorly adapted, poorly selective and costly. Innovations are therefore needed to find treatment methods that are efficient, inexpensive, technologically feasible and environmentally friendly. Generally, in France, the solution consists either in asking the competent authorities for operating exemptions or, more often, in seeking another water resource.

For industrial-scale selenium removal, the first possible method is iron coprecipitation and adsorption, coupled, if necessary, with a coagulation-flocculation. Other treatments include reduction techniques, adsorption, e.g. using metal oxides, activated alumina or activated carbon; ion exchange; reverse osmosis and nanofiltration; showing 75-99\% removal efficiencies depending on selenium form. For 
drinking water production, lime softening (decarbonation) and reverse electrodialysis show lower removal, below $70 \%$. For the treatment of industrial effluents, a combination of physicochemical processes such as chemical reduction, coprecipitation, coagulation, adsorption, filtration is generally used (Rene et al. 2019). Biological techniques such as microbial reduction, aerobic wetlands and biochemical reactors can also be used. Adsorption on non-conventional materials, e.g. biosorbents, and innovative biological techniques such as microalgal-bacterial treatment, bioremediation, and phytoremediation are being explored (Crini 2017; He et al. 2018b). Among innovative treatments to removing selenium, one of the most promising approaches is fixed-bed biological treatment in terms of efficiency and cost. The next section present selenium chemistry, occurrence and decontamination methods from water and wastewater.

\subsection{Selenium Chemistry and Applications}

For more general information on selenium, the reader can consult a very interesting technical document, published in March 2014 by Health Canada of the Canadian Federal Department (Health Canada 2014; www.santecanada.gc.ca). Other comprehensive reports are given in OEHHA (2010), BRGM (2011) and ANSES (2012). Book references include Rosenfeld and Beath (1964), Combs and Combs (1986), Frankenberger and Benson (1994), Frankenberger and Engberg (1998), Hatfield (2001), Lemly (2002), Surai and Taylor-Pickard (2008), Reilly (2006), Woollins and Laitinen (2011), Preedy (2015), Crini et al. (2017), and van Hullebusch (2017).

\subsubsection{Selenium, a Metalloid}

Selenium (Se) belongs to the non-metallic family but is considered as a metalloid because selenium has properties of both metals and non-metals. This chemical element was identified as a new substance in 1817 by the Swedish chemist Berzelius in leaden chamber mud during sulfuric acid production. It was given the name selenium in resemblance after the Greek goddess of the moon "Selene", in homology to the chemically similar tellurium.

Selenium belongs to the elements of group 16 (chalcogens) of the periodic table, together with oxygen, sulphur, tellurium and polonium. Se has thus similar chemical and physical properties with these elements. Particularly, selenium displays a chemical behavior similar to sulfur, and as a result, Se is found associated with naturel sulfides, e.g. pyrite and chalcopyrite, mainly in trace concentrations. Selenium can conduct electricity or act as an insulator and display unipolar conductance of electricity. The most outstanding physical property of crystalline selenium is its photoconductivity. The gray, metallic form of Se is the most stable under ordinary conditions. This form has the unusual property of greatly increasing in 
electrical conductivity when exposed to light (Combs and Combs 1986; Simonoff and Simonoff 1991; White and Dubrovsky 1994; Frankenberger and Engberg 1998; Plant et al. 2003; Fernández-Martínez and Charlet 2009; Lide 2009; INERIS 2011; INRS 2011; Eklund and Persson 2014; Health Canada 2014).

Selenium has five redox states: -II, -I, 0, +IV and +VI (Table 3.1). There are also six stable selenium isotopes. Selenium speciation is complex because it exists in different oxidation states in nature, in both inorganic and organic forms, in solid, liquid and gas phase (Haygarth 1994). Biological transformations of selenium are manifold. In selenium-contaminated environments, a cocktail of different Se species may be present due to the variety of transformations, which poses a major challenge for the analysis of selenium speciation, and therefore the difficulty of choosing an appropriate method for selenium removal.

Elemental selenium $\mathrm{Se}(0)$ is present in nature as a non-soluble form. $\mathrm{Se}(0)$ occurs in different allotropic forms and may be amorphous or crystalline; seven different crystalline forms have been described. Se chemistry is complex, e.g. selenium can be mixed with sulfur in any ratio. Elemental selenium is precipitated after microbial reduction processes and also by inorganic processes. The oxidation states $\mathrm{Se}(-\mathrm{II})$ and $\mathrm{Se}(-\mathrm{I})$ are stable under strongly reducing conditions in metallic selenides and organic compounds (Table 3.1). The -II state is also present in nature as a product of microbial processes, e.g. $\mathrm{H}_{2} \mathrm{Se}$, and in metastable anions such as selenosulfate $\mathrm{SO}_{3} \mathrm{Se}^{2-}$, which is involved in the formation of metallic selenides. Volatile $\mathrm{H}_{2} \mathrm{Se}$ is an analogue to $\mathrm{H}_{2} \mathrm{~S}$ under strongly reducing conditions. Organic species include: volatile compounds formed upon bacterial methylation, e.g. dimethylselenide and dimethyldiselenide; products of microbial methylation processes, e.g. dimethylseleniumsufilde and dimethyseleniumdisulfide; selenocysteine present in organic tissues; selenomethionine in

Table 3.1 The different forms of selenium compounds

\begin{tabular}{|c|c|c|c|c|c|}
\hline Compound & $\begin{array}{l}\text { Oxidation } \\
\text { state }\end{array}$ & Form & $\begin{array}{l}\text { Solubility } \\
(\mathrm{g} / \mathrm{L})\end{array}$ & $\begin{array}{l}\mathrm{pKa}_{1} \text { and } \\
\mathrm{pKa}_{2}\end{array}$ & Example(s) \\
\hline Selenides & -II, -I & Inorganic & Insoluble & 3.8 and $14^{\mathrm{a}}$ & $\mathrm{H}_{2} \mathrm{Se}, \mathrm{SO}_{3} \mathrm{Se}_{2}^{-}$ \\
\hline $\begin{array}{l}\text { Elemental } \\
\text { selenium }\end{array}$ & 0 & Inorganic & Insoluble & & $\begin{array}{l}\text { crystalline trigonal } \\
\mathrm{Se}\end{array}$ \\
\hline Selenite $^{b}$ & $+\mathrm{IV}$ & Inorganic & $>850\left(20^{\circ} \mathrm{C}\right)$ & 2.7 and 8.54 & $\begin{array}{l}\mathrm{SeO}_{3}^{2-}, \mathrm{HSeO}_{3}^{-}, \\
\mathrm{H}_{2} \mathrm{SeO}_{3}\end{array}$ \\
\hline Selenate ${ }^{c}$ & $+\mathrm{VI}$ & Inorganic & $>840\left(20^{\circ} \mathrm{C}\right)$ & $\begin{array}{l}-2.01 \text { and } \\
1.8\end{array}$ & $\mathrm{SeO}_{4}^{2-}, \mathrm{HSeO}_{4}^{-}$ \\
\hline Selenium dioxide & $+\mathrm{IV}$ & Gas & & & $\mathrm{SeO}_{2}$ \\
\hline $\begin{array}{l}\text { Methylated } \\
\text { species }\end{array}$ & -II & Organic & & & $\left(\mathrm{CH}_{3}\right)_{2} \mathrm{Se}$ \\
\hline Selenomethionine & -II & Organic & & 1.56 and 9.5 & $\mathrm{C}_{5} \mathrm{H}_{11} \mathrm{NO}_{2} \mathrm{Se}$ \\
\hline Selenocysteine & -II & Organic & & $\begin{array}{l}2,5.2 \\
\text { and } 10\end{array}$ & $\mathrm{C}_{3} \mathrm{H}_{7} \mathrm{NO}_{2} \mathrm{Se}$ \\
\hline
\end{tabular}

${ }^{\mathrm{a}} \mathrm{H}_{2} \mathrm{Se}$

${ }^{b} \mathrm{Na}_{2} \mathrm{SeO}_{3}$

${ }^{\mathrm{c}} \mathrm{Na}_{2} \mathrm{SeO}_{4}$ 
plants; trimethylselenonium, an urinary metabolite; selenoproteins such as proteins and enzymes; and selenocyanate present in industrial wastewaters.

Table 3.2 compares the different forms of selenium from a chemical and geochemical point of view. Inorganic species of selenium $+\mathrm{IV}$ and $+\mathrm{VI}$ are soluble

Table 3.2 Main differences between the different forms of selenium from a chemical and geochemical point of view

\section{Elemental selenium}

- insoluble

- garlic smell in water

- mildly reducing

- colloidal: $1 \mathrm{~nm}$ to $1 \mu \mathrm{m}$

- red-color

- associated with natural organic matter

\section{Selenate}

- soluble

- not odiferous in water

- weakly adsorbed (outer-sphere)

- adsorption: surface hydroxyl group, oxyhydroxide charge

- net positive at lower $\mathrm{pH}$ : for anion adsorption

- net negative at higher $\mathrm{pH}$ : for cation adsorption

- two adsorption types: outer-sphere (weak ionic charge attraction - ionic strength, $\mathrm{pH}$ ), inner-sphere (strong covalent bonds - $\mathrm{pH}$ )

- low precipitation and adsorption capacities

- aqueous chemistry similar to that of sulfates

- low reduction kinetics

- microbial reduction to selenite and elemental selenium

\section{Selenides}

- soluble unless metals are present

- garlic smell in water

- precipitation

- strongly reducing

- may adsorb weakly

$-\mathrm{H}_{2} \mathrm{Se}$ toxicity

\section{Selenite}

- soluble

- not odiferous in water

- more strongly adsorbed (inner-sphere)

- reduction kinetics faster than selenate

- microbial reduction to elemental selenium and selenide

- reduced by organic acids

- more toxic than selenate

\section{Organic selenium}

- formed from biological activity, e.g. in plants, microorganisms

- some compounds are volatile 
selenite group : $\mathrm{SeO}_{3}{ }^{2-}$<smiles>[13CH3][13CH2][13CH3]</smiles>

selenate group : $\mathrm{SeO}_{4}{ }^{2-}$<smiles></smiles>

$\mathrm{Se}(\mathrm{VI})$

Scheme 3.1 Structures of selenite and selenate oxyanions, showing distances between Se and $\mathrm{O}$ atoms

oxyanions known as selenite and selenate, respectively (Scheme 3.1). Oxyanion selenite $\mathrm{SeO}_{3}{ }^{2-}$ has a $\mathrm{C}_{3 \mathrm{v}}$ symmetry with pyramidal shape which is reduced to $\mathrm{C}_{1}$ upon protonation. The oxidation state $+\mathrm{IV}$ also exists as gaseous selenium dioxide $\mathrm{SeO}_{2}$, which is present in volcanic eruptions and combustions processes. Selenite is a weak acid occurring as $\mathrm{H}_{2} \mathrm{SeO}_{3}, \mathrm{HSeO}_{3}{ }^{-}$and $\mathrm{SeO}_{3}{ }^{2-}$, depending upon $\mathrm{pH}$. Selenite is present in oil refinery wastewaters, for example. In the moderate redox potential range, selenite is the major species, and selenite mobility is governed by adsorption/ desorption processes on various solid surfaces including organic matter. Oxyanion selenate $\mathrm{SeO}_{4}{ }^{2-}$ has a $\mathrm{T}_{\mathrm{d}}$ tetrahedral symmetry, reduced to $\mathrm{C}_{3 \mathrm{v}}$ upon single protonation and to $\mathrm{C}_{\mathrm{s}}$ upon double protonation. This fully oxidized form exists in solution as biselenate $\mathrm{HSeO}_{4}{ }^{-}$or selenate $\mathrm{SeO}_{4}{ }^{2-}$ with a $\mathrm{pKa}_{2}$ of 1.8 . The doubly protonated species with $\mathrm{pKa}_{1}$ of -2.01 do not exist under natural conditions. Selenate species are predominant in waters, sediments and soils. Noteworthy, selenate has high solubility, low precipitation and adsorption capacities, and the aqueous chemistry of selenate and sulfate are quite similar (Fordyce 2007).

The inorganic forms selenate and selenite are the two most common oxyanions in water, due in particular to their high solubility (White and Dubrovsky 1994). For example, these two most oxidized species are frequently encountered in surface waters and are transported mostly in particulate-associated form. Both oxyanions display a high bioavailability and bioaccumulation potential (Sharma et al. 2015).

\subsubsection{Industrial Applications of Selenium}

In the industry, selenium is considered as a rare metal with many and varied applications. The most important applications are electronics, optoelectronics, glass, metallurgy, chemistry, pigments and nutrition (Surai and Taylor-Pickard 2008; Bañuelos et al. 2014; Gu et al. 2019; Zhu et al. 2019). These industries require only small quantities of Se. In addition, despite numerous applications, selenium currently competes in industry with other elements such as silicon, germanium, sulfur and tellurium. For example, many photocell applications using selenium are replaced by 
other devices using elements that are more sensitive and more readily available than selenium.

Due to its photovoltaic, photoconductive and photosensitive properties and its ability to transform light into electricity, selenium is used extensively in electronic and electrical industries, mainly in rectifiers for electroplating, and in photoelectric cells (Zhu et al. 2019). Below its melting point, Se is a semiconductor, a property highly sought-after in the electronics sector. Other uses include metal alloys such as lead plates used in storage batteries, light meters, solar cells, detectors, colorimeters, photographic photosensitizers, photocopiers, and semiconductors ( $\mathrm{Gu}$ et al. 2019; Zhu et al. 2019). Rechargeable metal batteries using selenium or selenide as cathodes have attracted considerable attention during the past few years because selenium/selenide possess a high volumetric energy density that is comparable to that of sulfur, and a moderate output voltage (Gu et al. 2019). Various other devices such as alarm devices, mechanical opening and closing devices, safety systems, and television rely on properties of selenium. Selenium is widely used in photocopying, xerography to copy documents, e.g. photographic toner, toning of photographs, and in sound films. For example, Se is used artistically to intensify and extend the tonal range of black and white photographic images.

The second major application of selenium is in the glass industry. Here, Se is used to decolorize glass by neutralizing the glass greenish tinge caused by ferrous impurities. Selenium is also added to glass to reduce the transmission of solar heat. As a red pigment, Se is used to make ruby-red colored glasses and enamels for ceramics and steel ware. For example, selenium imparts to glass a clear red color that is useful in signal lights. Se is used in the paint, plastic and ceramic industries to produce stains and dyes. Selenium is also used as an additive to stainless steel, e.g. to control porosity in stainless-steel castings. The third main use is sodium selenite for animal feeds and food supplements.

Selenium and derivatives are also used in the manufacture of many chemicals such as pigments, reducing agents, parasiticides, bactericides, insecticides, fertilizers, fungicides, herbicides, lubricating oils and solvents; they are also used in metallurgical applications, and in the military field. Selenium pigments are used to color many products such as plastics, paints, inks, glass, enamels and rubber. Selenious acid is used in the steel industry as an etchant. Selenium find applications as lubricants for metal polishing and is replacing lead in brass alloy plumbing fittings. Selenium serves for the vulcanization of rubber to increase resistance to abrasion; here selenium diethyldithiocarbonate acts as an accelerator and vulcanizing agent. In the rubber industry, Se also promotes resistance to heat and oxidation, and increases the resilience of rubber. Selenium is used as a paint and varnish remover, and as a solvent for rubber resins and other organic substances. Selenium catalysts, due to their high efficiency, moderate reaction conditions, good functional compatibility and excellent selectivity, have attracted a lot of interest over the past two decades as recently discussed by Shao et al. (2019).

Finally, selenium find applications in pharmaceuticals where selenium sulphide is used as a catalyst, and in cosmetology and agriculture. Selenium has been applied in producing cortisone, and radioactive selenium has been utilized in radiography. 
Nanoparticles containing selenium were proposed for the diagnosis and therapy of Alzheimer's disease (Gupta et al. 2019), and as biosensors for detection of biological targets (Gandin et al. 2018). Selenium sulfide and other selenium-based compounds are added to anti-dandruff shampoos. As fungicide, Se is used in the manufacture of deodorant. Selenium is also used as a protective agent against pests. Mechora (2019) recently summarized pest control by selenium. Selenium can repel pests, reduce their growth, or cause toxic effects while having a positive effect on plant growth. Accumulated selenium in plants protects plants against aphids, weevils, cabbage loopers, cabbage root flies, beetles, caterpillars, and crickets due to both deterrence and toxicity. Mechora (2019) concluded that the use of selenium can be an alternative pest management method to conventional plant protection products that pose environmental and health problems.

Further developments are expected in the near future in the following domains: cancer prevention and therapy (Gandin et al. 2018; Sayehmiri et al. 2018; Tan et al. 2019b), biomedical, imaging and detection (Gandin et al. 2018; Gupta et al. 2019), designing selenium functional foods and beverages (Adadi et al. 2019), and agrochemistry (Garduño-Zepeda and Márquez-Quiroz 2018; Mechora 2019). Selenium has most probably a protective role against the development of prostate cancer, and therefore selenium supplementation is suggested for prevention of prostate cancer (Sayehmiri et al. 2018). Selenium supplementation also yielded promising results concerning radioprotection in tumor patients and should be considered as a promising adjuvant treatment option in subjects with a relative selenium deficit (Muecke et al. 2018). The agronomic and genetic biofortification of crops with selenium are novel strategies to improve the nutraceutical quality of staple crops. Biofortification with selenium in agricultural crops is increasingly becoming a solution to solve trace element deficiency in the human population, as well as to increase the content of bioactive compounds (Garduño-Zepeda and Márquez-Quiroz 2018).

\subsubsection{Selenium in the Environment}

Selenium has been found in all environmental compartments of the Earth, including the atmosphere, geosphere, hydrosphere and biosphere, due to the presence of both natural, e.g. alteration and leaching of the earth's crust, volcanism, and anthropogenic processes such as fossil fuel combustion and mining (Sharma et al. 2015). Se is found in the environment in both inorganic and organic forms, it is generally present in selenide, selenite or selenate forms, and more rarely in the elemental state (Shrift 1964; Rosenfeld and Beath 1964; Combs and Combs 1986; Combs 1988; Ihnat 1989; Frankenberger and Benson 1994; Frankenberger and Engberg 1998; Lemly 2002, 2004; Plant et al. 2003; Fernández-Martínez and Charlet 2009; Chapman et al. 2010; Bañuelos et al. 2014; Pettine et al. 2015; Sharma et al. 2015; Wu and Sun 2016; Donner et al. 2018; Kumkrong et al. 2018; LeBlanc et al. 2018; Etteieb et al. 2020).

Selenium concentrations in natural waters is a subject of intense interest (Sharma et al. 2015). Selenium in groundwater is of both natural, e.g. from inputs such as soil 
leaching, or anthropogenic origin, e.g. industrial emissions, metal refining and coal combustion. Inorganic forms of selenate and selenite and organic species such as mono- and dimethylated derivatives have been reported in aquatic systems, the two common forms being oxyanions (White and Dubrovsky 1994; Lemly 2002; Fernández-Martínez and Charlet 2009; Chapman et al. 2010; Sharma et al. 2015). However, the valence states of the selenium in water are still poorly known and few studies have been published on transformations of selenium species in aqueous systems (Sharma et al. 2015; Pettine et al. 2015; Wu and Sun 2016; Donner et al. 2018). This depends on Se origin, e.g. natural leaching of soils or industrial discharges.

Due to their high solubility, oxyanions are mobile in soils, which explains their presence in some catchment areas. Due to rock erosion, selenium also enters inland waters and oceans. Selenate and selenite can be found in fresh and salt waters. Therefore, not only drinking water play an important role in human exposure to selenium but also the oceans via seafood (Fernández-Martínez and Charlet 2009; Santos et al. 2015). The global average concentration of selenium in freshwater is $0.02 \mu \mathrm{g} / \mathrm{L}$ and less than $0.08 \mu \mathrm{g} / \mathrm{L}$ in seawater. Groundwater generally contains higher selenium levels, from a few $\mu \mathrm{g} / \mathrm{L}$ to more than $50 \mu \mathrm{g} / \mathrm{L}$, than surface water due to contact with rocks (Fernández-Martínez and Charlet 2009; Santos et al. 2015). In industrial wastewater, concentrations are much higher (Crini 2017).

The bioavailability, mobility and reactivity of selenium in waters are also determined by Se speciation. Selenium speciation is controlled by physical processes, e.g. adsorption effects of soil and sediments; chemical processes, e.g. pH, redox conditions, organic matter, and presence of competitive ions; and biological processes, e.g. bacterial transformations. In natural waters of $\mathrm{pH}$ 6-9, under oxidizing conditions, $\mathrm{Se}(\mathrm{VI})$ is predominant in a divalent ionic form, i.e. the selenate anion $\mathrm{SeO}_{4}{ }^{2-}$. $\mathrm{Se}(\mathrm{IV})$ is the most frequent form encountered under reducing conditions; the hydrogenoselenite ion $\mathrm{HSeO}_{3}{ }^{-}$being the dominant form below $\mathrm{pH}$ 8.15. At a $\mathrm{pH}$ above 8.15, the divalent selenite anion $\mathrm{SeO}_{3}{ }^{2-}$ is the dominant form. Insoluble reduced species such as elemental selenium and selenides are generally released as colloidal suspensions into surface waters. The organic forms of selenium found in natural waters are produced by microbiological assimilation and degradation (Ivanenko et al. 2018). A comprehensive discussion on the chemistry and biogeochemistry of selenium in terms of variation of $\mathrm{pH}$ and redox conditions can be found in the reviews by Fernández-Martínez and Charlet (2009) and by Sharma et al. (2015).

\subsubsection{Selenium and Industrial Emissions}

Selenium in water also come from anthropogenic sources such as mining, oil refining, agricultural irrigation and discharges from industries producing and using selenium compounds (Crini 2017; Dinh et al. 2018; Donner et al. 2018; Tabelin et al. 2018). Mining and metal refining (copper), coal mining and fossil fuel combustion in coal-fired power plants are industrial sectors particularly affected by selenium releases (Plant et al. 2003; Wen and Carignan 2007; Fernández-Martínez and Charlet 2009; BRGM 2011; Health Canada 2014; Santos et al. 2015). These Se 
releases are mainly responsible for the migration of selenium to different compartments of the environment. In mining wastewaters, selenium is found at concentrations from $3 \mu \mathrm{g} / \mathrm{L}$ to more than $12 \mathrm{mg} / \mathrm{L}$. Wastewater resulting from flue-gas-desulfurization contains selenium at a typical concentrations of $1-10 \mathrm{mg} / \mathrm{L}$ (Santos et al. 2015). Other contaminated wastewaters such as coal mining pond water, uranium mine discharges, gold mine effluent, petroleum industry wastewater and lead smelter wash water also contain significant levels of selenium. Other human activities such as agricultural irrigation can also promote corrosion of selenium-bearing iron rocks, thus leaching selenium into aquifers as soluble oxyanions of $\mathrm{Se}(\mathrm{IV})$ and $\mathrm{Se}(\mathrm{VI})$. Selenium is also present in sewage treatment plants, mainly in sludge (Crini 2017).

\subsection{Selenium and Water: A Substance of Concern?}

Selenium is ubiquitous in the environment. Life is exposed to selenium through Se presence in soil, air, water and food, the two latter being the major sources of human exposure (Rosenfeld and Beath 1964; Combs and Combs 1986; Combs 1988; Reilly 2002; Fernández-Martínez and Charlet 2009; ANSES 2012; Fordyce 2013; Health Canada 2014; Santos et al. 2015; Donner et al. 2018). In Canada, food is recognized as the main source of selenium, while in France this is debated (Crini 2017).

Nowadays, it is widely recognized that selenium is both essential to human health and toxic in high quantities or in certain forms (Mayland 1994; Amiard 2011; Chauhan et al. 2019; Ibrahim et al. 2019; Kieliszek 2019; Varlamova and Maltseva 2019). Humans need to absorb small amounts of selenium daily in order to maintain good health and to prevent diseases, and food usually contains enough selenium because Se is naturally present in cereals, breads, nuts, fish, eggs, milk, meat, crab and tuna (Combs 1988; Mayland 1994; Hatfield 2001; Surai and Taylor-Pickard 2008; Amiard 2011). Selenium is essential to human health and should be present in the diet of all age groups to provide an adequate intake because Se is a key component of amino acids, e.g. selenocysteine and selenomethionine in selenoproteins found in all forms of life (Cai et al. 2019; Ibrahim et al. 2019; Varlamova and Maltseva 2019). In adults and teenagers, Se daily needs are estimated at 50-200 $\mu \mathrm{g} /$ day while in children they range from 30 to $120 \mu \mathrm{g}$ /day. The water consumed also provides selenium (Reilly 2002; Crini 2017; Kieliszek 2019). However, despite Se nutritional benefits, it is one of the most toxic natural elements, and therefore particularly followed from a regulatory point of view.

In the field of water pollution, a worldwide problem is the presence of selenium in drinking water, groundwater and wastewater. Although benefits and toxicity of selenium are known, the levels considered to represent a threat to humans and environment are not yet well established (Fordyce 2013; Santos et al. 2015). For drinking water, according to European standards (Directive 98/83, European Commission, EU 1998) and Canadian water quality guidelines (Kwon et al. 2015), the selenium threshold should not exceed $10 \mu \mathrm{g} / \mathrm{L}$, while the upper limit set by the United State Environmental Protection Agency USEPA $(2004,2016)$ is $50 \mu \mathrm{g} / \mathrm{L}$. The EU has 
revised the drinking water directive on 16 December 2020 for total selenium which is now $20 \mu \mathrm{g} / \mathrm{L}$ (https://eur-lex.europa.eu/legal-content/EN/TXT/PDF/?uri=CELE $\mathrm{X}: 32020 \mathrm{~L} 2184 \&$ from=EN). Standards are also different in other countries: $50 \mu \mathrm{g} / \mathrm{L}$ (class 2) or $20 \mu \mathrm{g} / \mathrm{L}$ (class 1) for South Africa, and $10 \mu \mathrm{g} / \mathrm{L}$ for Australia and New Zealand. Regulatory wastewater discharge standards for selenium also vary from country to country. There is a lack of clarity in national, European and international regulations concerning selenium (Fordyce 2013; Santos et al. 2015; Crini 2017; Kumkrong et al. 2018; LeBlanc et al. 2018).

In France, various departments such as Seine-et-Marne, Essonne, Loiret, Vienne and Marne have selenium issues because rocks and soils are naturally rich in selenium are concerned. The quality limit for selenium in tap water intended for human consumption is $10 \mu \mathrm{g} / \mathrm{L}$ according to the Code de la Santé Publique (Public Health Code, Order of 11 January 2007). However, this value is exceeded in several regions for certain drilling waters (AFSSA 2007; Vilaginès 2010). In some seleniferous areas, natural water concentrations can reach values of $50-300 \mu \mathrm{g} / \mathrm{L}$ (Vilaginès 2010). Over the past ten years, French public authorities have thus taken on the dimension of the selenium phenomenon (Crini 2017). A French Mayor must request an operating derogation if the selenium content is $10-40 \mu / \mathrm{L}$, with a restriction on use, particularly for children under 4 years of age if the content exceeds $20 \mu / \mathrm{L}$. This three-year derogation must allow time to provide a technical solution to this excess of selenium. Many cities are waiting for the standard to be raised because treatment would be very expensive. L'Agence Nationale de Sécurité, The National Health Security Agency, has set the value at $30 \mu \mathrm{g} / \mathrm{L}$ in October 2012 without any consumption restrictions. For several years, the World Health Organization has also recommended changing the threshold from 10 to $40 \mu \mathrm{g} / \mathrm{L}$, it has provisionally set the value at $40 \mu \mathrm{g} / \mathrm{L}$ in 2011. To solve the problem of selenium in drinking water, some American regions have chosen to mix water to reduce material requirements and costs, others have chosen low selenium supply sources or to remove excess selenium using treatment processes in public distribution systems or at home (Crini 2017).

For industry, selenium is also considered as an emerging hazardous substance. In Europe, the release of selenium-contaminated water into the environment through industrial processes is currently a regulatory, environmental and health concern (Crini 2017).

\subsection{Methods to Remove Selenium from Water}

\subsubsection{Main Treatment Methods}

There is actually no single method to ensure adequate treatment, and, in practice, a combination of different methods is used to achieve the targeted water quality in the most economical way; for example, achieving residual concentrations below the European Union regulation limit of $10 \mu \mathrm{g} / \mathrm{L}$ for drinking water. Selenium removal methods are classified into three categories: chemical, biological and physical 


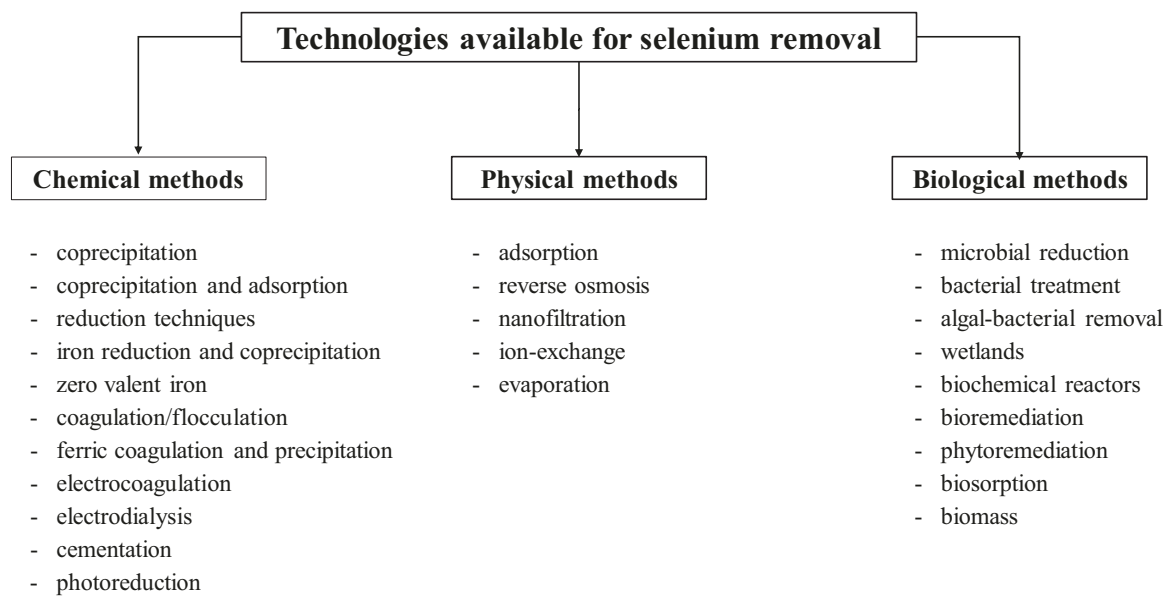

Fig. 3.1 Classification of the technologies for selenium removal

technologies (Fig. 3.1, Koren et al. 1992; Twidwell et al. 1999; Shamas et al. 2009; Sandy and DiSante 2010; Moore and Mahmoudkhani 2011). Technologies can also be classified into conventional methods, e.g. coprecipitation, reduction-adsorption and oxidation-reduction; established removal processes, e.g. adsorption, ionexchange, membrane filtration, and emerging removal methods such as fluidized bed reactors, algal-bacterial removal and catalyzed cementation (Crini 2017). Nonetheless, only few methods are commonly used by the industry, mainly for economic reasons. In general, the removal of contaminants from effluents is done by chemical and biological means, with research focusing on effective and less costly combinations. Table 3.3 summarizes advantages and disadvantages of the main technologies for the treatment of selenium-contaminated water and industrial wastewater.

\subsubsection{Coprecipitation}

The main technology used at the industrial scale to remove metals and metalloids from wastewaters is direct precipitation. However, selenium is difficult to precipitate because it is mainly found in the form of oxyanions in wastewaters, which are highly soluble and perfectly stable (Plotnikov 1960). In addition, similar to selenocyanate, selenite and selenate may also form a variety of stable complexes with several transition metals.

One solution is to use iron coprecipitation coupled, if necessary, with a coagulation-flocculation step (Fig. 3.2). This technology is also known as ferrihydrite adsorption and some authors mention a double technology: coprecipitation and adsorption (Merrill et al. 1986, 1987; MSE 2001; Twidwell et al. 2005; Gingerich 


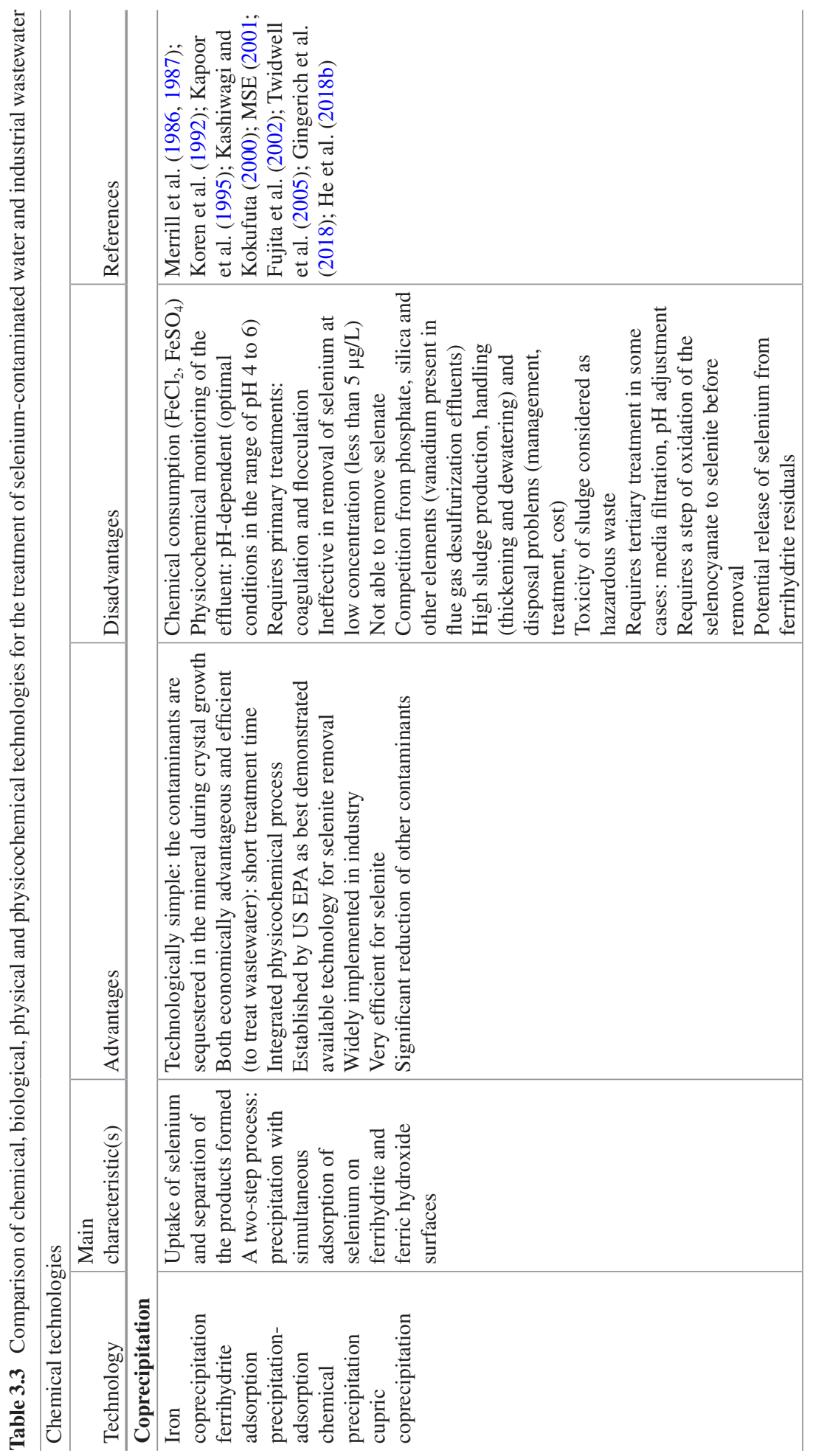




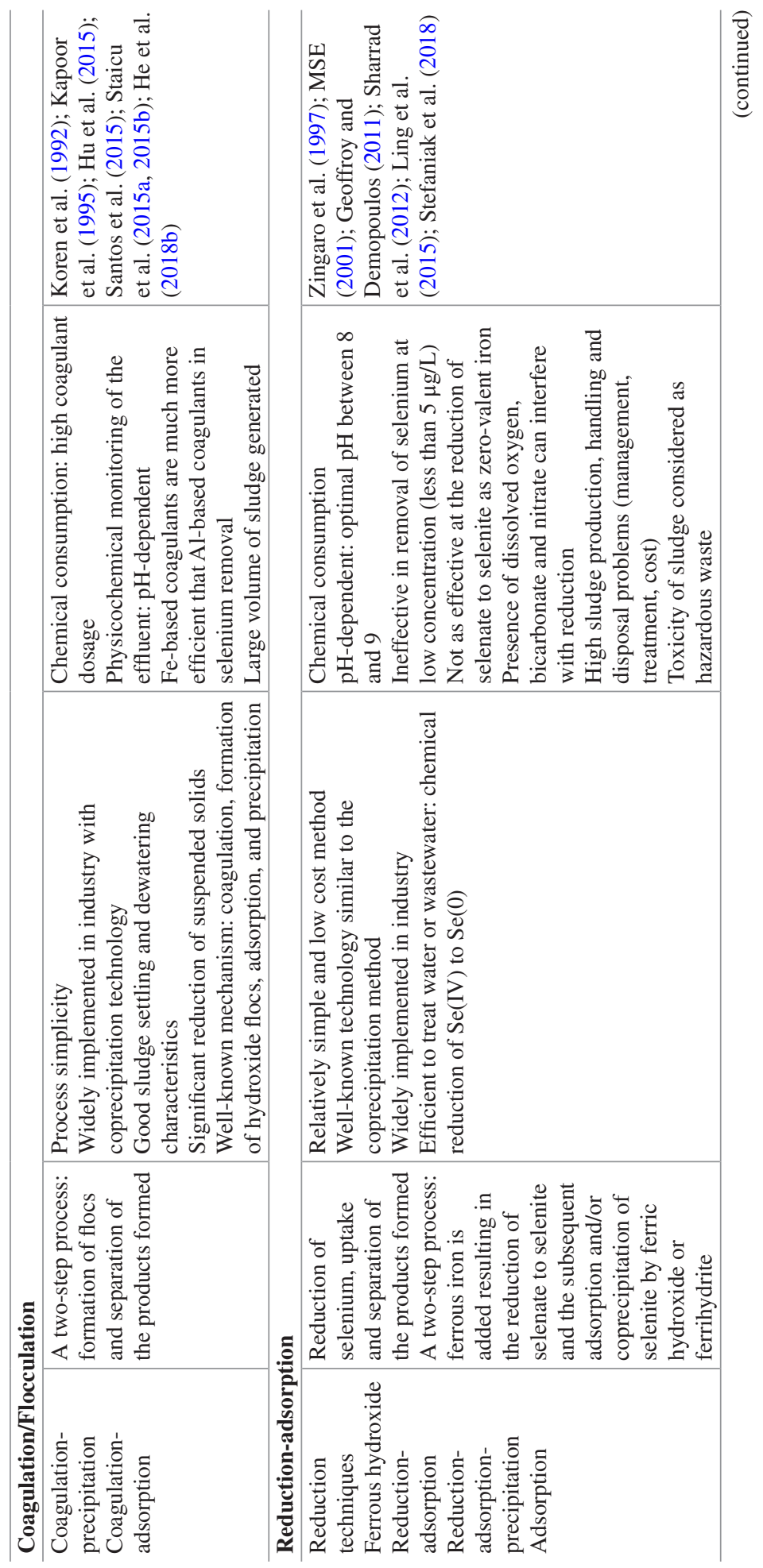




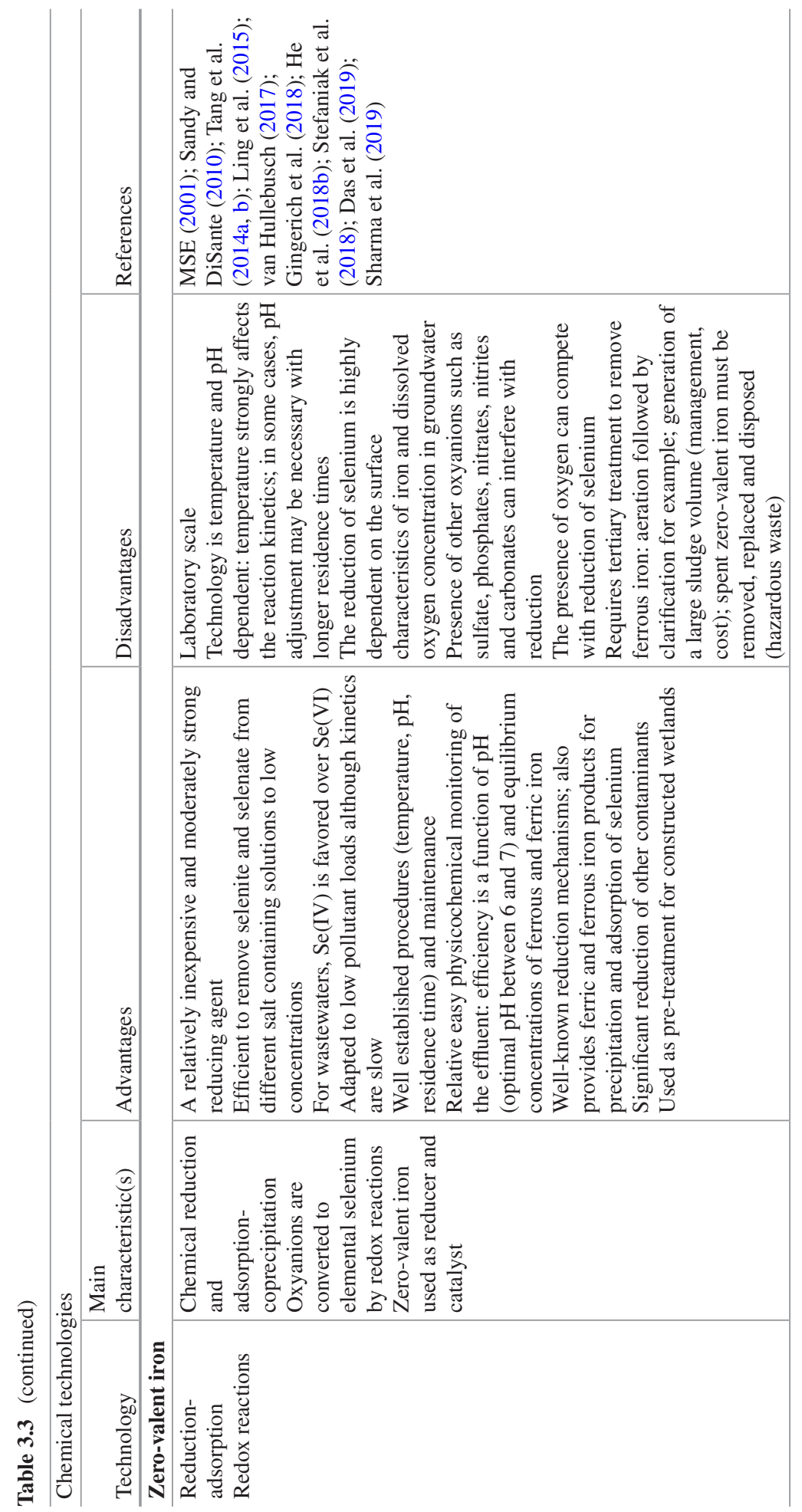




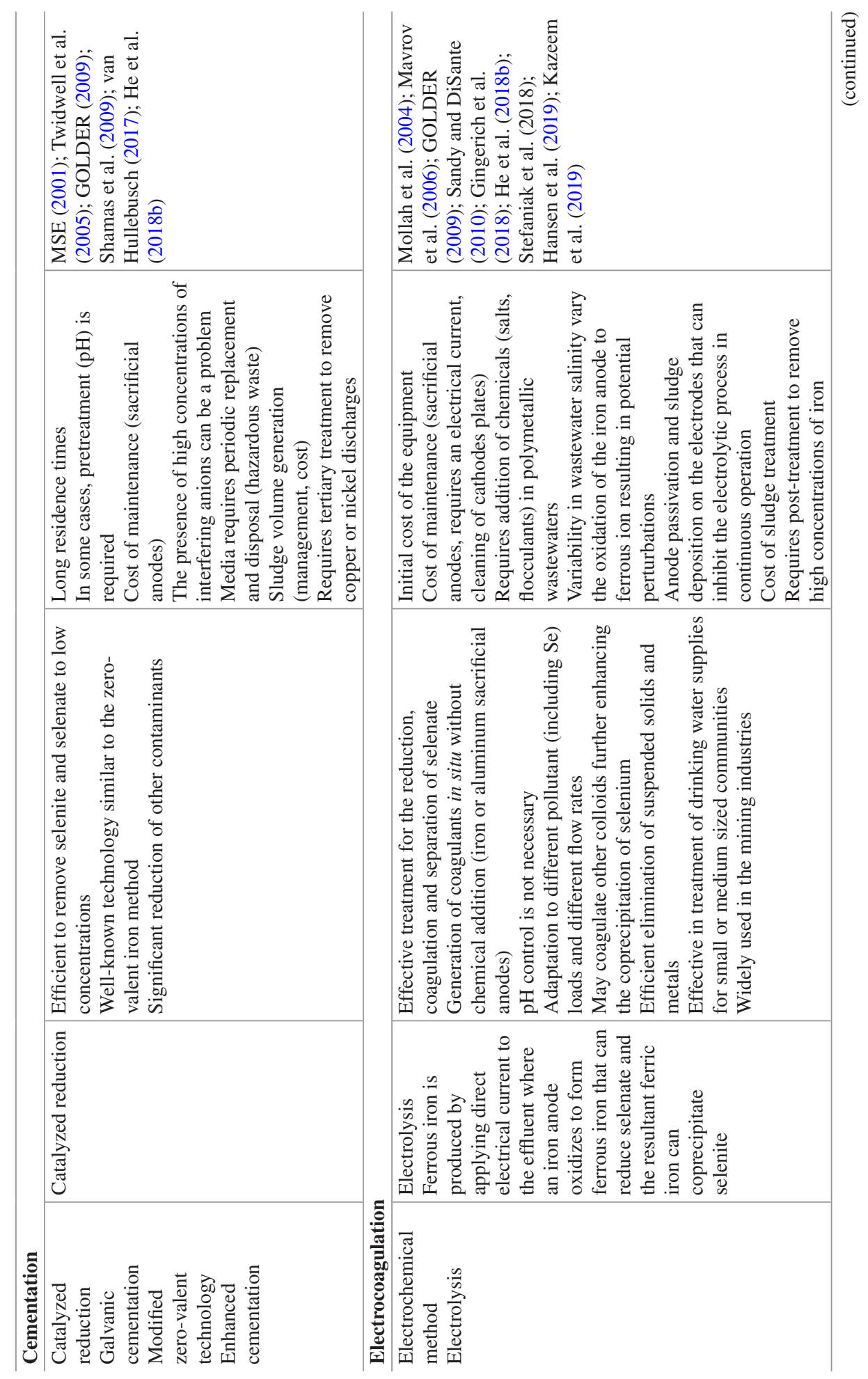




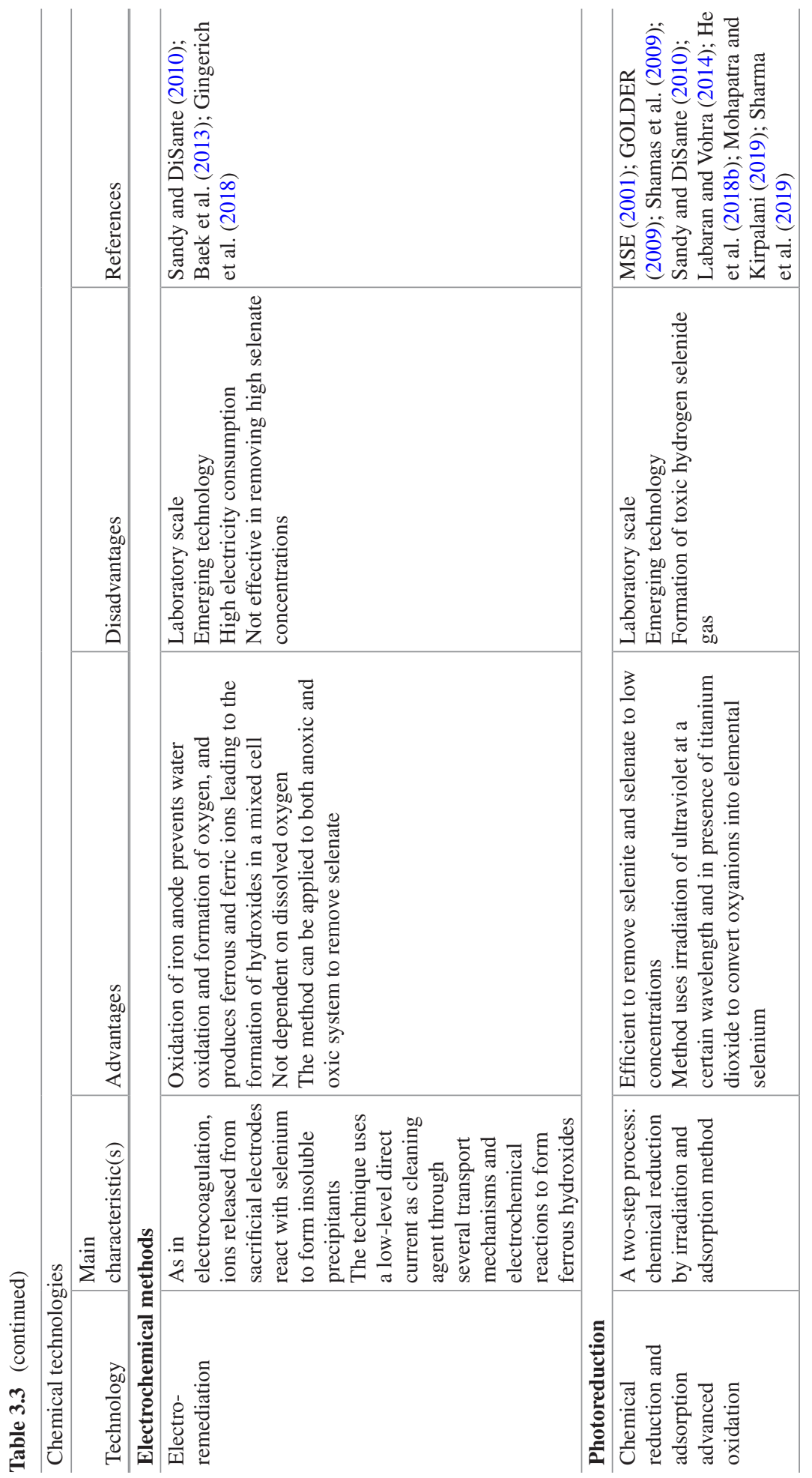




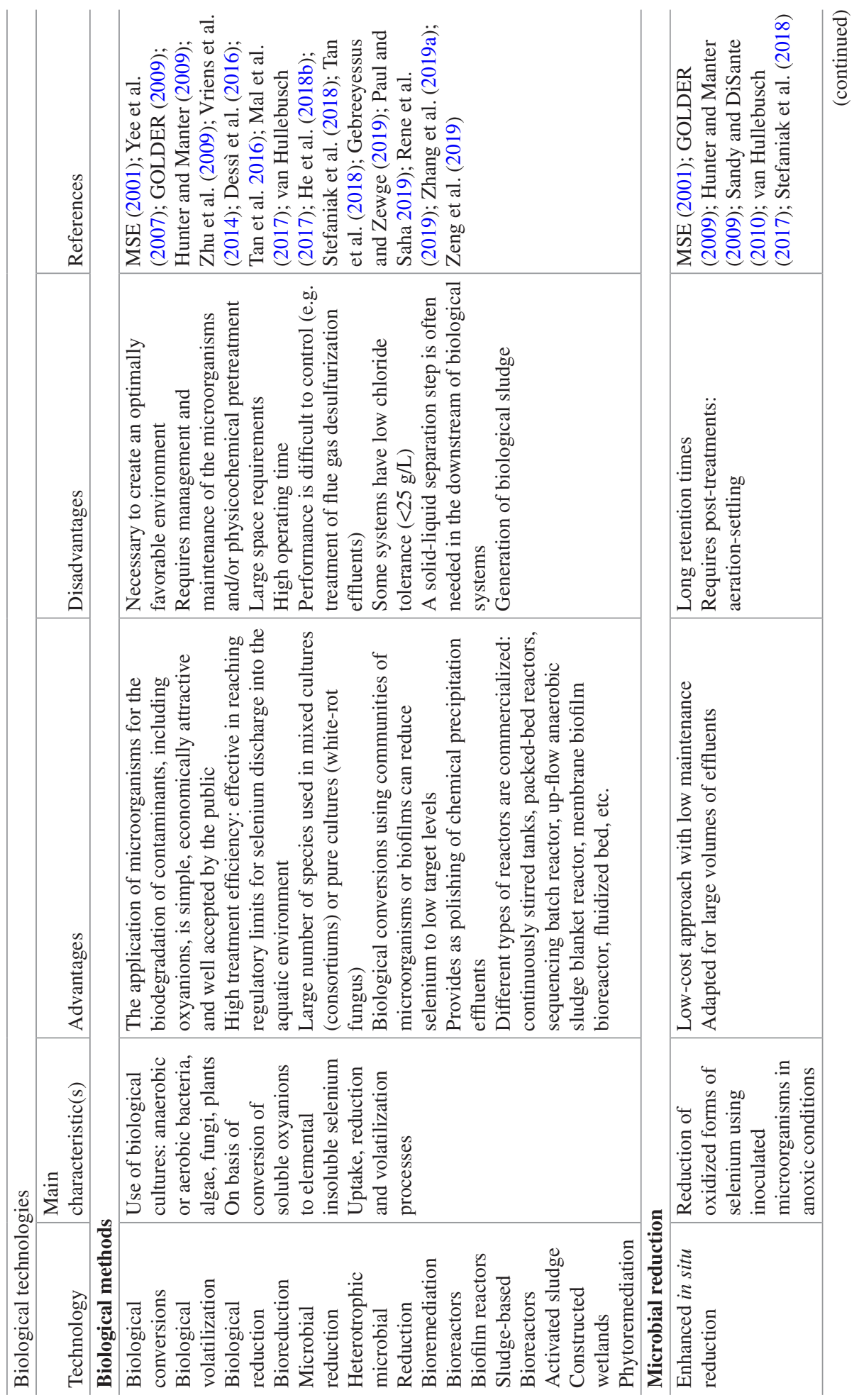




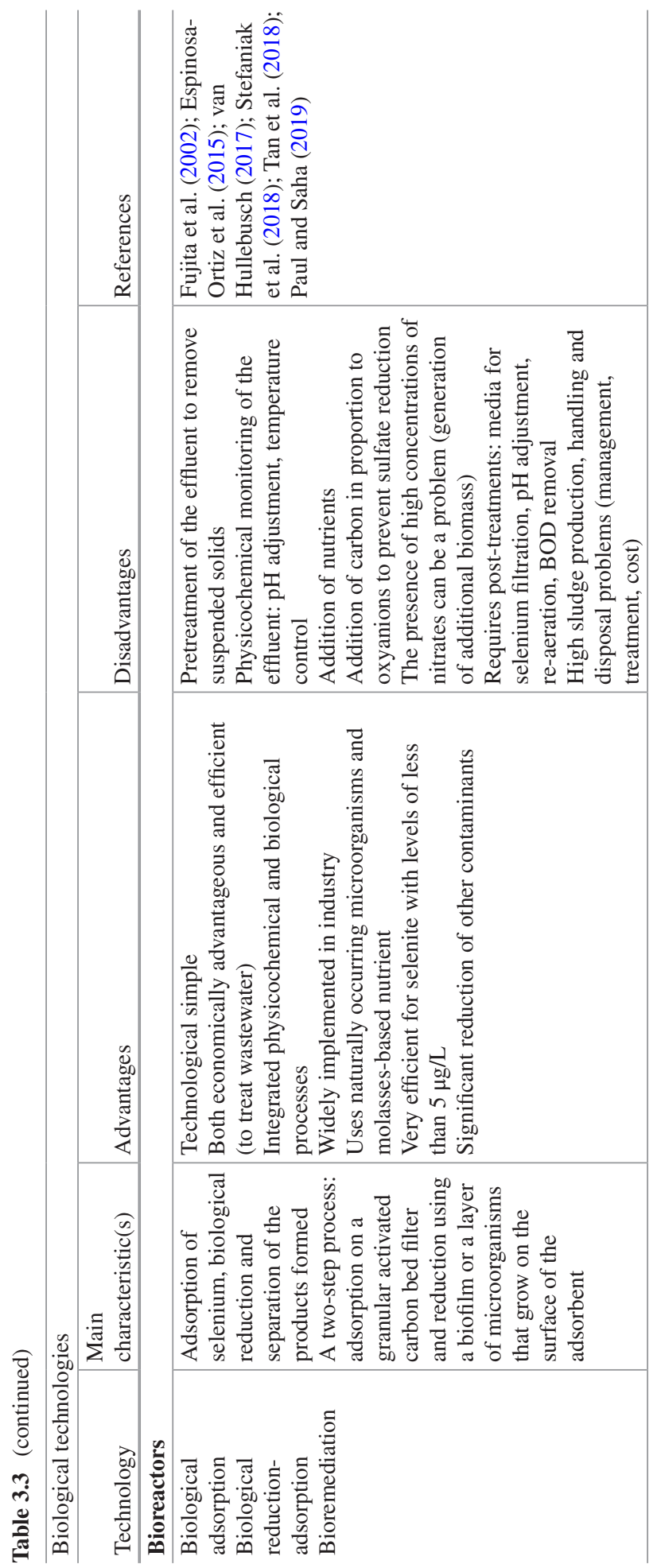




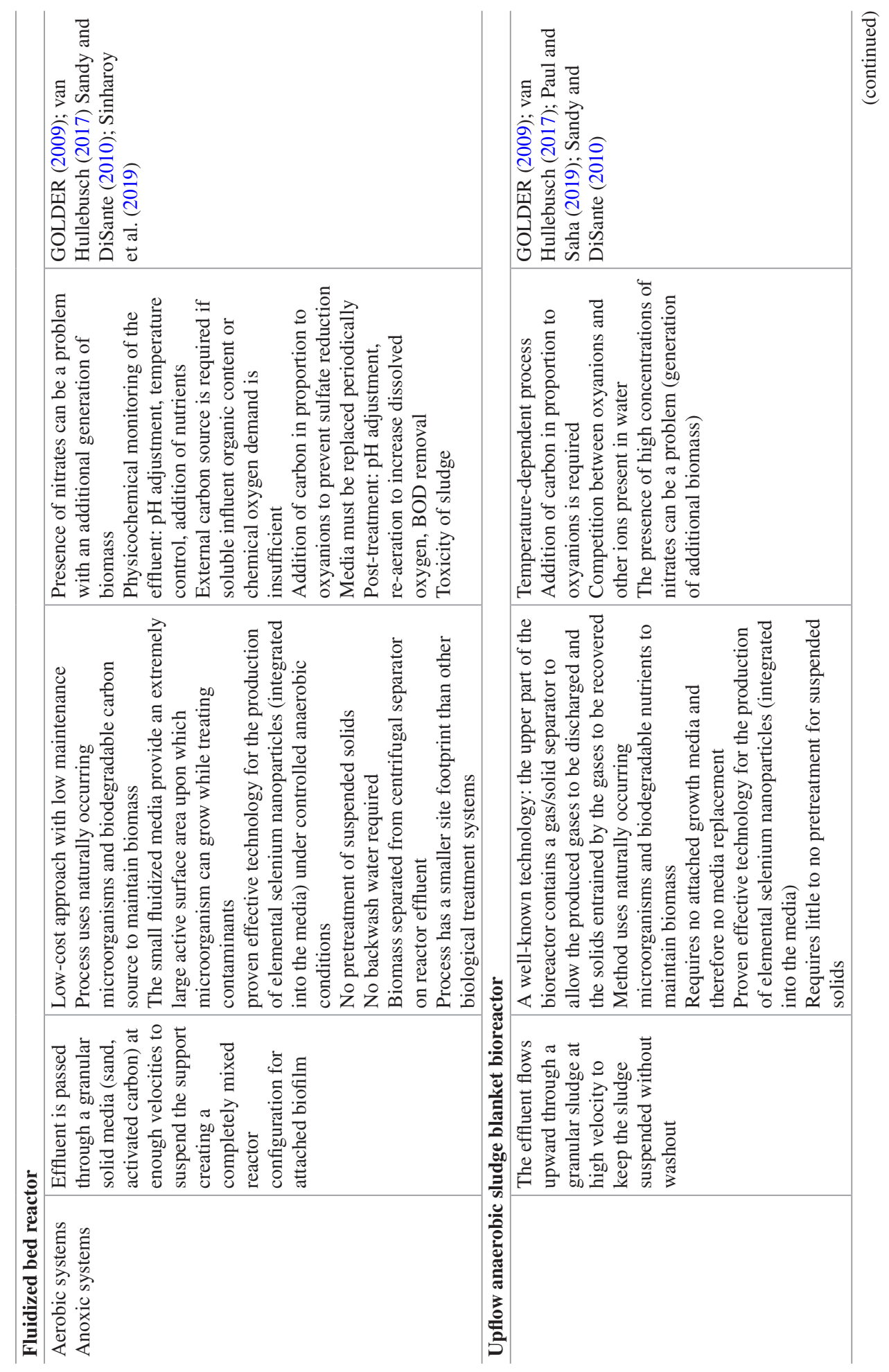




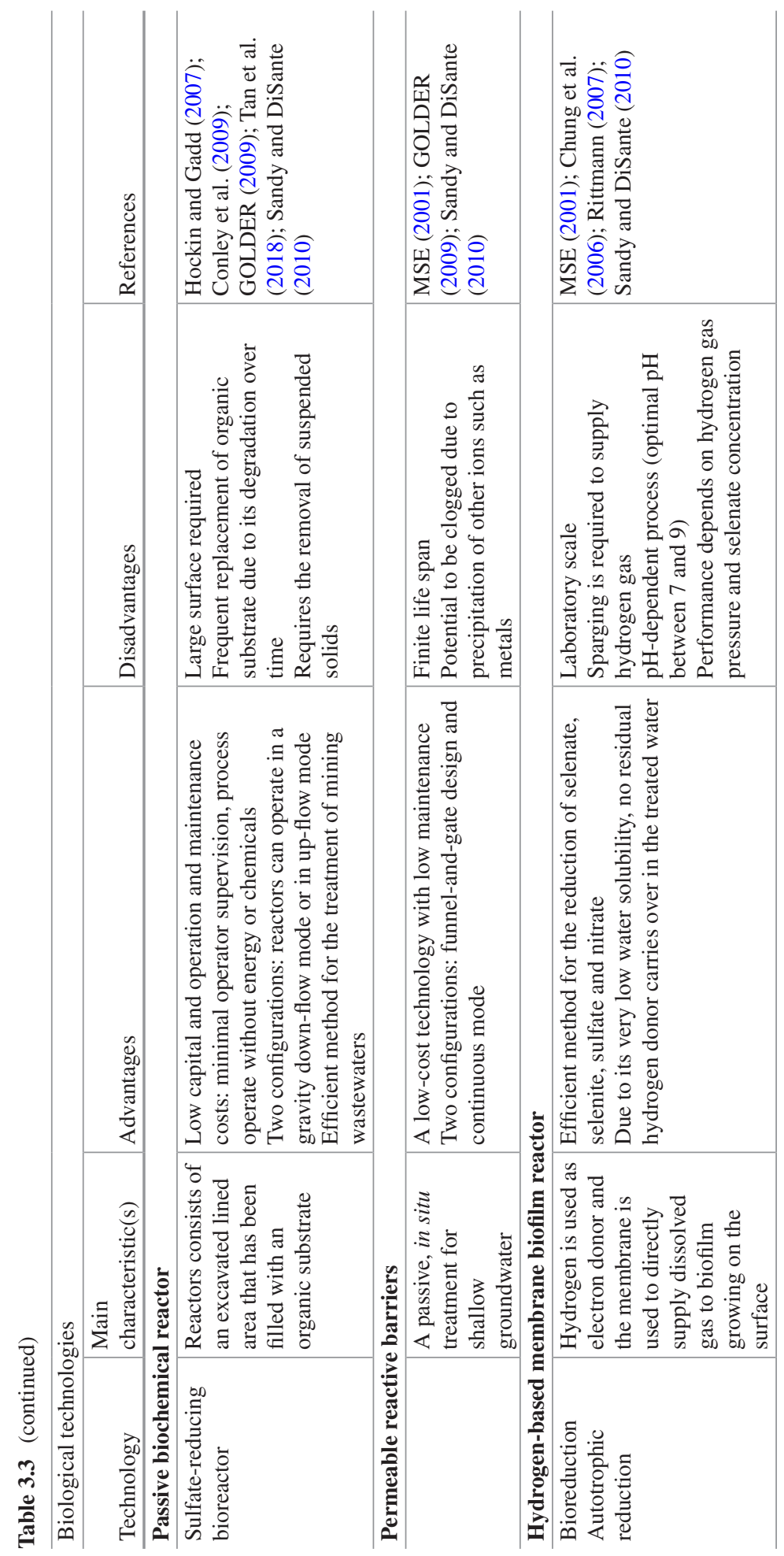




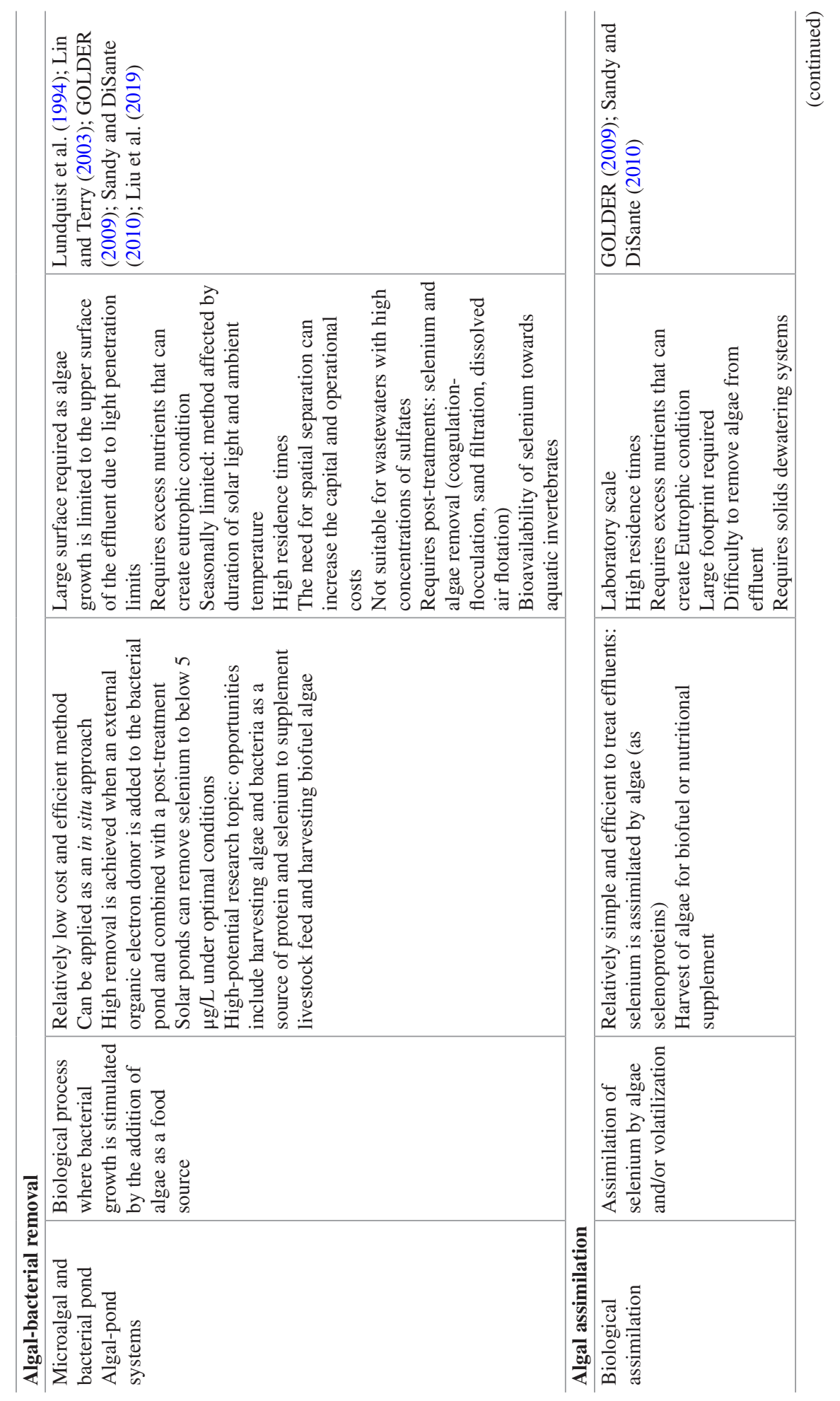




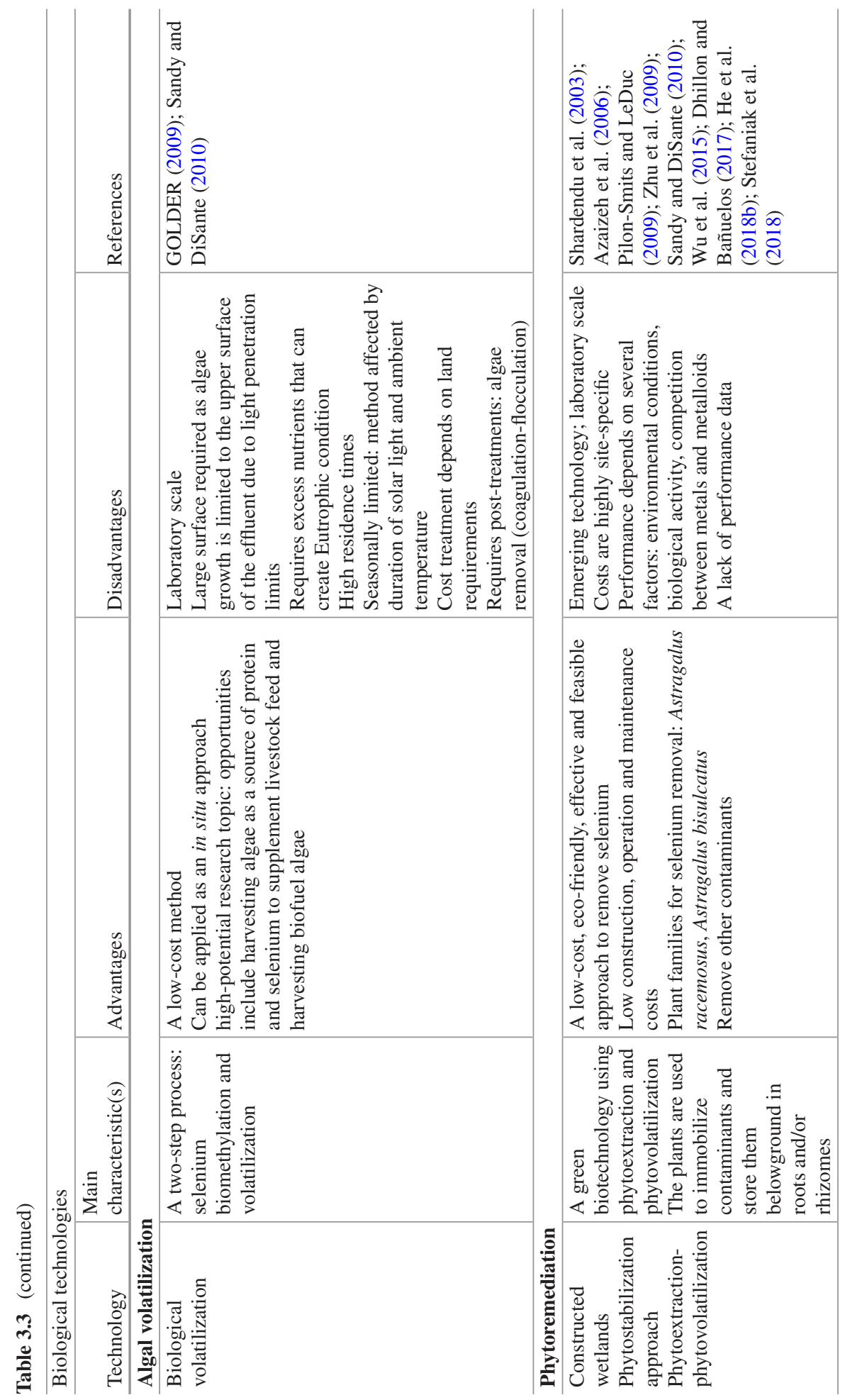




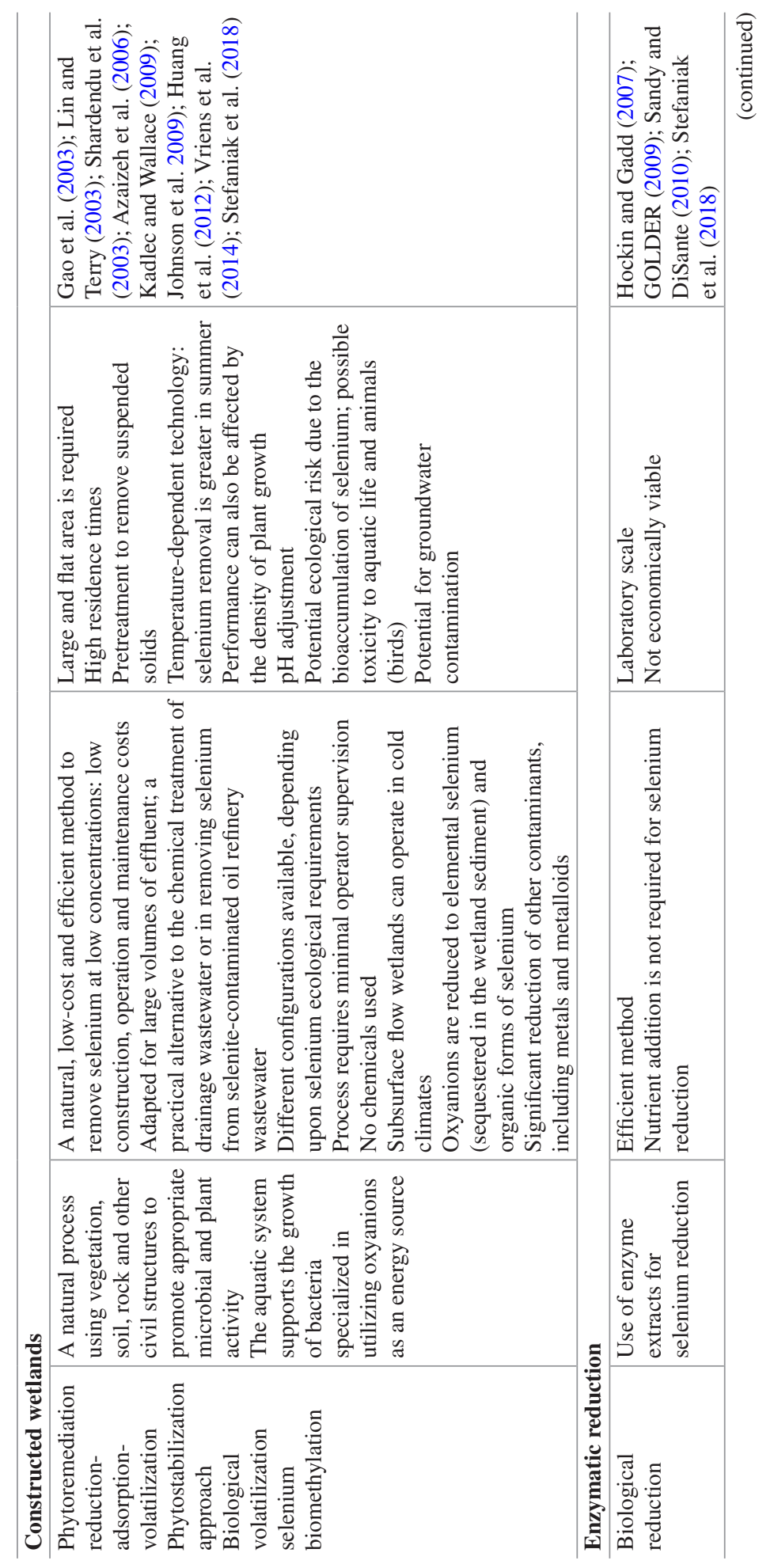




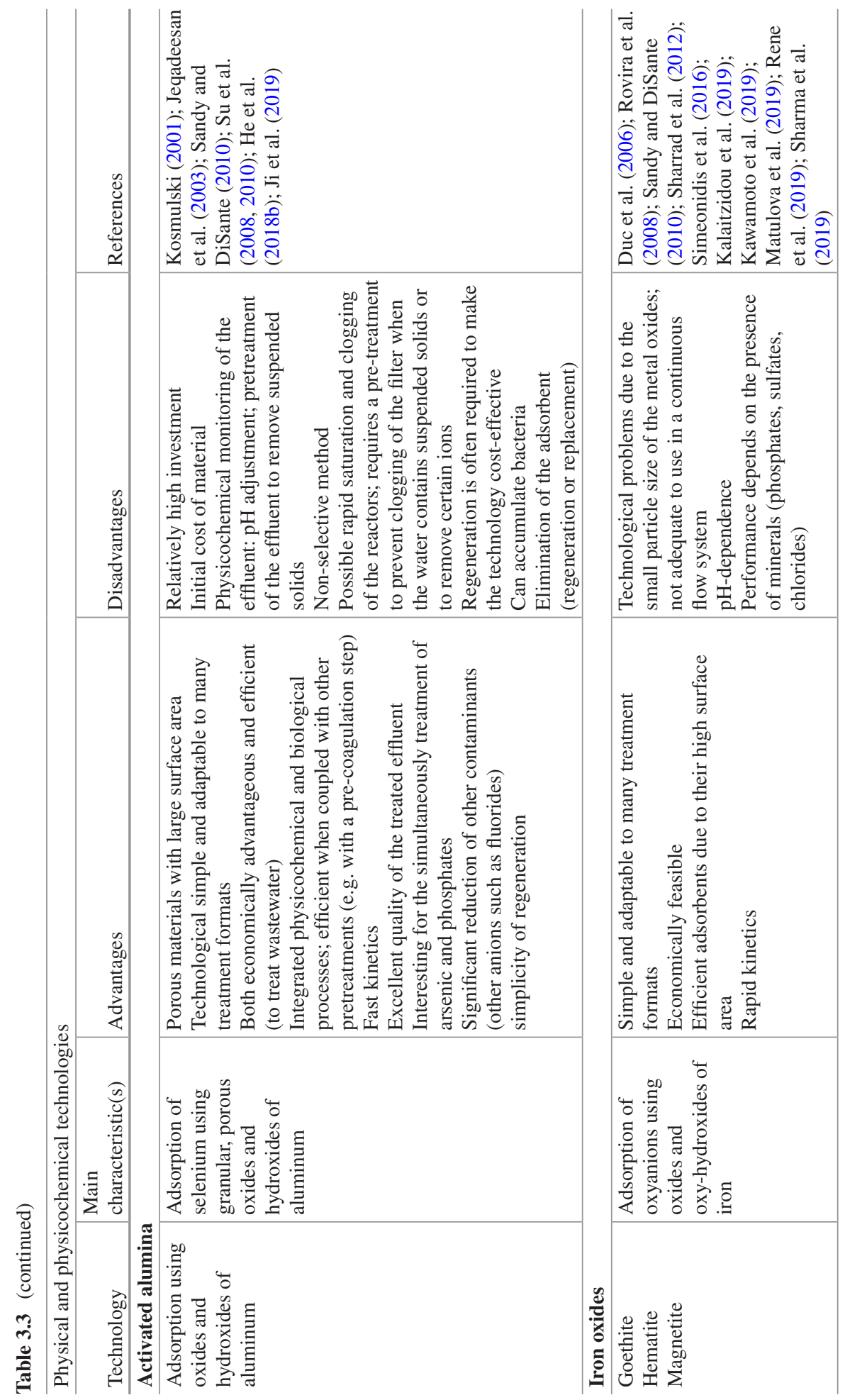




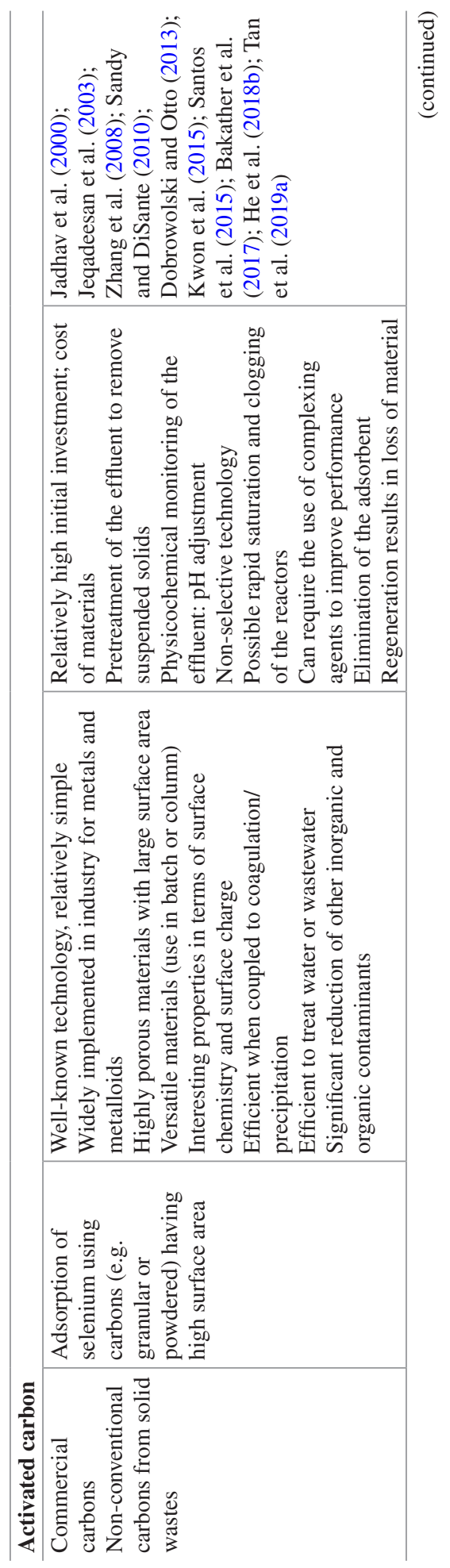




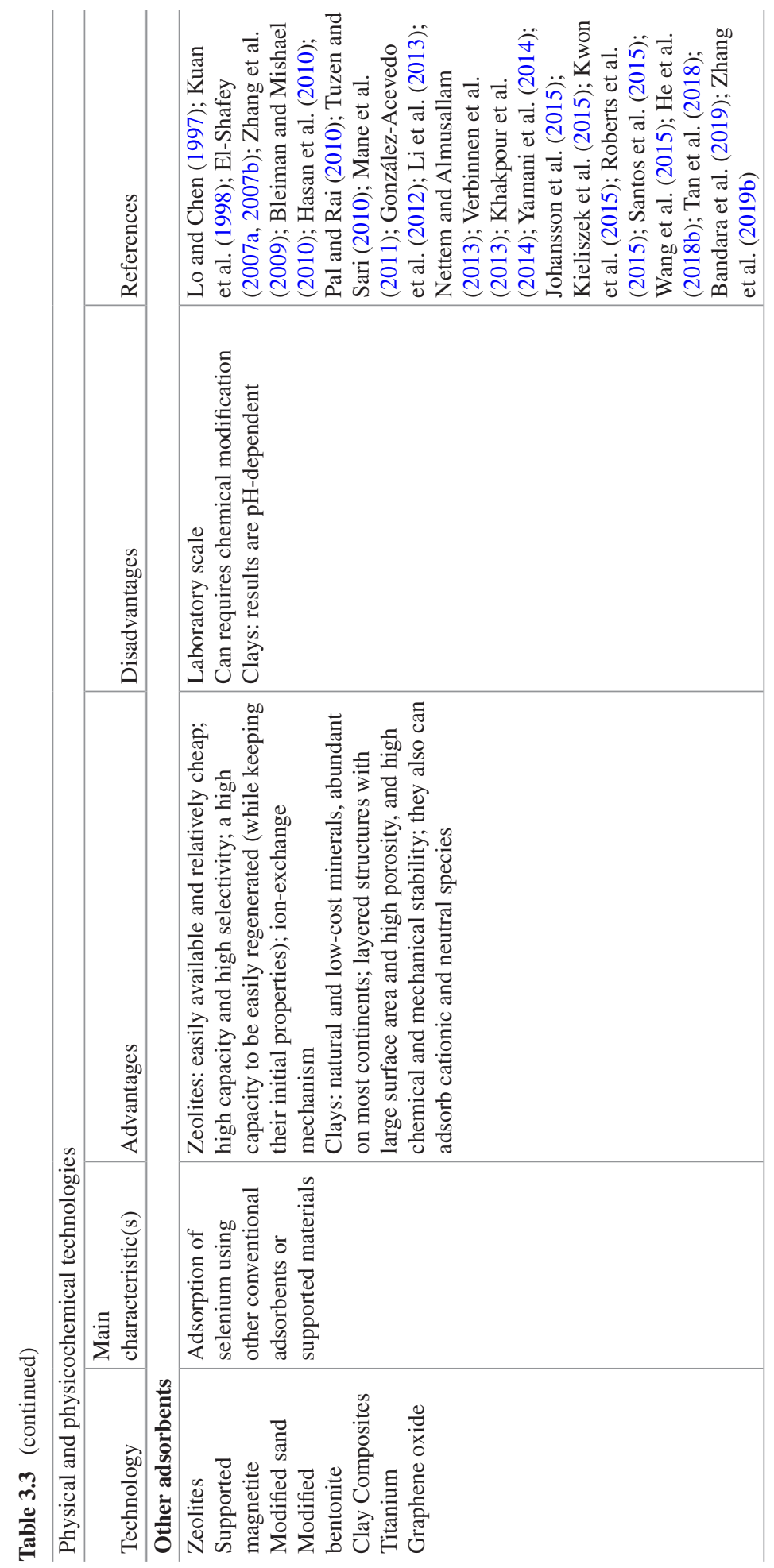




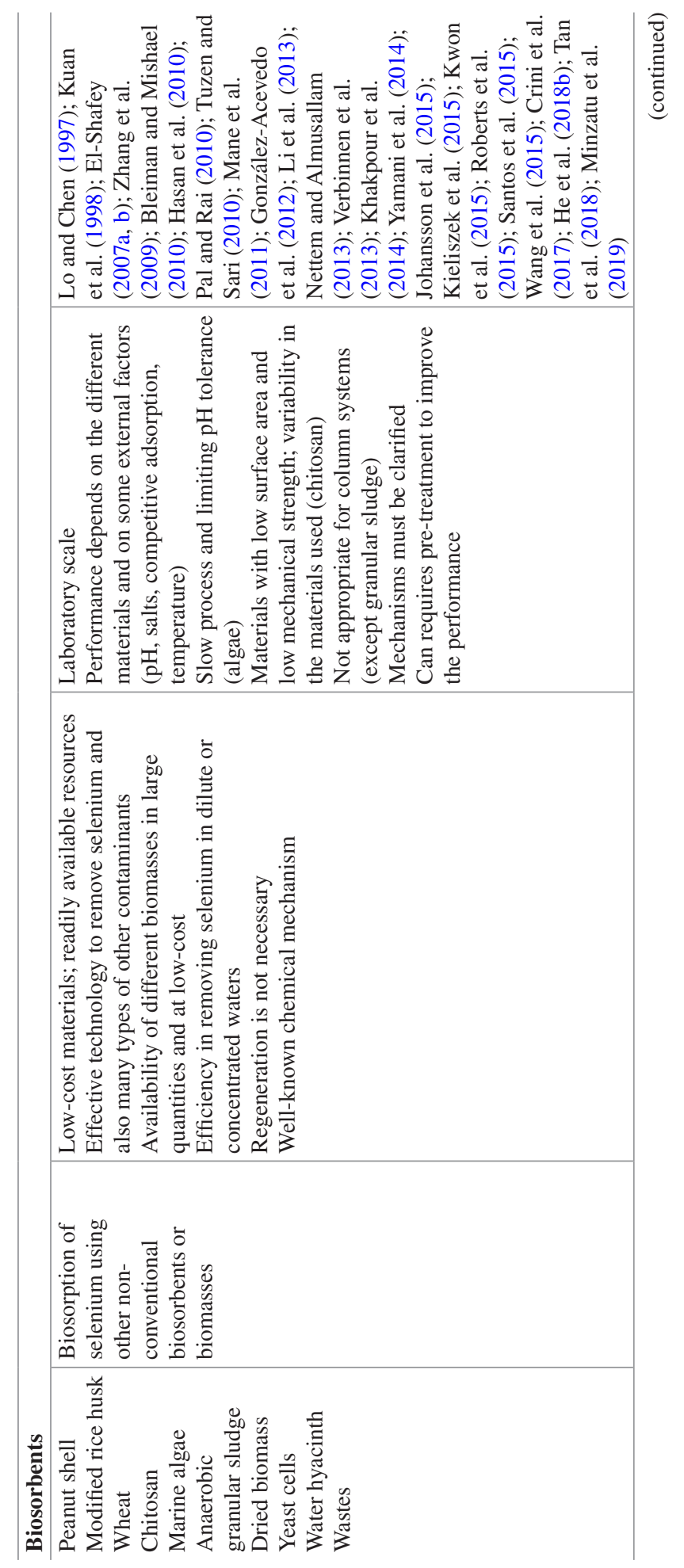




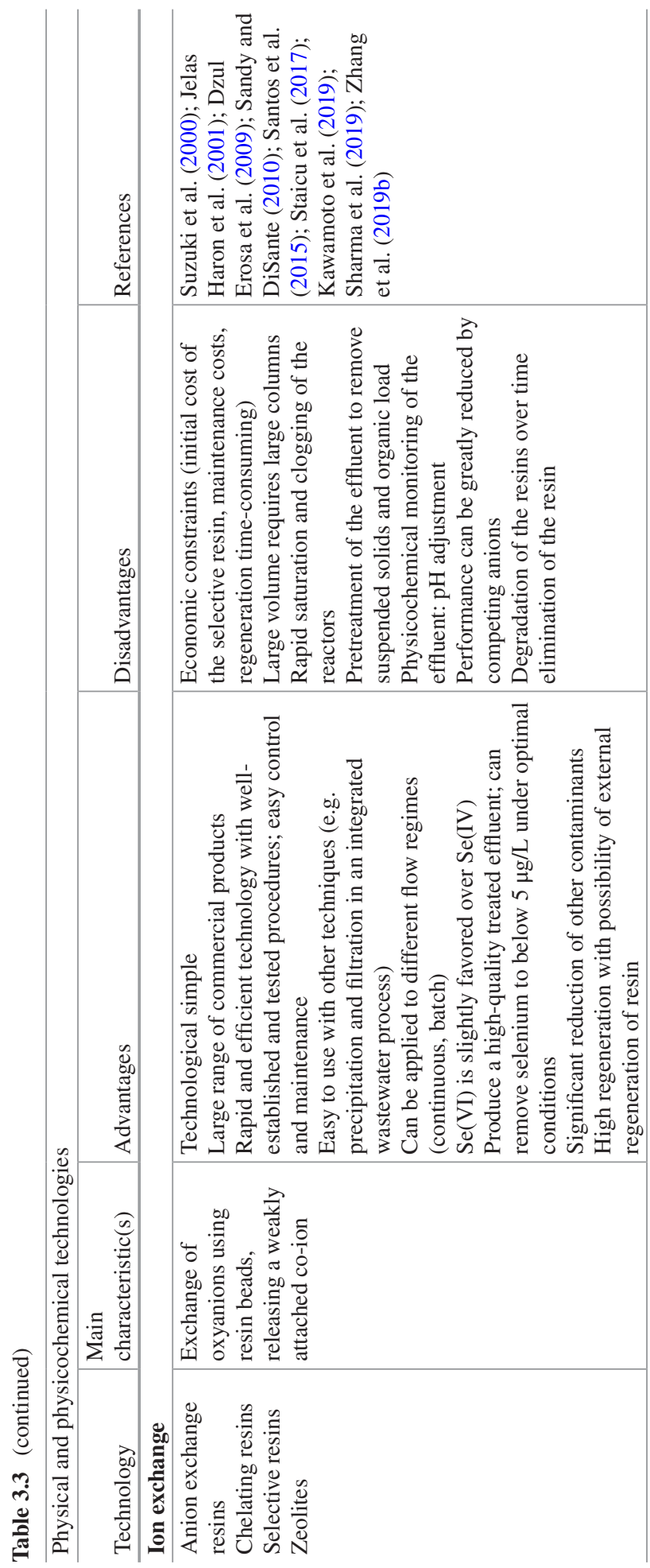




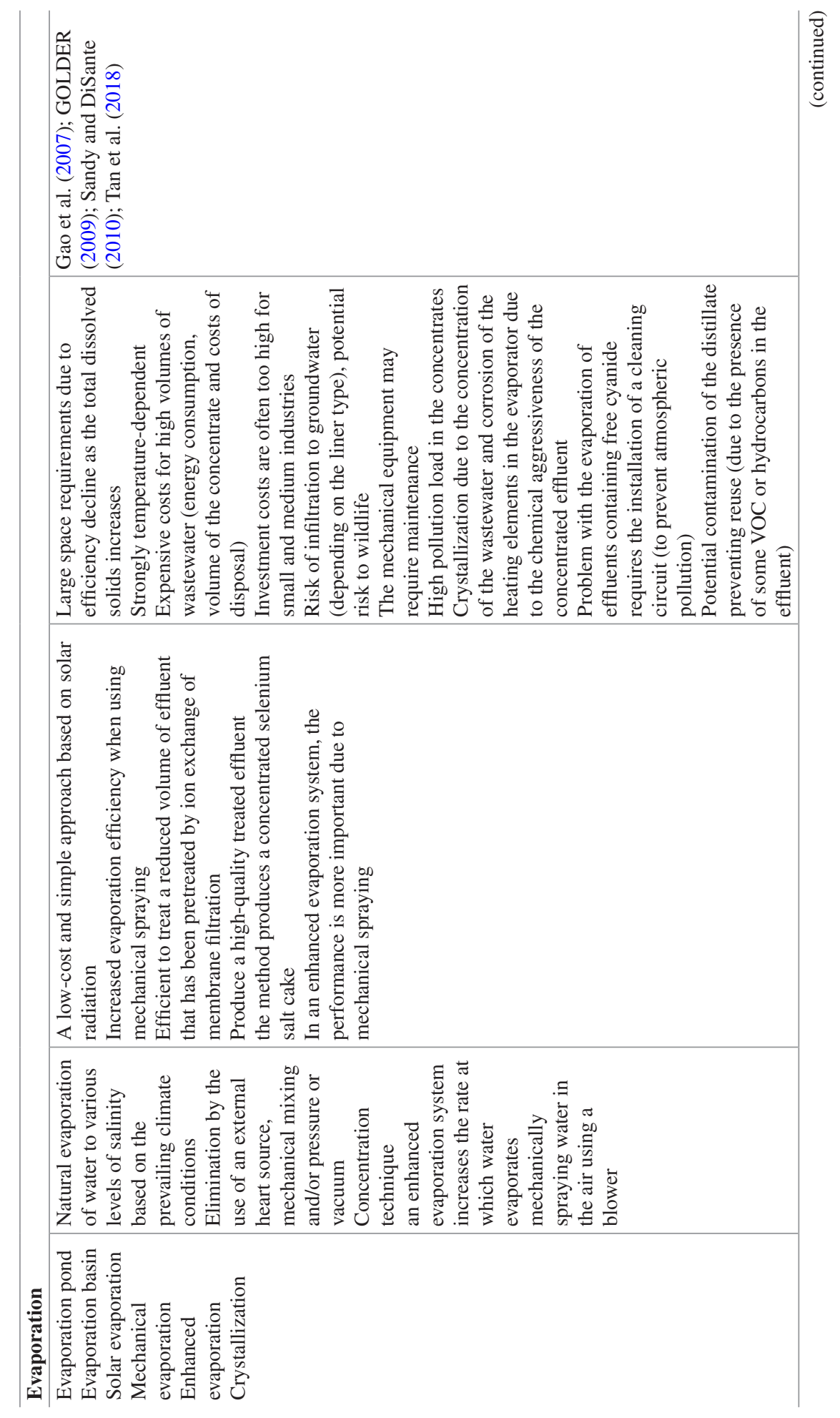




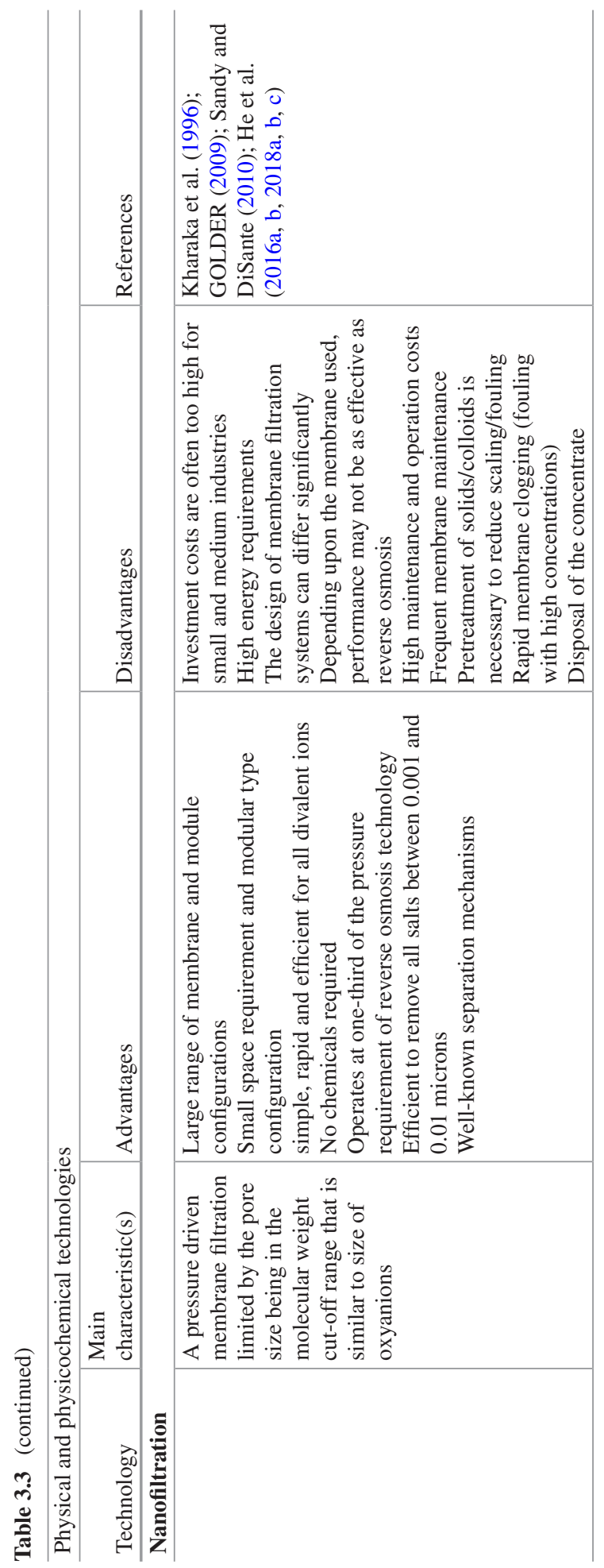




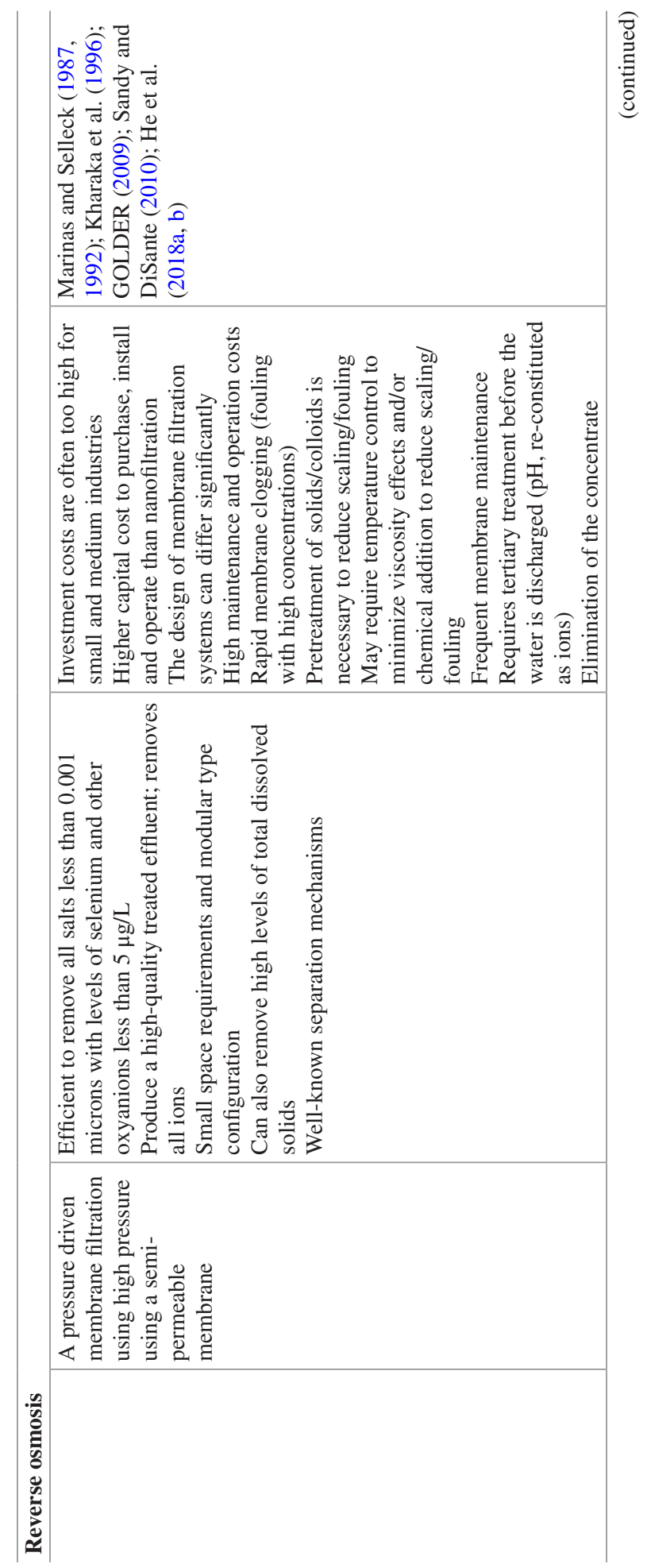




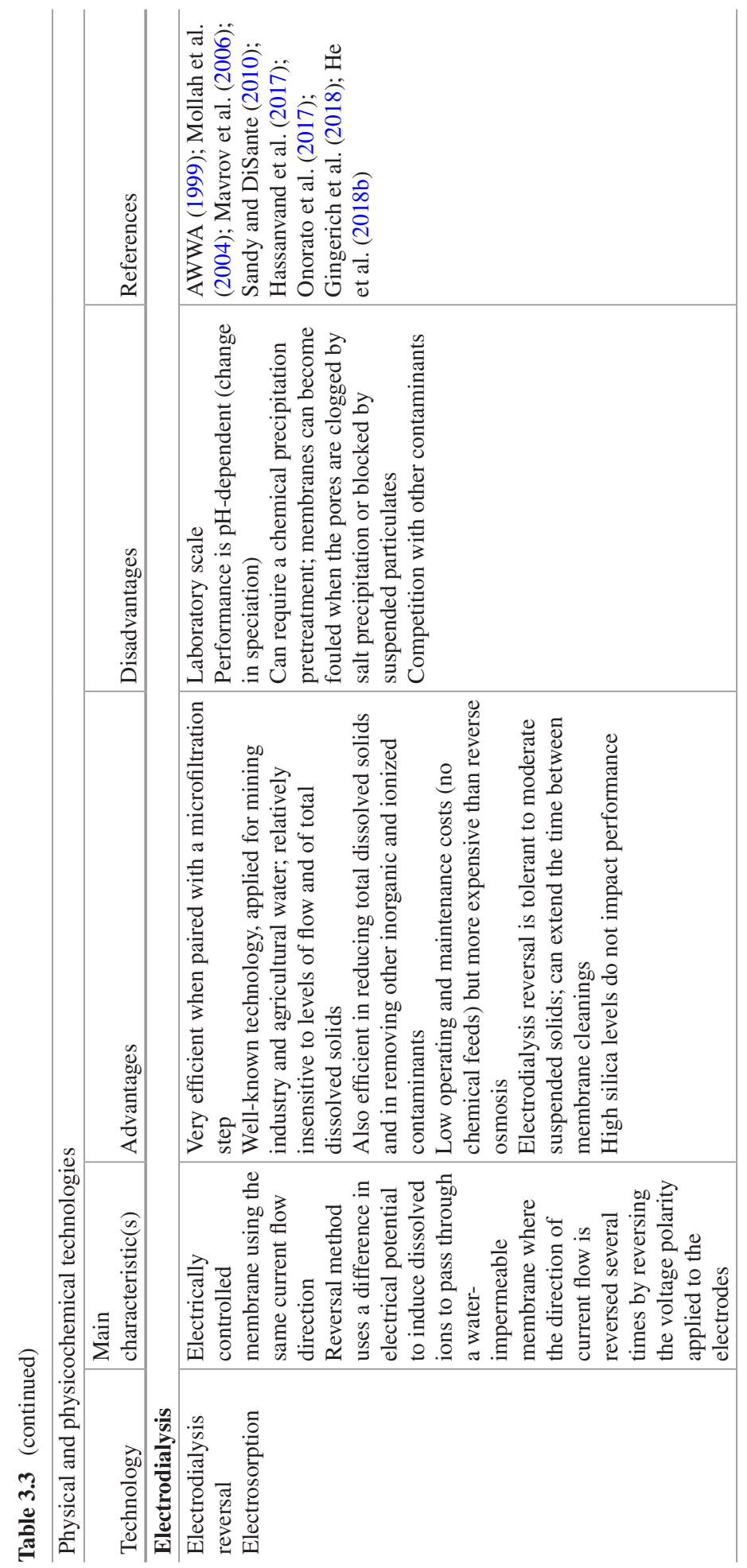




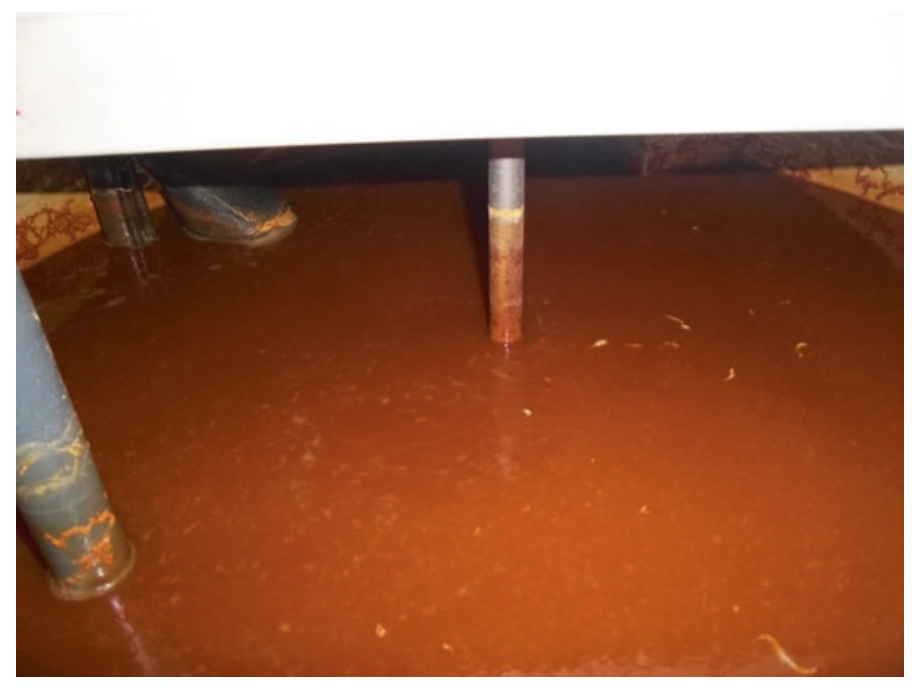

Fig. 3.2 An iron coprecipitation unit at an industrial scale (Copyright: G. Crini, Besançon, France)

et al. 2018; He et al. 2018b). Indeed, the method is a two-step physicochemical treatment consisting of (1) the addition of ferric salts such as ferric chloride or ferric sulfate to the effluent at proper conditions such as $\mathrm{pH}$ adjustment, rapid mixing and/ or flocculant addition, and (2) simultaneously adsorption of selenium onto the precipitated iron hydroxide and ferrihydrite surfaces, here the contaminants are sequestered into the mineral matrix during crystal growth. Specifically, amorphous iron(III) oxyhydroxide (ferrihydrite) is formed when the ferric salt is added to the waste. Ferrihydrite $\mathrm{Fe}_{2} \mathrm{O}_{3}-0.5 \mathrm{H}_{2} \mathrm{O}$, a poorly soluble crystalline form of ferric hydroxide $\left(\mathrm{Fe}(\mathrm{OH})_{3}\right)$, matures to more crystalline ferrioxyhydrites $\mathrm{FeO}(\mathrm{OH})$ and ferrioxides $\mathrm{Fe}_{2} \mathrm{O}_{3}$. Both dissolved and particulate elements are adsorbed onto and trapped within the precipitate, which is then settled out to leave a clarified effluent.

Iron coprecipitation is able to remove trace elements such as selenium and arsenic in complex mixtures, with elimination efficiencies for selenium - as selenite form - between 50\% and 80\% (Koren et al. 1992; Kapoor et al. 1995). Selenite is strongly adsorbed on the ferrihydrite floc, whereas selenate is more loosely bound. By comparison, arsenic removals are higher, of $90 \%$ and above, under comparable conditions with iron dosages of 14-28 mg/L. In some effluents, the technology is also able to remove other metals at neutral to alkaline $\mathrm{pH}$. However, iron coprecipitation is not an effective treatment for removal selenate, because adsorption depends on the oxidation state of the selenium. In addition, the presence of other anions such as sulfate can strongly reduce the effectiveness of coprecipitation of selenate by ferrihydrite (Merrill et al. 1986, 1987; Koren et al. 1992; Kapoor et al. 1995; MSE 2001; Twidwell et al. 2005; Gingerich et al. 2018; He et al. 2018b).

The two outstanding characteristics of iron coprecipitation are simplicity and selectivity (Table 3.3). In a comprehensive pilot study, Merrill et al. (1986, 1987) demonstrated the technical and economic feasibility of iron coprecipitation for the 
removal of $\mathrm{Se}(\mathrm{IV})$ from the ash pond effluent of a coal-fired power plant. Other contaminants can also be removed simultaneously. However, the removal performance of all trace elements is strongly affected by the $\mathrm{pH}$ of the solution. This treatment is inefficient for selenate due to the competition of sulfates for the same adsorption sites, selenate and sulfates have similar chemical properties. Major elements such as calcium, magnesium and bicarbonate do not compete with trace elements for adsorption sites. The mechanism of iron coprecipitation-adsorption is described in Merrill et al. (1986, 1987). The main disadvantages included the consumption of reagents, e.g. $\mathrm{FeCl}_{2}$ and $\mathrm{FeSO}_{4}$, adjusting the $\mathrm{pH}$ at optimal values between 4 to 6 , the sludge volume creating handling and disposal problems) and the difficulty to obtain concentrations below $5 \mu \mathrm{g} / \mathrm{L}$ for treated wastewater.

Later, iron coprecipitation has been tested at full-scale in a variety of industries, for example to treat coal-mining pond water, mining wastewater, gold mine effluents, and petrochemical wastewater (Koren et al. 1992; Kapoor et al. 1995). Iron coprecipitation was efficient to treat selenite but not able to remove selenate, yielding selenocyanate-laden effluents. Kashiwagi and Kokufuta (2000) and Fujita et al. (2002) also demonstrated that, after reducing of Se(VI) to Se(IV), selenium can be removed from agricultural and industrial wastewater by coprecipitation, decreasing concentrations below $50 \mu \mathrm{g} / \mathrm{L}$. The technology involved a three-step physicochemical process in which an oxidant and a ferric salt were added to the effluent under appropriate conditions. If the effluent contains selenocyanates, the technology requires pre-treatment by oxidation.

The US Environmental Protection Agency, in the Reference Guide to Treatment Technologies for Mining Influenced Water, EPA 542-R-14-001, 2014, recommends the iron coprecipitation method as the best available technology for selenite removal. In France, iron precipitation is widely implemented in the industry. Advantages and disadvantages are presented in Table 3.3.

\subsubsection{Reduction Techniques}

Unlike $\mathrm{Cr}(\mathrm{VI}) / \mathrm{Cr}(\mathrm{III})$ systems where only $\mathrm{Cr}(\mathrm{VI})$ species can be converted to less soluble species and the precipitated form $\mathrm{Cr}(\mathrm{III})$, the two prevalent forms of selenium $\mathrm{Se}(\mathrm{IV})$ and $\mathrm{Se}(\mathrm{V})$ are highly soluble, which renders separation difficult. For selenium species, a possible solution is to use reduction coupled with precipitation. Reduction techniques can be chemical or biological, and involve the use of a strong reducing agent or a selenium-reducing bacteria. The precipitation step uses a precipitant or coagulant (Zingaro et al. 1997; MSE 2001; Geoffroy and Demopoulos 2011; Sharrad et al. 2012; Ling et al. 2015; Stefaniak et al. 2018).

Reduction to metallic selenium and subsequent precipitation can be used to remove selenium as reported by Geoffroy and Demopoulos (2011). The authors proposed chemical precipitation with sodium sulfide. Here, synthetic weak sulfuric acid streams containing $300 \mathrm{mg} / \mathrm{L}$ of Se(IV) were used to simulate the typical conditions encountered in acidic effluents from industrial zinc refineries. High levels of 
selenium removal were observed. The precipitate of selenium sulfide obtained from sodium sulfide was extremely stable at $\mathrm{pH} 7$ but partially dissolved at $\mathrm{pH}$ values of 3,5 and 10. Besides, the removal of selenium by precipitation using dithionite $\mathrm{H}_{2} \mathrm{~S}_{2} \mathrm{O}_{4}$ or hydrosulfite - has also been tested, but in this case the resulting selenium sulfide precipitate was unstable and decomposed into several sulfur species of variable oxidation states. Other strong reducing chemical agents such as carbohydrazide and hydrazine have been proposed. These chemicals remove oxygen from oxyanions under basic conditions, effectively reducing oxyanions to elemental selenium. However, carbohydrazide and hydrazine are toxic and must be handled properly. In addition, their anhydrous forms are volatile, corrosive and form explosive mixtures with air. In France, their use is strictly controlled (Crini 2017).

Another reducer is ferrous hydroxide. This technology, referred as reductionadsorption, reduction-adsorption-precipitation or simply adsorption process with ferric hydroxide as adsorbent, is similar to the coprecipitation method. It is widely implemented in the industry due to its simplicity and relatively low-cost. The process involves two steps: ferrous iron is first added to the water in a nearly neutral medium, e.g. addition of sodium hydroxide to ferrous sulfate, which then induces the reduction of selenate to selenite and the subsequent adsorption and/or coprecipitation of selenite by ferric hydroxide or ferrihydrite under reducing conditions at an optimal pH of 8-9. The technology is highly $\mathrm{pH}$-dependent; other disadvantages, similar to the ferrihydrite adsorption technology, are mentioned in Table 3.3.

Another process involves the use of zero-valent iron as reducer in an oxidationreduction process to remove selenium by chemical reduction of its oxidized forms and then the implementation of adsorption/coprecipitation of the reduced elements. The aim is the formation of green rust, a complex ferrous ferrihydroxide coprecipitate, which reduces selenate to selenite and selenite to elemental selenium. A similar technology uses elemental iron in the form of filings, steel wool or iron impregnated foam forms to reduce selenate and selenite. Elemental iron as low-cost reducer is easily available, easy to handle, and can produce a low reduction potential in aqueous solution (Table 3.3).

The mechanisms for selenium removal using zero-valent iron are well-known. In this technology, iron acts as a catalyst and an electron donor for the reaction. Iron also produces a variety of ferrous and ferric iron products that can provide both additional reduction, e.g. to reduce selenate to selenite then to elemental selenium, and adsorption, e.g. ferrihydrite amorphous solids adsorb selenite. The elemental form of selenium, as insoluble nanoparticles, is embedded in the iron solids. The presence of other oxyanions such as carbonate and sulfate in wastewater can contribute to the oxidation of the zero-valent media. Zero-valent iron materials can be in the form of powder, granules or fibers used in tanks or filter vessels. This form is important for the effectiveness of the reactions. Depending on the $\mathrm{pH}$, between 4 and 5, and redox potential, selenium can be reduced to selenite, elemental selenium or selenide.

In water and wastewater treatment, the use of zero-valent iron is advantageous due to its non-toxic nature, abundance, relatively low-cost, easy preparation, moderately strong reducing properties and availability (MSE 2001; Sandy and DiSante 
2010; Tang et al. 2014a, b; Ling et al. 2015; van Hullebusch 2017; Gingerich et al. 2018; He et al. 2018b; Stefaniak et al. 2018; Das et al. 2019; Sharma et al. 2019). For wastewater treatment, $\mathrm{Se}(\mathrm{IV})$ is favored over $\mathrm{Se}(\mathrm{VI})$. The main characteristics of the zero-valent iron method are its simplicity as a simple and combined process with minimal monitoring and maintenance, its adaptability with materials in powder, granular or fibrous forms, and its effectiveness in removing selenium. The main disadvantage is the fact that the reduction of selenium is highly dependent on the surface characteristics of iron and dissolved oxygen concentration in groundwater. Here, it is also important to control wastewater and reactor characteristics, e.g. pH, temperature, ionic strength, dissolved oxygen, suspended solids, and oxyanions. Other disadvantages are explained in Table 3.3.

In recent years, zero-valent iron nanoparticles of specified size, high large surface area and exceptional performances have been proposed to remove not only metals but also organics because of their capability to oxidize and degrade contaminants (Ling et al. 2015; van Hullebusch 2017; Gingerich et al. 2018; He et al. 2018b; Stefaniak et al. 2018; Sharma et al. 2019). Ling et al. (2015) reported that Se(IV) can be easily separated from water, reduced and encapsulated by nanoscale zerovalent iron. For example, $1.3 \mathrm{mM}$ selenite was quickly removed from water within 3 min with $5 \mathrm{~g} / \mathrm{L}$ of nanoscale zero-valent iron. An interesting mechanism of selenite in a single core-shell structured material particle was suggested using the method of spherical aberration corrected scanning transmission electron microscopy integrated with X-ray energy dispersive spectroscopy.

Chemical reduction techniques such as cementation and photoreduction have been proposed to convert selenate and selenite to elemental selenium (Table 3.3). These technologies are also two-step processes, combining reduction and adsorptio n/coprecipitation methods (MSE 2001; Twidwell et al. 2005; GOLDER 2009; Shamas et al. 2009). Cementation is a catalyzed reduction, consisting in the recovery of an ionized metal from effluents by spontaneous electrochemical reduction to its elemental metallic state, with oxidation of a sacrificial metal. The technology has been widely used in hydrometallurgy and in the purification process of stream and wastewaters. Some authors refer to it as galvanic cementation or modified zerovalent treatment. Indeed, the technology is similar to the zero-valent iron method and is efficient to remove selenite and selenate. The addition of copper or nickel to a zero-valent iron technology is used to catalyze the reduction of selenium by creating a greater electrochemical potential between the elemental iron and soluble selenium. The cementation process has several advantages such as recovery of metals in essentially pure metallic form, simple control requirements and low energy consumption (Table 3.3). The main disadvantages are excess sacrificial metal consumption and sludge volume generation (MSE 2001; Twidwell et al. 2005; GOLDER 2009; Shamas et al. 2009; van Hullebusch 2017; He et al. 2018b).

Photoreduction combines a chemical reduction and the adsorption technology. Photoreduction uses ultraviolet irradiation at a certain wavelength in presence of titanium dioxide to convert oxyanions to elemental selenium (MSE 2001; GOLDER 2009; Shamas et al. 2009; Sandy and DiSante 2010; Labaran and Vohra 2014; He et al. 2018b; Sharma et al. 2019). Titanium dioxide is used as photocatalyst for the 
reduction of selenium forms. Contaminants that adsorb to the surface of the photocatalyst undergo chemical oxidation-reduction and adsorption reactions induced by the electrons and holes created by ultraviolet exposure. The elemental forms of the treated species are then desorbed and the surface of the photocatalyst is regenerated. Photoreduction is an effective method to reduce selenate and selenite but its main disadvantage is the formation of toxic hydrogen selenide gas (Table 3.3).

\subsubsection{Coagulation-Flocculation Processes}

Ferric salts are cationic coagulants. Their addition to water and wastewater at $\mathrm{pH} 7$ and above forms iron hydroxides capable of removing selenium by adsorption via coprecipitation. Further bonding of iron hydroxides together by addition of a flocculant forms larger, denser aggregates that settle rapidly and are easier to separate. However, this flocculation step is not systematically necessary. As in all coagulation processes, the contaminant removal efficiency depends on the coagulant used, its dose and the $\mathrm{pH}$ of the water to be treated (Koren et al. 1992; Kapoor et al. 1995; Hu et al. 2015; Santos et al. 2015). Performance also depends on the oxidation state and concentration of selenium in raw water. Coagulation-flocculation separation processes are widely implemented in the industry with a coprecipitation technology. They are effective in removing selenite ions but much less effective in removing $\mathrm{Se}(\mathrm{VI})$. Coagulation by ferric salts is much more effective than by aluminum salts such as aluminum sulfate, aluminum chloride and polyaluminum chloride (Hu et al. 2015). Apart from the classical theories of coagulation and flocculation, the mechanisms described in the literature mainly involve adsorption phenomena on the hydroxide flocs formed, particularly for $\mathrm{Se}(\mathrm{VI})$ species coagulated by $\mathrm{Fe}(\mathrm{III})$. The main disadvantage is the large volume of sludge generated due to the high consumption of chemical substances (Table 3.3).

To improve performance, a pre-chlorination step can be done, during which chlorine will tend to oxidize Se(IV), thus decreasing Se in drinking water. Yet the results are highly dependent on $\mathrm{pH}$ and free chlorine concentration. In the case of wastewaters enriched in $\mathrm{Se}(\mathrm{VI})$, a pre-step of reduction to $\mathrm{Se}(\mathrm{IV})$ is also required. Lime softening is another treatment effective in removing Se(IV) with yields close to $50 \%$ for treatments at $\mathrm{pH}$ higher than 11.5 (Santos et al. 2015). However, this treatment has no effect on $\mathrm{Se}(\mathrm{VI})$ and is strongly influenced by $\mathrm{pH}$. There are also soda decarbonation processes, which are technically simpler, but less efficient than lime, and more expensive. These two selenium removal processes, coagulation and lime softening, are considered as roughening processes and are generally used as pre-treatments just before the main treatment step, by adsorption for example. They are not economically interesting to eliminate selenium at trace levels. 


\subsubsection{Electrocoagulation}

Electrocoagulation is an effective electrochemical treatment for the reduction, coagulation and separation of selenate (Mavrov et al. 2006; Mollah et al. 2004; GOLDER 2009; Sandy and DiSante 2010; Gingerich et al. 2018; He et al. 2018b; Stefaniak et al. 2018; Hansen et al. 2019). This technology is based on an electrolysis consisting of creating metallic hydroxides flocs within the water or wastewater by electrodissolution of soluble anodes, usually made of iron or aluminum, by applying direct electrical current to an electrochemical cell. This involves in situ generation of coagulants by dissolving electrically either iron or aluminum ions from iron or aluminum electrodes, respectively. The generation of metallic cations takes place at the anode due to the electrochemical oxidation of the metal, whereas at the cathode the production of hydrogen gas typically occurs. $\mathrm{H}_{2}$ gas would also help to float the flocculated particles out of the water. The technology, sometimes called electroflocculation, requires simple equipment with different possible configurations, e.g. iron in plate form or packed form of scraps, small retention time and is easy to operate, contributing to the reduction of operating costs. Figure 3.3 shows an electrocoagulation unit at the industrial scale. The mechanisms of electrode oxidation, gas bubble generation, flotation and sedimentation of flocs formed, are well known. Aluminum is usually used for water treatment, and iron for wastewater treatment. Other advantages are mentioned in Table 3.3. The main disadvantage is the large quantities of sludge that require disposal of as hazardous waste.

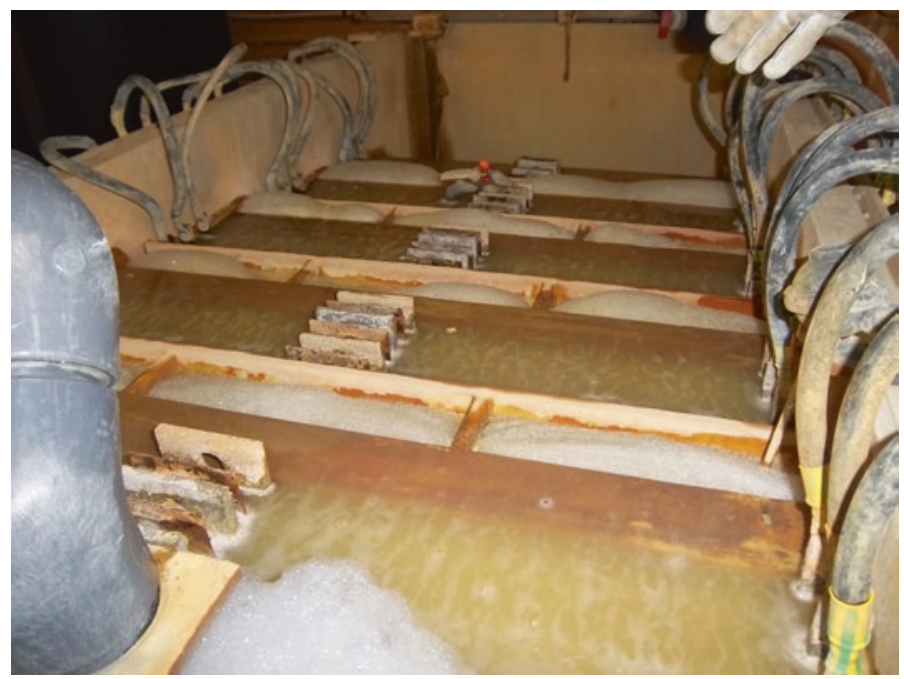

Fig. 3.3 Electrocoagulation unit at the industrial scale (Copyright: G. Crini, Besançon, France) 


\subsubsection{Metal Oxides}

Liquid/solid adsorption is one of the most frequently used techniques for the decontamination of aqueous media worldwide. Adsorption is a method of separation in which substances such as selenium present in a liquid become bound to the surface of a solid material. It is a process of partition of the substance to be removed, called adsorbate, between the aqueous solution and the solid, named adsorbent. This surface phenomenon involves complex interactions between the adsorbent and adsorbate. The performance of an adsorbent depends primarily on its physical and chemical properties. Environmental parameters such as temperature, $\mathrm{pH}$ and competitive contaminants also play a role in determining the adsorption capacity of an adsorbent (Crini and Badot 2007, 2010).

There are two main types of adsorption, physical and chemical, yet some authors mention another type of adsorption, ion-exchange. Some authors consider ionexchange as a chemical mechanism, named 'chemisorption', while others consider ion-exchange as a physical treatment, named 'physisorption'. In the industry and literature, coagulation using aluminum or ferric salts for selenium removal is considered as an adsorption-oriented technology, the application of aluminum salts being similar to that of ferrihydrite systems. Adsorption treatment technologies are now preferred because of their simplicity (technologically simple, easy of use), efficiency, residence times of less than a few minutes, and low-cost (minimal labor cost) for point-of-use applications (Simeonidis et al. 2016; Kalaitzidou et al. 2019). However, although extensive experimental studies on selenium removal have been reported, the mechanisms are not fully understood and there is still much debate.

Many natural and synthetic materials have been proposed for the removal of selenium from water, the most commonly used being metal oxides, ferric hydroxide, activated alumina and activated carbons. These adsorbents are interesting because they are very broad spectrum materials that also remove efficiently other metals and metalloids present in water and wastewater. Due to their great capacity to adsorb contaminants, metal oxides are the most effective adsorbents if the adsorption system is properly designed they give a good-quality output (Balistrieri and Chao 1987, 1990; Hayes et al. 1987; Zhang and Sparks 1990; Glasauer et al. 1995; Lo and Chen 1997; Zingaro et al. 1997; Su and Suarez 2000; Peak and Sparks 2002; Duc et al. 2006; Sandy and DiSante 2010; Rovira et al. 2008; Simeonidis et al. 2016; Kalaitzidou et al. 2019; Sharma et al. 2019). This advantage of metal oxides is mainly due to their structural characteristics, porous texture and high specific surface area. From literature data, the adsorption of Se(IV) onto metal oxides is effective over a wide range of $\mathrm{pH}$, whereas the removal of $\mathrm{Se}(\mathrm{VI})$ is more difficult. In general, adsorption processes are ineffective at $\mathrm{pH}$ values greater than 10 . The dominant selenium form in acidic $\mathrm{pH}$ is selenious acid $\left(\mathrm{H}_{2} \mathrm{SeO}_{3}\right)$. Between $\mathrm{pH} 3.5$ and 9 , mostly biselenite $\mathrm{H}_{2} \mathrm{SeO}_{3}{ }^{-}$anion exist, while at $\mathrm{pH}$ higher than 9 selenite $\mathrm{SeO}_{3}{ }^{2-}$ are predominant.

Granular ferric hydroxide is an iron-based adsorbent substrate commonly used to remove arsenic from drinking water (Crini and Badot 2010). Studies have shown 
that this material can also be interesting to remove selenium. Adsorption on various metal oxides, especially iron and aluminum, at $\mathrm{pH}$ between 6 and 8 is also possible and always leads to greater efficiency in the case of Se(IV) removal. Iron is widely distributed in soil and it is well known that iron-based oxides can act as adsorbents for pollutant removal. In addition, using iron compounds is an environment-friendly method due to low Fe toxicity. However, some competing ions such as silica and phosphate can cause problems and reduce the adsorption capacity of these oxides.

The two forms of selenium display different degree of adsorption to iron and aluminum oxides: oxides adsorb Se(IV) more easily than $\mathrm{Se}(\mathrm{VI})$. The most studied iron-based materials are two oxides, hematite $\mathrm{Fe}_{2} \mathrm{O}_{3}$ and magnetite $\mathrm{Fe}_{3} \mathrm{O}_{4}$, and an oxy-hydroxide, goethite (FeOOH), a most stable varieties of iron(III) oxy-hydroxide with surface area lower than $20 \mathrm{~m}^{2} / \mathrm{g}$. These oxides are natural, inexpensive and effective (Balistrieri and Chao 1987, 1990; Hayes et al. 1987; Zhang and Sparks 1990; Glasauer et al. 1995; Lo and Chen 1997; Zingaro et al. 1997; Peak and Sparks 2002; Su and Suarez 2000; Duc et al. 2006; Rovira et al. 2008; Sandy and DiSante 2010; Sharrad et al. 2012; Simeonidis et al. 2016; Kalaitzidou et al. 2019; Kawamoto et al. 2019; Matulova et al. 2019; Rene et al. 2019; Sharma et al. 2019). The affinity for $\mathrm{Se}(\mathrm{VI})$ is always greater than for $\mathrm{Se}(\mathrm{IV})$ and the mechanisms are mainly due to surface complexation by formation of Lewis acid-base complexes, and precipitation, e.g. as ferric selenite. For hematite and goethite, the performance decreases at high $\mathrm{pH}$ due to the predominance of selenium species (Zhang and Sparks 1990; Peak and Sparks 2002; Duc et al. 2006; Rovira et al. 2008; Kawamoto et al. 2019; Rene et al. 2019). Curiously, it was reported that even at high selenium concentrations, not all active sites are occupied (Rovira et al. 2008). In general, to avoid generating a large amount of sludge, the column method is preferable.

Sharrad et al. (2012) evaluated the FeOOH performance on selenium reduction. Their study clearly demonstrated that this commercial adsorbent was a viable alternative to conventional oxides and other adsorbents due to its high surface area, large particle size (an important filter media quality requirement), relatively low cost, and rapid kinetics. However, the adsorption of selenite is significantly affected by both $\mathrm{pH}$ and coexisting contaminants such as phosphates; the maximal performance was achieved at $\mathrm{pH} 5$. The adsorption capacity was explained by the increase of positive charge density with decreasing $\mathrm{pH}$. Sharrad et al. (2012) concluded that this technology is promising for selenium removal.

$\mathrm{FeOOH}$ showed higher uptake capacities for $\mathrm{Se}(\mathrm{IV})$ than for $\mathrm{Se}(\mathrm{VI})$ since $\mathrm{FeOOH}$ forms inner-sphere complexes with Se(IV), while complexes formed with $\mathrm{Se}(\mathrm{VI})$ are outer-sphered in nature. Recently, Kalaitzidou et al. (2019) also pointed out that $\mathrm{FeOOH}$ reuse for $\mathrm{Se}(\mathrm{VI})$ removal was economically feasible and the recovery of selenium by this technology contributed to green chemistry. The high affinity of this iron oxy-hydroxide with oxyanions is promising for selenium removal from drinking water in full-scale water treatment plants. Matulova et al. (2019) demonstrated that goethite, one of the most common oxy-hydroxides in the environment, is efficient as adsorbent to remove selenite; this method is viable although the performance depend on the $\mathrm{pH}$ and the presence of anions such as sulfate and chloride. 
The main problem with metal oxide adsorption is the difficulty of using metal oxides in a continuous flow system due to their small particle sizes. For this reason, many studies have proposed the use of other adsorbents such as aluminum oxides/ oxy-hydroxides, e.g. activated alumina and gibbsite, and carbons. Others have proposed various iron-coated materials for the adsorption of selenium from water, such as iron-oxide-coated sand, iron-coated granular activated carbons, and zeolitemodified adsorbents (Lo and Chen 1997; Kuan et al. 1998; Zhang et al. 2008; Kwon et al. 2015). Lo and Chen (1997) studied the adsorption of selenite ions on sand coated with ferric oxide: by using $100 \mathrm{~g}$ of material per liter of $10 \mathrm{mg} / \mathrm{L}$ selenium solution, they obtained a 100\% reduction in 10 min. Kuan et al. (1998) proposed sand coated with aluminum oxide and found similar results. Kwon et al. (2015) studied the impregnation of magnetite nanomaterials onto carbonaceous supports. These composites represent a unique material with tunable uptake properties for removing inorganic selenite in aqueous solutions. Evans et al. (2019) proposed magnetic adsorbents for selective removal of selenite from contaminated waters. Meso- and microporous tire-derived carbon frameworks as a support for magnetic iron oxide nanoparticles has been developed. Carbon-supported magnetic adsorbents displayed higher performance compared to conventional oxides. Minzatu et al. (2019) proposed a new technique to produce an ecofriendly composite material by doping graphite with iron oxide, which was used for retention of selenium and arsenic from aqueous solutions; the maximum adsorption capacity was $625 \mu \mathrm{g}$ $\mathrm{Se}(\mathrm{VI})$ and $400 \mu \mathrm{g} \mathrm{As}(\mathrm{V})$ per gram of adsorbent.

\subsubsection{Activated Alumina}

Aluminum oxides/oxyhydroxides such as activated alumina $\gamma-\mathrm{Al}_{2} \mathrm{O}_{3}$ and gibbsite $\mathrm{Al}(\mathrm{OH})_{3}$ are commonly used for selenium removal due to their large surface area of about $300 \mathrm{~m}^{2} / \mathrm{g}$, size and particular porosity (Kosmulski 2001; Jeqadeesan et al. 2003; Sandy and DiSante 2010; Su et al. 2008, 2010; He et al. 2018b; Ji et al. 2019). Processes using these materials are versatile due to their efficiency, low-cost and overall technological simplicity. Selective adsorption of selenium from drinking water by activated alumina adsorbents shows removal higher than $90 \%$ (Kosmulski 2001; Su et al. 2008, 2010; Ji et al. 2019). Coupled with a pre-coagulation step, this is one of the most effective methods. Adsorption-oriented processes using alumina are also used in water treatment because they make it possible to eliminate other oxyanions and contaminants such sulfate, arsenate, fluoride and silica, at the same time. Activated aluminum oxides can be used in different techniques (Crini 2017; Ji et al. 2019): in batch, in resins or in beds arranged in series or in parallel, where raw water continuously flows through the beds.

Alumina preferably adsorbs Se(IV) mainly by physicochemical mechanisms involving surface adsorption and ion exchange. Since $\mathrm{Se}(\mathrm{VI})$ has a low affinity for activated alumina relative to other ions, $\mathrm{Se}(\mathrm{VI})$ adsorption is likely to be hindered by interference from other ions. The adsorption capacity of alumina for $\mathrm{Se}(\mathrm{VI})$ is 
approximately $1 / 13$ of the capacity for Se(IV) under similar conditions. Sulphate ions significantly interfere with the removal of $\mathrm{Se}(\mathrm{VI})$ by activated alumina, whereas the presence of calcium and magnesium may improve the adsorption of $\mathrm{Se}(\mathrm{VI})$ by a secondary adsorption phenomenon, which involves simultaneous adsorption of multivalent cations by anions or simultaneous adsorption of multivalent anions by cations. Since activated alumina is amphoteric, adsorption depends on $\mathrm{pH}$. At a $\mathrm{pH}$ below 8.2, the surface of activated alumina displays a positive net charge and will thus adsorb the anions present in the water. Other factors to be taken into account are the oxidation state of the contaminants, contact time, competing ions, as well as the concentration of the regenerant and its flow rate. Regeneration techniques are simple, they consist of rinsing the beds with successive washes, e.g. rinsing with a sodium hydroxide solution, rinsing with water and treating with sulphuric acid for the recovery of $\mathrm{Se}(\mathrm{IV})$, and with hydrochloric acid for the recovery of $\mathrm{Se}(\mathrm{VI})$. In addition to its cost, other disadvantages should be considered, including fouling of the activated alumina bed and degradation of the alumina during regeneration, which leads to an increased pressure drop in the substrate bed (Table 3.3).

\subsubsection{Activated Carbons}

Due to their large specific surface area, higher than $1000 \mathrm{~m}^{2} / \mathrm{g}$, microporosity and the occurrence of diverse surface functional groups, commercial activated carbons, in raw, modified or supported forms, are also proposed to remove selenium, although their efficiency is lower than that of aluminas (Sorg and Logsdon 1978). The two most commonly used techniques are the batch method, using carbon in powdered form, and percolation in reactors with the granular form. The surface chemistry of carbons, e.g. isoelectric point and acid-base properties, is the key element for the performance of the materials. In general, in a decontamination system, activated carbons are used in pre-treatment to remove as many pollutants as possible, including selenium. Therefore this is not a selective adsorption but rather a global adsorption (Jadhav et al. 2000; Jeqadeesan et al. 2003; Zhang et al. 2008; Sandy and DiSante 2010; Dobrowolski and Otto 2013; Kwon et al. 2015; Santos et al. 2015; Bakather et al. 2017; He et al. 2018b). Granular activated carbons are the most promising adsorbents, particularly iron-coated carbons due to their applicability to continuous processes.

Zhang et al. (2008) studied the removal of selenite from aqueous phase using iron-coated granular activated carbons. The commercial Darco® carbon coated with $0.1 \mathrm{M}$ ferrous chloride achieved the highest selenite removal, above $97 \%$. High removal efficiency of selenite occurred in a wide range of $\mathrm{pH}$, i.e., 2-8, but the efficiency decreased above $\mathrm{pH}$ 8. Adsorption kinetics showed that selenite removal efficiency reached more than $90 \%$ after $6 \mathrm{~h}$ adsorption for initial selenium concentration of $2 \mathrm{mg} / \mathrm{L}$ and equilibrium was obtained after $48 \mathrm{~h}$. The adsorption capacity reached $2.5 \mathrm{mg} \mathrm{Se} / \mathrm{g}$ adsorbent at equilibrium for an initial concentration of $2 \mathrm{mg} / \mathrm{L}$ at $25^{\circ} \mathrm{C}$. Oxyanion competitive adsorption showed that $0.1-5 \mathrm{mM}$ sulfate barely 
affected selenite adsorption. Other anions such as phosphate, silicate and carbonate impacted selenite adsorption to various degrees, with phosphate completely excluding selenite adsorption.

\subsubsection{Others Conventional Adsorbents}

Adsorption of selenium species using other conventional adsorbents such as zeolites, supported magnetite, sand, bentonite, titanium and clays was studied (Lo and Chen 1997; Kuan et al. 1998; Lenz et al. 2006; El-Shafey 2007a, b; Zhang et al. 2009; Bleiman and Mishael 2010; Hasan et al. 2010; Pal and Rai 2010; Tuzen and Sari 2010; Mane et al. 2011; González-Acevedo et al. 2012; Li et al. 2013; Nettem and Almusallam 2013; Verbinnen et al. 2013; Khakpour et al. 2014; Yamani et al. 2014; Johansson et al. 2015; Kieliszek et al. 2015; Kwon et al. 2015; Roberts et al. 2015; Santos et al. 2015; Wang et al. 2015; He et al. 2018b; Tan et al. 2018).

For example, Bar Yosef and Meek (1987), and more recently Wang et al. (2015) have proposed raw or modified clays as effective materials for selenium removal. The results are explained by the predominance of complexation phenomena on the surface of the materials due to their large surface area and high porosity. Clays are also considered as natural and low-cost minerals and efficient to adsorb cationic and neutral species. However, clay performance is highly $\mathrm{pH}$-dependent. Shi et al. (2009) studied the adsorption of Se(IV) on titanium dioxide (rutile). Other hybrid materials have been proposed such as zeolite-modified magnetite (Verbinnen et al. 2013) and polymer-clay composites (Santos et al. 2015).

\subsubsection{Ion-Exchange Resins}

More than $80 \%$ selenium removal efficiency can be achieved in drinking water using strongly basic anion exchange resins (Tanaka et al. 1983). This technology is based of exchange of oxyanions using resin beads, releasing a weakly attached coion. Indeed, the resin carries a positive chemical group covalently bonded to the support and the exchangeable counter-ion carries a negative charge: we speak of anion exchangers. Commercial resins of the cross-linked polymer type grafted by tertiary amine functional groups (and/or primary and secondary amines) such as Amberlite ${ }^{\circledR}$ IRA-67 (cross-linked acrylic gel) or Duolite ${ }^{\circledR}$ A7 (phenol-formaldehyde polycondensed gel) have particular chemical structures in the form of highly porous spherical balls. These resins offer excellent stability (physical, mechanical), fast kinetics, remarkable resistance to clogging and a high exchange capacity (Tanaka et al. 1983). In general, Se(VI) is slightly favored over Se(IV). Nevertheless, conventional ion exchangers are not selective with respect to a single ion to be exchanged. This may induce preference by affinity, and therefore competition, which is often the case for industrial effluents, as well as for groundwater rich on 
sulphates, phosphates and others. In that case, one can either use a chain of several ion exchangers with weak and strong anions, or use chelate resins.

Ion-exchange using anion exchange resins, chelating resins, selective resins or zeolites is technological simple, rapid with well-established and tested procedures (Table 3.3). The technology can be easily integrated in a wastewater process and can be applied to different flow regimes (batch, column). The main disadvantage of the ion-exchange technology is economic constraints, including initial cost of the resin, maintenance costs, and regeneration time-consuming. This regeneration of the resins is essential because resin capacity is gradually and rapidly exhausted. In addition to the cost of the resin process, resins are fragile and very sensitive to the presence of organic contaminants, suspended solids, calcium or iron, which can clog and clog reactors in the long term; pre-precipitation and filtration steps are thus necessary.

Commercial resins have a low selectivity for Se(IV) compared to other ions. For example, since the affinity for sulfate is almost as high as that for $\mathrm{Se}(\mathrm{VI})$ and since sulfate is generally present in much higher concentrations, this results in competition with $\mathrm{Se}(\mathrm{VI})$ for binding at ion exchange sites. More generally, strongly basic anion exchange resins have a lower affinity for Se(IV) anions than for $\mathrm{Se}(\mathrm{VI})$ anions, nitrate and sulfate. The $\mathrm{pH}$ of the treated water is an important factor affecting ion exchange for the removal of Se(IV). Other factors influencing performance are the oxidation state of selenium, the concentration of anions in competition and the type of resin chosen (Suzuki et al. 2000; Jelas Haron et al. 2001; Dzul Erosa et al. 2009; Sandy and DiSante 2010; Santos et al. 2015; Staicu et al. 2017; Kawamoto et al. 2019; Sharma et al. 2019). Indeed, the exchange behavior of the hydrogen selenite ion $\left(\mathrm{HSeO}_{3}{ }^{-}\right)$and the selenite ion $\left(\mathrm{SeO}_{3}{ }^{2-}\right)$ must also be taken into consideration, as the selectivity towards the monovalent anion is lower than that towards the divalent anion. In addition, since selenium is usually present at trace levels in drinking water, Se removal efficiency depends on the concentration of other anions, e.g. sulphate, nitrate, chloride and bicarbonate. Dzul Erosa et al. (2009) showed that the commercial resins were effective in removing $\mathrm{Se}(\mathrm{IV})$ and $\mathrm{Se}(\mathrm{VI})$ but that the results were highly dependent on competition with other species present in the solution, especially sulfates, and also on $\mathrm{pH}$. A solution is to combine a chlorine oxidation step from $\mathrm{Se}(\mathrm{IV})$ to $\mathrm{Se}(\mathrm{VI})$ with an ion exchange treatment. More specific resins, socalled chelating resins, can also be used. Chelating resins are made of a functionalized polymer support with more specific groups, hence their greater selectivity. The disadvantage of chelating resins remains their cost, which is 4-5 times higher than for conventional resins.

Much research is being conducted on the chemical modification of commercial resins. A practical and effective method removing $\mathrm{Se}(\mathrm{IV})$ from water using a $\mathrm{Fe}^{3+}$ type cation exchange resin was recently proposed by Kawamoto et al. (2019). The first step consisted in the addition of ferric ions $\mathrm{FeCl}_{3}$ onto a commercial strong acid-type cation exchange resin, e.g. sodium type. In this process, called coadsorption, the anion was also adsorbed. Then, in a second step, the availability of the resin was studied for selenium removal at $\mathrm{pH} 3,0.1 \mathrm{M} \mathrm{NaCl}$. A column in which $12.8 \mathrm{~g}$ of resin was packed was able to remove $0.1 \mathrm{mg} / \mathrm{L}$ selenium in 3 tons of synthetic 
solution. Surprisingly, the amount of Se(IV) adsorbed onto the resin increased with the increase of ionic strength. Indeed, this trend is opposite compared to selenium adsorption on ferric oxides and hydroxides. Another advantage of their method was the easy desorption of ferric ions as $\mathrm{FeCl}_{4}{ }^{-}$complex ion using a small amount of hydrochloric acid and the quick regeneration of the resin. However, the method did not allow $\mathrm{Se}(\mathrm{VI})$ removal and the performance was also dependent of the presence of phosphate ions. Staicu et al. (2017) studied for the first time selenium removal from real flue gas desulfurization wastewater generated by a coal-power plant using a commercial iron oxide impregnated strong base anion exchange resin combined with barium precipitation. Their study clearly showed that a combined technology was efficient in removing selenium from effluents despite the high presence of sulfates and other ions.

\subsubsection{Membrane Filtration}

Membrane techniques such as nanofiltration (Kharaka et al. 1996; GOLDER 2009; Sandy and DiSante 2010; He et al. 2016a, b, 2018a) and mostly reverse osmosis (Marinas and Selleck 1987, 1992; Kharaka et al. 1996; GOLDER 2009; Sandy and DiSante 2010; He et al. 2018b) are effective techniques for removing ionic species $\mathrm{Se}(\mathrm{IV})$ and $\mathrm{Se}(\mathrm{VI})$. They rely on filtration and separation processes on micropores, with diameter lower than $2 \mathrm{~nm}$, by hydrostatic pressure. Efficiency depends mainly on the quality of the water to be treated, the type of membrane, and the recovery capacity of the system (Marinas and Selleck 1992; Kharaka et al. 1996; Santos et al. 2015). Generally, cellulose acetate membranes are used which give the best abatement. Marinas and Selleck $(1987,1992)$ previously reported that the technologies achieved more than $99.5 \%$ rejection for selenium oxyanions and $99 \%$ for nitrates.

Reverse osmosis allows Se concentrations below $5 \mu \mathrm{g} / \mathrm{L}$ to be reached. Since reverse osmosis treatment systems generally produce high quality drinking water, the ability to mix treated water with raw water to produce treated water of acceptable quality can be a factor in the choice of treatment (Crini 2017). Filtration technology has also been applied in the treatment of selenium contaminated agricultural drainage waters (Marinas and Selleck 1987; Kharaka et al. 1996). However, filtration techniques generate only small volumes of concentrate, yet the total volume in case of agricultural drainage waters is immense. Filtration technologies are expensive and limited by different constraints such as gypsum precipitation observed at higher water recoveries. Other disadvantages are reported in Table 3.3.

Nanofiltration process works at low pressure, about $1 / 3$ of that of traditional reverse osmosis, and is effective for all divalent ions. Reverse osmosis is much more efficient at removing all ions than nanofiltration, but at a much higher cost. Nanofiltration and reverse osmosis require pretreatment of solids and colloids to reduce membrane scaling and fouling, and therefore regular maintenance. For example, the presence of impurities, e.g. iron, manganese, silica and scale producing compounds, and the turbidity, are impacting process performance. The 
processes also pose the problem of concentrate disposal. The cost of the process is a real disadvantage, not only in terms of initial investment and maintenance, but also through the elimination of the waste generated. Finally, treated water generally requires post-treatment, which consists of adjusting the $\mathrm{pH}$ and alkalinity.

\subsubsection{Electrodialysis and Reverse Electrodialysis Processes}

Electrodialysis is an electrochemical separation process in which charged species from water pass through a semi-permeable membrane under the influence of an electrical potential (AWWA 1999; Mollah et al. 2004; Strathmann 2004; Mavrov et al. 2006; Sandy and DiSante 2010; Hassanvand et al. 2017; Onorato et al. 2017; Gingerich et al. 2018; He et al. 2018b). The membranes form parallel stacks, and each successive membrane carries a direct electrical current. Cations and anions migrate through cationic and anionic membranes, respectively. In the reverse electrodialysis process, the polarity of the electrodes changes regularly on either side of the ion exchange membranes, causing an inversion of ion displacement, minimizing scale accumulation on the membranes (Mollah et al. 2004; Mavrov et al. 2006). These processes are efficient, fully automated and suitable for any volume to be processed (Table 3.3). However, pre-treatment is essential because membranes get fouled when the pores are clogged by salt precipitation or blocked by suspended particulates. Another problem is competition with other contaminants.

\subsubsection{Biological Techniques}

In the biological approach to water treatment, many terminologies are used, including biological conversion, biological volatilization, biological reduction, bioreduction, microbial reduction, microbial metabolism, heterotrophic microbial reduction, biotransformation, biomineralization, bioaccumulation, bioreactors, algal-bacterial technology, enzymatic processes, biosorption, bioremediation, phytoremediation, phytotechnology, agro-remediation, mycoremediation, phycoremediation, phytostabilization, rhizofiltration, rhizodegradation, phytodegradation, phytoextraction, phytoaccumulation and phytovolatilization. Some terms can also be classified into sub-classes. A review of the literature on these terms reveals that their definition has evolved over the years, which can be attributed to the diversity of the mechanisms involved and the techniques uses (Lundquist et al. 1994; Parker and Page 1994; Cantafio et al. 1996; Carvalho et al. 2001; MSE 2001; Yee et al. 2007; GOLDER 2009; Hunter and Manter 2009; Zhu et al. 2009; Vriens et al. 2014; Santos et al. 2015; Dessì et al. 2016; Tan et al. 2016; Terry 2016; Mal et al. 2017; van Hullebusch 2017; He et al. 2018b; Stefaniak et al. 2018; Tan et al. 2018; Calix et al. 2019; Gebreeyessus and Zewge 2019; Paul and Saha 2019; Rene et al. 2019; Zhang et al. 2019a; Zeng et al. 2019). However, all the biological approaches are based on the 
use and growth of microorganisms, algae or plants. Each biological technology has its own advantages and disadvantages (Table 3.3).

Bacteria, microbes, algae and fungi are capable of reducing metals including selenium and thus produce insoluble forms that can be eliminated from contaminated water by precipitation or adsorption mechanisms. Biological community analysis shows that various selenium-reducing microorganisms contribute to the selenium cycle. Similar oxidation-reduction reactions of selenium are observed in chemical and biological reactions, yet microorganisms mediate reactions using their metabolic pathways. Microorganisms receive energy by transfer of electrons from an electron donor, i.e. food organic carbon, to an electron acceptor, which represents respiration of the microorganism with production of carbon dioxide and biomass. There are generally two main types of environments, those rich in oxygen and those where oxygen and oxidized nitrogen are absent. Oxygen is the most favorable electron acceptor for microorganisms, e.g. for microbial aerobic oxidation of organics for energy production resulting in the energy source and electron acceptor being converted to carbon dioxide and water. Microorganisms can be heterotrophs, obtaining energy from the oxidation of organic compounds, or autotrophs, where energy comes from the oxidation of inorganic compounds.

Nitrate-reducing bacteria are heterotrophic bacteria that use organic carbon as electron donor and selenate or selenite as their acceptor. Thus, they obtain both their energy and cellular growth from reaction with selenite and selenate. In some cases the environment must be controlled to exclude oxygen. For example, in an anoxic environment, bacteria called denitrifiers can use oxidized inorganic compounds, e.g. selenate or selenite, as electron acceptors, but only in the absence of oxygen. In this case, bacteria will use nitrate as an electron acceptor. This is why, in general, biological methods for treating selenium are classified into aerobic, e.g. microbial aerobic oxidation, and anaerobic techniques: denitrifying bacteria, bioreactors and constructed wetlands.

A simple classification makes it possible to distinguish biological treatments either in active technologies such as microbial reduction or in passive technologies, for example aerobic wetlands and biochemical reactors. Active treatment is subject to relatively constant monitoring to control and enhance the environment. Active treatment also requires chemical and physical monitoring, e.g. pH, chemical oxygen demand, biochemical oxygen demand, and total organic carbon. Active treatment also consumes energy. Whereas passive treatment has advantages such as little or no energy input, minimal monitoring and maintenance, natural processes and materials, suitable for low flows, but passive treatment generally requires more land and isolated locations. This classification is controversial since, for example, bioreactors can be either active or passive processes.

Typical conventional biological technologies that have been applied for the removal of selenium include created wetlands involving phytoremediation, volatilization, reduction and adsorption in sediments, algal-bacterial removal, and biological removal using dissimilatory metal reducers. These techniques can be classified as biological conversions, i.e. uptake, reduction and volatilization processes. 
Biological conversions using microorganisms can be used to remove selenate and selenite oxyanions from wastewater and water (Santos et al. 2015). Microorganisms act to reduce, oxidize, precipitate, absorb and adsorb contaminants from effluents. Similarly to chemical treatment, challenges of biological treatments include low selenium concentrations in the effluent to be treated, presence or absence of nitrate, and competition from other oxyanions, e.g. sulfate. Many factors such as $\mathrm{pH}$, temperature and salinity of the effluent are influencing microbial reduction. Biological reduction is currently the subject of intense research for the elimination of selenium. Typically, a biological technique is combined with other conventional physicochemical processes such as coagulation, adsorption and filtration. When the biological route for selenium-loaded wastewater is implemented, the main objective is to obtain biogenic selenium $\operatorname{Se}(0)$ as a solid end product. However, this element has colloidal stability between $\mathrm{pH} 2-12$ due to its surface charge and nanometric size, making it difficult to remove from the effluent (Staicu et al. 2015a, b). It is thus necessary to couple the biological treatment with a coagulationflocculation or filtration step.

The algal-bacterial technology is interesting because it avoids the commonly encountered competitive inhibition of nitrate on selenate reduction (Lundquist et al. 1994; Lin and Terry 2003; GOLDER 2009; Sandy and DiSante 2010). Microalgae are grown in a first step to reduce nitrate concentrations, and subsequently the settled algal biomass is used as a carbon source for selenium reducing bacteria in a spatially separated treatment step.

Phytoremediation is a process allowing the removal of contaminants from contaminated soils, air and water by plants (Harvey et al. 2002; McGrath et al. 2002). Selected plants can either accumulate or detoxify the contaminants (Terry 2016; Gebreeyessus and Zewge 2019; Rene et al. 2019). Phytoremediation is perceived as a simple, acceptable, cost-effective and effective cleanup technology. Phytoremediation comprises several techniques that use plants and associated microorganisms to remediate contaminated environments and matrices. These techniques can be divided into four types, i.e. phytoextraction, phytofiltration, phytostabilization and phytovolatilization, depending on the plants and the conditions used, and on the type of contaminants to remove and the level of cleanup required. Phytoremediation is carried out in situ and this may reduce the exposure of the contaminated substrate to humans, wildlife and the environment. To remove selenium, recent data from constructed wetlands showed that phytoremediation appears attractive due to its field scale application advantage (Gebreeyessus and Zewge 2019). Flow-through or subsurface wetlands provide an inexpensive and efficient technology for the treatment of selenium in large volume of agricultural drainage waters and flue gas desulfurization effluents. Soluble selenium is removed by different processes such as uptake by plants (phytoextraction), volatilization by plants, fungi and bacteria and microbial and geochemical reduction. However, the main disadvantage is that it is a very slow process. Another problem is the bioaccumulation of selenium and its exposure to wildlife (Table 3.3). 


\subsubsection{Emerging Non-conventional Adsorbents}

Currently explored methods include biosorption on non-conventional adsorbent materials, named biosorbents due to their biological origin. Biosorption uses natural, low-cost materials from renewable resources, generally agricultural or marine, as an alternative in water treatment. This process takes advantage of the presence of many reactive groups on the surface of these materials, which are generally polysaccharides. Biosorbents include chitosan, biomass (microorganisms), and agricultural wastes, e.g. peanut shells and rice husks. These materials are capable of complexing contaminants, including selenium species, present in trace amounts in complex mixtures, to meet the regulatory limit in wastewater (Kidgell et al. 2014; Crini 2017). In general, kinetics are fast and retention capacities are high. The mechanisms are explained mainly by ion-exchange.

One of the biosorbents proposed is chitosan, a biopolymer obtained from chitin, the most abundant polysaccharide after cellulose. As a cationic polyelectrolyte, chitosan behaves as a polycation with a high charge density in an acidic environment, which is a very interesting property for water treatment. In addition, chitosan is known for its versatility and can be used both in solution and in the solid state under different forms, e.g. powders, beads and fibers. Chitosan can act both as an adsorbent and a flocculant, and is currently the subject of extensive research to remove contaminants. Chitosan is used in particular to prepare composite materials of high mechanical stability for use in continuous or batch reactors. Several studies have proposed coating chitosan on materials such as clay or oxides (Bleiman and Michael 2010; Yamani et al. 2014). For example, the use of chitosan-clay composites has resulted in an absorption capacity of $18.4 \mathrm{mg} \mathrm{Se}(\mathrm{VI})$ per g of substrate. This composite had an affinity for selenium compared to other ions present, and was able to reduce a $\mathrm{Se}(\mathrm{VI})$ concentration from $0.64 \mathrm{mg} / \mathrm{L}$ to a level below $0.01 \mathrm{mg} / \mathrm{L}$ in groundwater (Bleiman and Michael 2010).

The use of microorganisms such as fungi, yeasts, bacteria and algae, as biosorbents has proven to be a cost effective, efficient to reduce selenium species to their elemental forms, and a safe technique for metal and metalloid removal. Dead biomass is preferred to avoid toxicity and the requirement of growth medium that would increase the operational costs. Application of bacteria for the reduction of selenium oxyanions is interesting because the process takes less time and is easy to manage. It is also possible to use different types of heterotrophic aerobic and anaerobic and chemotropic bacteria. Even if selenium concentration is very low, the process is efficient, reaching final concentration bout $5 \mu \mathrm{g} / \mathrm{L}$ or even less, and is technically and economically viable. Fungi and yeasts such as Aspergillus niger, Rhizopus arrhizus, Saccharomynces cerevisiae or Phanaerochaete chrysosporium are able to bind selenium in its organic and inorganic forms. They can bioaccumulate selenium intracellularly by active transportation of selenium in the cells, and extracellularly by interactions with proteins, phospholipids and polysaccharides. Several varieties of marine algae have the ability to interact with selenium, even in 
trace amounts. This capacity is due to the presence of polysaccharides, proteins and lipids at cell surface, capable of complexing selenium (Tuzen and Sari 2010).

Many studies are available in the literature although there is not yet an industrial sector for the production of dedicated materials for water treatment (Lo and Chen 1997; Kuan et al. 1998; El-Shafey 2007a, b; Zhang et al. 2009; Bleiman and Mishael 2010; Hasan et al. 2010; Pal and Rai 2010; Tuzen and Sari 2010; Mane et al. 2011; González-Acevedo et al. 2012; Li et al. 2013; Nettem and Almusallam 2013; Verbinnen et al. 2013; Khakpour et al. 2014; Kidgell et al. 2014; Yamani et al. 2014; Johansson et al. 2015; Kieliszek et al. 2015; Kwon et al. 2015; Roberts et al. 2015; Santos et al. 2015; Wang et al. 2015; He et al. 2018b; Tan et al. 2018). Nevertheless, pilot tests are currently emerging at the industrial stage (Santos et al. 2015; Crini 2017), which suggests that this technology will be developed. All the results described have been obtained on polycontaminated groundwater and synthetic solutions of selenium. Indeed, there is little work on complex real industrial effluents. In addition, the mechanisms of elimination are still poorly understood. Further research and optimization are needed to determine the feasibility of using non-conventional adsorbents in applications to remove selenate and selenite from water/wastewater.

\subsection{Examples of Treatment for Selenium Removal}

\subsubsection{Selenate Removal by Zero-Valent Iron}

Zero-valent iron has been used to treat wastewater and groundwater contaminated by selenium (Zhang et al. 2005; McCloskey et al. 2008; Olegario et al. 2010; Yoon et al. 2011; Gibson et al. 2012; Liang et al. 2013; Das et al. 2017, 2019). As already stated, zero-valent iron is an attractive treatment option because it is non-toxic, has a high reactivity, is readily availability, and is cost effective (Zhang et al. 2005; Ezzatahmadi et al. 2017; Liu and Wang 2019). Zero-valent iron has a concentric structure with a rim of iron oxide surrounding a metallic iron $\left(\mathrm{Fe}^{0}\right)$ core $(\mathrm{Li}$ and Zhang 2006; Liu et al. 2017; Ezzatahmadi et al. 2017; Das et al. 2019). Contaminants adsorb to the iron oxide rim via surface complexation reactions (Li and Zhang 2006; Liu et al. 2017) while the metallic core acts as an electron donor (reductant) (Eq. 3.1) (Li and Zhang 2006; Liu et al. 2017).

The reduction process in equation (3.1) can be enhanced by ferrous iron $\left(\mathrm{Fe}^{2+}\right)$, which can also donate an electron to the zero-valent iron surface and oxidize to $\mathrm{Fe}(\mathrm{III})$ oxides or hydroxides ( $\mathrm{Li}$ and Zhang 2006). As such, zero-valent iron can oxidize under both oxic (fast process) (Eq. 3.2) and anoxic (slow process) (Eq. 3.3) conditions (Zhang et al. 2005). As a result, corrosion and oxidation of zero-valent iron is more pronounced in oxic than anoxic conditions (Zhang et al. 2005; Das et al. 2019).

The removal of selenate [Se(VI)] and selenite [Se(IV)] from solution with zerovalent iron and nano-scale zero-valent iron has been evaluated under oxic (Zhang 
et al. 2005; Olegario et al. 2010; Yoon et al. 2011; Liang et al. 2013; Das et al. 2017) and anoxic (Gibson et al. 2012; Tang et al. 2014a, b; Das et al. 2019) conditions. The formation of $\mathrm{OH}^{-}$and $\mathrm{H}_{2}$, as in Eqs. 3.2 and 3.3, respectively, increases the solution $\mathrm{pH}$ and decreases the redox potential during $\mathrm{Se}(\mathrm{VI})$ removal by zero-valent iron (Shrimpton et al. 2015; Das et al. 2017, 2019).

In summary, $\mathrm{Se}(\mathrm{VI})$ removal by zero-valent iron can be described as the adsorption of soluble $\mathrm{Se}$ (VI) onto the iron oxide layer followed by reduction to less soluble Se species such as Se(IV) and subsequent reduction to insoluble Se species such as elemental selenium [Se(0)] and or selenide [Se(-II)] (Genin et al. 1998; Murphy 1988; Yoon et al. 2011; Gibson et al. 2012; Liang et al. 2013; Yoon et al. 2016) (Eqs. 3.4 and 3.5). Figure 3.4 shows $\mathrm{Se}(\mathrm{VI})$ adsorption and subsequent reduction to $\mathrm{Se}(\mathrm{IV}), \mathrm{Se}(0), \mathrm{Se}(-\mathrm{I})$ and $\mathrm{Se}(-\mathrm{II})$ by zero-valent iron.

$$
\begin{gathered}
\mathrm{Fe}^{0}=\mathrm{Fe}^{2+}+2 e^{-} \\
2 \mathrm{Fe}^{0}+2 \mathrm{H}_{2} \mathrm{O}+\mathrm{O}_{2}=2 \mathrm{Fe}^{2+}+4 \mathrm{OH}^{-} \\
\mathrm{Fe}^{0}+2 \mathrm{H}_{2} \mathrm{O}=\mathrm{Fe}^{2+}+2 \mathrm{OH}^{-}+\mathrm{H}_{2} \\
\mathrm{HSeO}_{4}{ }^{-}+3 \mathrm{H}^{+}+2 e^{-}=\mathrm{H}_{2} \mathrm{SeO}_{3}(a q)+\mathrm{H}_{2} \mathrm{O} \\
\mathrm{H}_{2} \mathrm{SeO}_{3}(a q)+4 \mathrm{H}^{+}+4 e^{-}=\mathrm{Se}(\mathrm{s})+3 \mathrm{H}_{2} \mathrm{O}
\end{gathered}
$$

Spectroscopic studies, including X-ray absorption near edge spectroscopy, extended X-ray absorption fine structure spectroscopy, and X-ray photoelectron spectroscopy, show that $\mathrm{Se}(\mathrm{VI})$ adsorbs onto zero-valent iron surfaces early but with increasing reaction time is reduced to $\mathrm{Se}(\mathrm{IV}), \mathrm{Se}(0), \mathrm{FeSe}_{2}[\mathrm{Se}(-\mathrm{I})]$ (ferroselite), and eventually selenide (FeSe) [Se(-II)] (Achavalite), suggesting a step-wise reduction mechanism of Se(VI) by zero-valent iron during the removal process (Zingaro et al. 1997; Roberson 1999; Olegario et al. 2010; Yoon et al. 2011; Gibson et al. 2012;

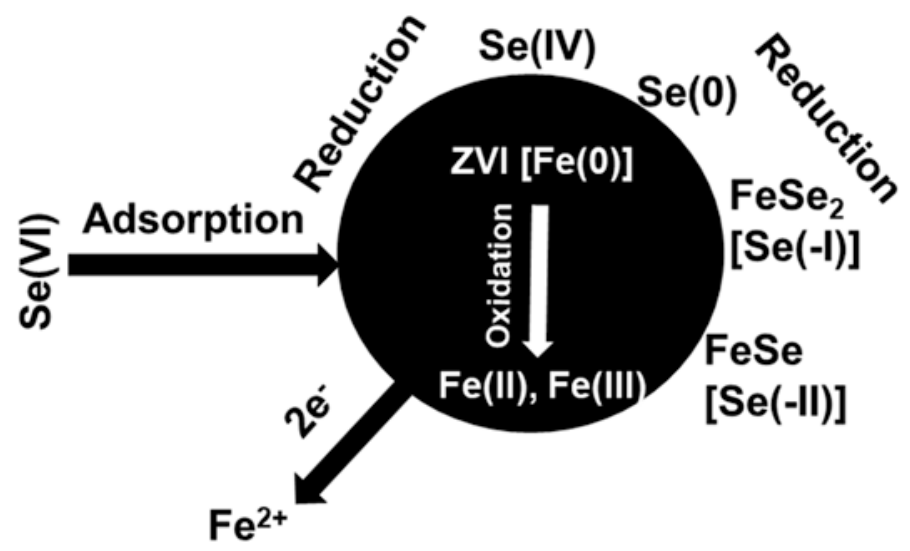

Fig. 3.4 $\mathrm{Se}(\mathrm{VI})$ adsorption and subsequent reduction to $\mathrm{Se}(\mathrm{IV}), \mathrm{Se}(0), \mathrm{Se}(-\mathrm{I})$, and $\mathrm{Se}(-\mathrm{II})$ by zerovalent iron. (Adapted from Shrimpton et al. 2015) 
Tang et al. 2014a; Shrimpton et al. 2015). Spectroscopic analyses also demonstrate that $\mathrm{Se}(\mathrm{VI})$ adsorption and subsequent reduction to other Se species is not only dependent on reaction time but also the initial Se(VI) concentration (Yoon et al. 2011). For example, selenium speciation on the surface is dominated by $\mathrm{Se}(-\mathrm{II})$ or $\mathrm{Se}(0)$ at dissolved $\mathrm{Se}(\mathrm{VI})$ concentrations below $25 \mathrm{mg} / \mathrm{L}$ but by both $\mathrm{Se}(\mathrm{VI})$ and $\mathrm{Se}(\mathrm{IV})$ at dissolved $\mathrm{Se}(\mathrm{VI})$ concentrations higher than $50 \mathrm{mg} / \mathrm{L}$, signifying partial reduction of adsorbed $\mathrm{Se}(\mathrm{VI})$ by zero-valent iron during the removal process (Yoon et al. 2011).

$\mathrm{Se}(\mathrm{VI})$ removal via reduction by zero-valent iron is a fast process under pristine conditions (Das et al. 2017, 2019). However, competing ions such as sulfate $\left(\mathrm{SO}_{4}{ }^{2-}\right)$, phosphate $\left(\mathrm{PO}_{4}{ }^{3-}\right)$, bicarbonate $\left(\mathrm{HCO}_{3}{ }^{-}\right)$, nitrate $\left(\mathrm{NO}_{3}{ }^{-}\right)$, and chloride $\left(\mathrm{Cl}^{-}\right)$can reduce the rate of $\mathrm{Se}(\mathrm{VI})$ removal in both oxic and anoxic environments (Zhang et al. 2005; Das et al. 2017, 2019). The rate-limiting effect of $\mathrm{SO}_{4}{ }^{2-}$ is attributed to similarities in the chemical properties of $\mathrm{SO}_{4}{ }^{2-}$ and selenate $\left(\mathrm{SeO}_{4}{ }^{2-}\right)$, resulting in competition for surface sites on zero-valent iron (Zhang et al. 2005). Similarly, $\mathrm{PO}_{4}{ }^{3-}$ also lowers the rate of $\mathrm{Se}(\mathrm{VI})$ removal by zero-valent iron, which is attributed to the reaction of aqueous $\mathrm{PO}_{4}{ }^{3-}$ with ferrous iron $\left(\mathrm{Fe}^{2+}\right)$ generated via oxidation of $\mathrm{Fe}^{0}$ during $\mathrm{Se}(\mathrm{VI})$ removal (Zhang et al. 2005). This reaction leads to the formation of iron-phosphate minerals such as vivianite $\left[\mathrm{Fe}_{3}\left(\mathrm{PO}_{4}\right)_{2}\left(\mathrm{H}_{2} \mathrm{O}\right)_{8}\right]$ and, as such, depletes the $\mathrm{Fe}^{2+}$ available for further $\mathrm{Se}(\mathrm{VI})$ reduction (Zhang et al. 2005). $\mathrm{PO}_{4}{ }^{3-}$ also has a higher affinity for iron oxide/hydroxide surfaces compared to $\mathrm{Se}(\mathrm{VI})$ and, as such, might reduce $\mathrm{Se}(\mathrm{VI})$ adsorption to zero-valent iron surfaces and in turn decrease its rate of removal (Goldberg 1985; Balistrieri and Chao 1987). Dissolved $\mathrm{HCO}_{3}{ }^{-}$can also decrease the rate of $\mathrm{Se}(\mathrm{VI})$ removal (Zhang et al. 2005) via precipitation of iron minerals (similar to $\left.\mathrm{PO}_{4}{ }^{3-}\right)$ such as siderite $\left(\mathrm{FeCO}_{3}\right)$ and thus depletes the $\mathrm{Fe}^{2+}$ available for Se(VI) reduction (Phillips et al. 2003; Zhang et al. 2005). Although $\mathrm{NO}_{3}{ }^{-}$ also limits the rate of $\mathrm{Se}(\mathrm{VI})$ removal by zero-valent iron (Zhang et al. 2005; Das et al. 2017, 2019), the effect is not as intense as noted for $\mathrm{SO}_{4}{ }^{2-}, \mathrm{PO}_{4}{ }^{3-}$, or $\mathrm{HCO}_{3}$. $\mathrm{NO}_{3}{ }^{-}$does not hinder the rate of $\mathrm{Se}(\mathrm{VI})$ removal when aqueous $\mathrm{NO}_{3}{ }^{-}$concentrations increase from 1 to $10 \mathrm{mM}$ (Zhang et al. 2005). The rate-limiting effect of $\mathrm{NO}_{3}{ }^{-}$is due to the oxidation of zero-valent iron by $\mathrm{NO}_{3}{ }^{-}$, resulting in the formation of an oxidative layer that passivates the zero-valent iron surface for $\mathrm{Se}(\mathrm{VI})$ removal (Reinsch et al. 2010). The presence of dissolved $\mathrm{Cl}^{-}$demonstrates little or no effect on $\mathrm{Se}(\mathrm{VI})$ removal by zero-valent iron. The rate of $\mathrm{Se}(\mathrm{VI})$ removal by zero-valent iron varies widely depending upon the solution chemistry as discussed above; nonetheless, the kinetics of $\mathrm{Se}(\mathrm{VI})$ removal can be best described by either a first-or pseudo-first-order reaction pathway irrespective of oxic and or anoxic test conditions (Zhang et al. 2005; Olegario et al. 2010; Yoon et al. 2011; Liang et al. 2015; Shrimpton et al. 2015; Das et al. 2017, 2019).

The presence of dissolved $\mathrm{SO}_{4}{ }^{2-}$ also plays a dominant role in controlling selenium speciation during $\mathrm{Se}(\mathrm{VI})$ removal by zero-valent iron under oxic conditions (Das et al. 2017). Concentrations of $\mathrm{Se}(0)$ decrease by more than $50 \%$ on zerovalent iron surfaces in the presence of $\mathrm{SO}_{4}{ }^{2-}$ irrespective of the type of zero-valent iron used during Se(VI) removal (Das et al. 2017). Testing conditions such as oxic versus anoxic also play a crucial role in Se speciation during $\mathrm{Se}(\mathrm{VI})$ removal by 
zero-valent iron. For example, $\mathrm{Se}(0)$ is the dominant reduction product $(70-80 \%)$ followed by $\mathrm{Se}(-\mathrm{II})(2-13 \%)$ during $\mathrm{Se}(\mathrm{VI})$ removal by zero-valent iron under anoxic conditions regardless of solution chemistry (e.g. presence of dissolved $\mathrm{SO}_{4}{ }^{2-}$, $\mathrm{NO}_{3}{ }^{-}$, or both) (Das et al. 2019). In contrast, reduction products are dominated by $\mathrm{Se}(\mathrm{IV})$ or an even mixture of $\mathrm{Se}(\mathrm{IV})$ and $\mathrm{Se}(0)$ depending on the solution chemistry under oxic conditions (Das et al. 2017).

$\mathrm{Se}(\mathrm{VI})$ reduction by zero-valent iron and subsequent selenium speciation on zero-valent iron surfaces also depend on the type of zero-valent iron (Das et al. 2017, 2019). For example, X-ray absorption near edge spectroscopy results demonstrate that $\mathrm{Se}(\mathrm{VI})$ reduction products are dominated by both $\mathrm{Se}(\mathrm{IV})$ and $\mathrm{Se}(0)$ under oxic test conditions. However, metallurgical granular Fe from Rio Tinto Metal Powders (Montreal, Canada) resulted in more $\mathrm{Se}(0)$ as a reduction product compared to ground cast Fe aggregate from Connelly-GPM Inc. (Chicago, USA) or Peerless Metal Powder and Abrasives (Detroit, USA) (Das et al. 2017).

Although zero-valent iron and nano-scale zero-valent iron have been used widely to remove dissolved $\mathrm{Se}(\mathrm{VI})$ from aqueous solutions, the precipitation of iron oxides and hydroxides onto zero-valent iron (magnetite, hematite, lepidocrocite, wüstite, ferrihydrite, schwertmannite, vivianite, mikasaite, etc., depending on solution chemistry) can decrease the Se(VI) removal efficiency of zero-valent iron due to passivation effects caused by these oxide/hydroxides coating onto the zero-valent iron surfaces (Olegario et al. 2010; Reinsch et al. 2010; Yoon et al. 2011; Gunawardana et al. 2012; Petr et al. 2012; Liu et al. 2017; Das et al. 2017, 2019). In addition, particle agglomeration of nano-scale zero-valent iron results in a decrease in the reactive surface areas and a lowering of the reactivity for contaminant removal (Ezzatahmadi et al. 2017). As such, additional testing has been conducted using organic matter (Gibson et al. 2012), divalent cations such as $\mathrm{Fe}^{2+}, \mathrm{Mn}^{2+}$ and $\mathrm{Co}^{2+}$ (Tang et al. 2014a, b), clay minerals such as bentonite (Li et al. 2015; Dong et al. 2016), and a weak magnetic field (Liang et al. 2014a, b) to augment both Se(VI) and Se(IV) removal by zero-valent iron.

Despite having a low surface area of $0.36-2.3 \mathrm{~m}^{2} / \mathrm{g}$ (Zhang et al. 2005; Yoon et al. 2011; Das et al. 2017, 2019) and concerns with respect to its longevity (Henderson and Demond 2007), zero-valent iron can remain active for many years depending on controlling factors (Henderson and Demond 2007). Under appropriate conditions, permeable reactive barriers using zero-valent iron could represent a valuable approach for selenium remediation and represent an alternative to other approaches, e.g. adsorption onto iron oxide and hydroxides, co-precipitation with ferrihydrite, membrane separation.

\subsubsection{Adsorption of Selenium Species by Iron-Oxy-Hydroxides}

Iron oxides and hydroxides have drawn attention from the scientific community with respect to their potential to sequester Se from aqueous solutions via adsorption due to their natural abundance, moderate to high specific surface areas, and surface 
affinity for selenium (Balistrieri and Chao 1990; Cornell and Schwertmann 2000). As such, a large number of laboratory studies spanning the last five decades have investigated the adsorption behavior and mechanism of two major Se species$\mathrm{Se}(\mathrm{IV})$ and $\mathrm{Se}(\mathrm{VI})$-onto iron oxides/oxy-hydroxides, including ferrihydrite $\left(5 \mathrm{Fe}_{2} \mathrm{O}_{3} .9 \mathrm{H}_{2} \mathrm{O}\right)$, goethite $\left[\alpha-\mathrm{FeO}(\mathrm{OH}]\right.$, hematite $\left(\alpha-\mathrm{Fe}_{2} \mathrm{O}_{3}\right)$, magnetite $\left(\mathrm{Fe}_{3} \mathrm{O}_{4}\right)$, maghemite $\left(\gamma-\mathrm{Fe}_{2} \mathrm{O}_{3}\right)$, and lepidocrocite $[\gamma-\mathrm{FeO}(\mathrm{OH}]$ (Hingston et al. 1971; Davis and Leckie 1980; Leckie et al. 1980; Benjamin and Bloom 1981; Balistrieri and Chao 1987; Hayes et al. 1987, 1988; Balistrieri and Chao 1990; Dzombak and Morel 1990; Zhang and Sparks 1990; Manceau and Charlet 1994; Hiemstra and Van Riemsdijk 1999; Su and Suarez 2000; Wijnja and Schulthess 2000; Rietra et al. 2001; Kang et al. 2002; Peak and Sparks 2002; Duc et al. 2006; Catalano et al. 2006; Martinez et al. 2006; Fukushi and Sverjensky 2007; Rovira et al. 2008; Chan et al. 2009a, b; Gonzalez et al. 2012; Das et al. 2013; Jordan et al. 2014).

Adsorption of both $\mathrm{Se}(\mathrm{IV})$ and $\mathrm{Se}(\mathrm{VI})$ species onto iron oxides and hydroxides depends on a variety of factors, such as solution $\mathrm{pH}$, selenium species, strength of electrolytes, concentrations of selenium species, types of adsorbate, concentrations of adsorbate, presence of competing ions, and more. Fig. 3.5 present a simplified diagram of both selenate and selenite adsorption onto iron oxide and hydroxides (Hayes 1987). Laboratory results indicate the adsorption of both Se(IV) and Se(VI) onto iron oxides and hydroxides is a fast process that reaches equilibrium within $25 \mathrm{~min}$ (Su and Suarez 2000). Adsorption of these two selenium species is strongly dependent on solution $\mathrm{pH}$, with greater sequestration occurring at lower versus higher pH conditions (Balistrieri and Chao 1987; Dzombak and Morel 1990; Su and Suarez 2000; Duc et al. 2006). This occurs because iron oxide and hydroxide surfaces are negatively charged above their point of zero charge value; thus, lesser electrostatic attraction for negatively charged ions such as $\mathrm{Se}(\mathrm{IV})$ and $\mathrm{Se}(\mathrm{VI})$ onto iron oxide and hydroxide surfaces leads to a lower adsorption efficiency (Benjamin et al. 1982; Cristiano et al. 2011). However, the free energy of adsorption is also dependent on both chemical (specific) and electrostatic effects (Stumm et al. 1970).

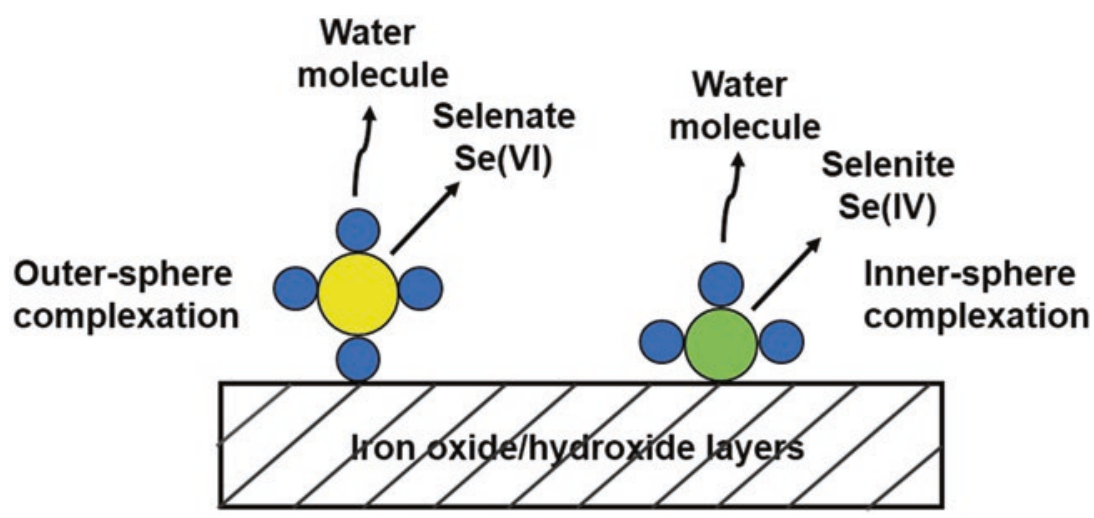

Fig. 3.5 Selenate and selenite adsorption onto iron oxide and hydroxides. (Adapted from Hayes 1987) 
So, the adsorption of anions such as Se(IV) can occur above the point of zero charge of iron hydroxide (such as goethite) when a specific constituent is dominant over a non-specific or electrostatic counterpart (Balistrieri and Chao 1987). Laboratory results also indicate $\mathrm{Se}(\mathrm{VI})$ adsorbs to a lesser extent than $\mathrm{Se}(\mathrm{IV})$ at a given $\mathrm{pH}$ and desorbs more rapidly with increasing solution $\mathrm{pH}$ compared to $\mathrm{Se}(\mathrm{IV})$ from iron hydroxide surfaces (Balistrieri and Chao 1987; Goldberg 2014). However, the percent of adsorption also depends on the adsorbing solids. For example, amorphous iron hydroxide (ferrihydrite) has a greater affinity for both $\mathrm{Se}(\mathrm{IV})$ and $\mathrm{Se}(\mathrm{VI})$ compared to goethite, hematite, and lepidocrocite under similar experimental conditions (e.g. $\mathrm{pH}$, strength of electrolytes, total selenium concentrations) ( $\mathrm{Su}$ and Suarez 2000; Kang et al. 2002; Peak and Sparks 2002; Das et al. 2013). Ionic strength also plays a crucial role in Se sequestration by iron oxides and hydroxides. For instance, $\mathrm{Se}(\mathrm{IV})$ adsorption did not noticeably affect onto the surface of either amorphous iron hydroxide or goethite; however, a remarkable decrease in $\mathrm{Se}(\mathrm{VI})$ adsorption occurred when the ionic strength increased by an order of magnitude from 0.01 to $0.1 \mathrm{M}$ (Su and Suarez 2000). Adsorption of selenium also depends on the concentration of sorbate, with higher concentrations resulting in greater adsorption. The adsorption of $\mathrm{Se}(\mathrm{IV})$ also increases with increasing goethite concentration, reflected by an increase in distribution coefficient value $\left(\mathrm{K}_{\mathrm{D}}\right)$ for a given solution $\mathrm{pH}$ (Balistrieri and Chao 1987). Anion competition can also affect Se adsorption onto iron hydroxide surfaces (depending on the affinity of anions on the surface of adsorbing solids) (Balistrieri and Chao 1987). Selenium adsorption decreases when phosphate, silicate, and arsenate are present in the system, followed by bicarbonate/ carbonate, citrate, molybdate, oxalate, fluoride and sulfate (Balistrieri and Chao 1987).

Experimental results obtained from laboratory tests on selenium adsorption behavior onto iron oxides and hydroxides have been successfully evaluated by a number of modeling approaches, such as those considering the distribution coefficient (Balistreri and Chao 1987) or Langmuir isotherms (Das et al. 2013; Kang et al. 2002; Peak and Sparks 2002; Rovira et al. 2008), as well as surface complexation models including CD-MUSIC (charge distribution multisite ion complexation), double-layer, and triple-layer models (Davis and Leckie 1980; Balistreri and Chao 1990; Dzombak and Morel 1990; Zhang and Sparks 1990; Hiemstra and Van Riemsdijk 1999; Rietra et al. 2001; Fukushi and Sverjensky 2007; Rovira et al. 2008; Goldberg 2014). Outputs from all of these adsorption models describing Se adsorption mechanisms and the nature of surface complexes onto iron oxides and hydroxides have been corroborated by spectroscopic studies based on extended $\mathrm{X}$-ray absorption fine structure spectroscopy, attenuated total reflectance-Fourier transform infrared spectroscopy, and Raman spectroscopy (Hayes et al. 1987; Manceau and Charlet 1994; Su and Suarez 2000; Wijnja and Schulthess 2000; Peak and Sparks 2002; Das et al. 2013).

Surface complexation models and spectroscopic studies on the mechanism and nature of surface complexes of Se(IV) on all iron oxides and hydroxides studied (e.g. ferrihydrite, goethite, hematite, maghemite, and magnetite) demonstrate strong inner-sphere surface complexation irrespective of solution $\mathrm{pH}$ (Balistrieri and Chao 
1987; Hayes et al. 1987; Su and Suarez 2000; Catalano et al. 2006; Duc et al. 2006; Martinez et al. 2006; Jordan et al. 2014). On the contrary, spectroscopic studies indicate $\mathrm{Se}(\mathrm{VI})$ forms a weakly bound outer-sphere complex on goethite even in highly acidic conditions ( $\mathrm{pH}=4)$, as reflected by the absence of a second shell (Se$\mathrm{Fe}$ ) in the absorption spectra (Hayes et al. 1987). However, results also demonstrate the nature of $\mathrm{Se}(\mathrm{VI})$ complexation onto goethite is $\mathrm{pH}$ dependent, with outer-sphere surface complexes dominating at $\mathrm{pH}$ values $\geq 6$ and inner-sphere surface complexes at $\mathrm{pH}$ values $\leq 5$ (Manceau and Charlet 1994; Wijnja and Schulthess 2000; Rietra et al. 2001; Peak and Sparks 2002). The formation of outer-sphere surface complexes of $\mathrm{Se}(\mathrm{VI})$ on goethite has also been reported at $\mathrm{pH}$ values below 5 (Hayes et al. 1987). However, results are contradictory with respect to the type and nature of surface complexes of Se(VI) on goethite surfaces. Spectroscopic and adsorption data obtained from a number of studies demonstrate $\mathrm{Se}(\mathrm{VI})$, similar to $\mathrm{Se}(\mathrm{IV})$, forms strong inner-sphere surface complexes on ferrihydrite, goethite, and lepidocrocite over a range of $\mathrm{pH}$ values and $\mathrm{Se}(\mathrm{VI})$ surface coverage (Manceau and Charlet 1994; Su and Suarez 2000; Peak and Sparks 2002; Fukushi and Sverjensky 2007; Das et al. 2013). Spectroscopic studies indicate the absorption spectra of $\mathrm{Se}(\mathrm{VI})$ on ferrihydrite, goethite, and lepidocrocite display a second shell (Se-Fe), suggesting inner-sphere complexation (either bidentate mononuclear or bidentate binuclear) on the iron hydroxide surfaces (Manceau and Charlet 1994; Peak and Sparks 2002; Das et al. 2013). Adsorption data indicate Se(VI) adsorption on goethite is dependent on the electrolyte strength, with lower adsorption at greater ionic strengths signifying an ion-pair type complex (outer-sphere) on goethite surfaces [shell of hydration of $\mathrm{Se}(\mathrm{VI})$ was retained during the adsorption process] (Hayes et al. 1987). Although ionic strength-dependent adsorption of $\mathrm{Se}(\mathrm{VI})$ onto iron hydroxide has been demonstrated (Hayes et al. 1987; Su and Suarez 2000), electrophoretic study indicate $\mathrm{Se}(\mathrm{VI})$, similar to $\mathrm{Se}(\mathrm{IV})$, has lowered electrophoretic mobility and point of zero charge on the goethite surface (Su and Suarez 2000). The shift in the both electrophoretic mobility and extended X-ray absorption fine structure spectroscopy towards lower values signifies inner-sphere complexation of $\mathrm{Se}(\mathrm{VI})$ on the goethite surface as chemically or specifically bound ions accumulate at the mineral-water interface, thus contributing additional negative charges on the surface and shifting the point of zero charge towards lower $\mathrm{pH}$ values (Sposito 1984; Su and Suarez 2000; Jordan et al. 2014). Thus, electrolyte strength-dependent adsorption of Se(VI) cannot alone be used to differentiate between outer- vs inner-sphere complexation onto iron hydroxide surfaces (Su and Suarez 2000).

In adsorption experiments, ferrihydrite has been found to sequestrate greater amounts of both selenium species compared to any other iron oxide or hydroxide tested, including hematite, goethite, and lepidocrocite (Kang et al. 2002; Peak and Sparks 2002; Das et al. 2013). Irrespective of the contradictory nature of surface complexation of $\mathrm{Se}(\mathrm{IV})$ and $\mathrm{Se}(\mathrm{VI})$ onto iron oxide and hydroxide surfaces discussed above, published studies generally agree that iron oxide and hydroxide surfaces have a higher affinity for $\mathrm{Se}(\mathrm{IV})$ compared to $\mathrm{Se}(\mathrm{VI})$ under a range of solution $\mathrm{pH}$ values, ionic strengths, surface loadings, etc.; as such, Se(IV) adsorbs more 
strongly onto iron oxide/hydroxide surfaces compared to Se(VI) for given geochemical conditions (Balistrieri and Chao 1987; Su and Suarez 2000).

\subsubsection{Supported Materials for Selenium Removal}

As noted in Table 3.3, there are conventional inorganic materials (metal oxides/oxyhydroxides, zero-valent iron) and organic materials (activated carbons, synthetic resins) and non-conventional materials (biosorbents) that have utility for adsorptionbased application. The adsorption-based removal of selenium species from aqueous media can be either physisorption or chemisorption in nature, depending on the nature of the adsorbent. Based on the foregoing discussion, the various inorganic and organic adsorbents have a wide range of efficiency, according to the external conditions, e.g. ionic strength, adsorbate concentration, adsorbent dosage, $\mathrm{pE}$, and $\mathrm{pH}$.

The use of nanomaterial adsorbents and their different morphological forms provide an opportunity to improve the adsorption efficiency of various materials. In the case of nanomaterials, there are challenges with their relative stability and practical utility in terms of recovery for multiple cycles of adsorption-desorption due to their high reactivity and high surface-to-volume $(\mathrm{S} / \mathrm{V})$ ratio. To address the shortcomings of chemical oxidation and agglomeration effects of nanomaterials in their dispersed form, the preparation of supported materials provides an opportunity to extend the field of application by improving the chemical stability and the recoverability through immobilization onto a suitable substrate. There are a range of selected examples of adsorbent preparation that illustrate the use of various types of conventional and unconventional substrates.

An example of the latter was shown by Kong and Wilson (2017), where they report on the preparation of goethite and its supported forms onto cellulose supports and to examine their utility as adsorbents for the uptake of 4-hydroxy-3-nitrobenzene arsenic acid (roxarsone) from aqueous media. A key result obtained in this work reveals that while iron oxide materials such as goethite are considered as efficient adsorbents for inorganic/organic oxyanions of arsenic, the supported nanomaterials had reduced iron leaching whilst maintaining comparable uptake of arsenic species at fractional $(30 \%)$ iron oxide content. The cellulose-goethite supported materials displayed favorable adsorption properties that rival those of the pure mineral phase of goethite. Similarly, Kwon et al. (2014) reported the use of iron oxide supported onto activated carbon for the adsorption of roxarsone and revealed that activated carbon supported magnetite may serve as multi-purpose adsorbents, where it was proposed that co-removal of inorganic and organic arsenicals can be achieved due to the presence of graphene and iron oxide adsorption sites. The removal of inorganic oxyanions was later supported in a kinetic adsorption study of selenite anions using magnetite and its supported materials onto activated carbon (Kwon et al. 2015).

A further illustration of the role of supported materials can be ascertained by a comparison of the uptake of hexavalent chromium by iron oxide $\left(\mathrm{Fe}_{3} \mathrm{O}_{4}\right)$ particles in 
its decorated nanoparticle form with $\mathrm{MoS}_{2}\left(\mathrm{MoS}_{2} @ \mathrm{Fe}_{3} \mathrm{O}_{4} \mathrm{NPs}\right)$ and supported forms. An approximate 18-fold increase was observed for the uptake of $\mathrm{Cr}(\mathrm{VI})$ between $\mathrm{MoS}_{2} @ \mathrm{Fe}_{3} \mathrm{O}_{4} \mathrm{NPs}$ and unmodified $\mathrm{Fe}_{3} \mathrm{O}_{4}$. Similar trends were shown for these iron oxide materials with various oxyanions, as shown for selenite and arsenate species (Kumar et al. 2017). Ramola et al. (2014) compared several feedstocks and the resulting biochar with and without ferric hydroxide impregnation of the biochar. In the case of orthophosphate adsorption, a 5-fold increase was noted for ferric ion-impregnated biochar over that of pristine biochar for this oxyanion system.

Chubar (2014) reported a Mg-Al-carbonate layered double hydroxide for the adsorption of selenite and selenate species. In the case of selenite, the following removal capacities were obtained: 80,120 and $160 \mathrm{mg}$ Se per gram (dry wt. basis of layered double hydroxide) whereas removal of selenate occurred at 30,45 and $90 \mathrm{mg}$ Se per gram (dry wt. basis of layered double hydroxide) at $\mathrm{pH} 8.5,7$ and 5, respectively. The interlayer carbonate ion of the layered double hydroxide played an important role in the removal of selenite, but it was a major mechanism for selenate adsorption by the layered double hydroxide. In this case, chemisorption was the key mechanism for selenite removal, whereas inner-sphere complexation was not detected for selenate adsorption for this adsorbent. The layered double hydroxide materials reported herein also reveal notably higher uptake for selenite and selenate, as compared against activated carbon and various metal oxides reported in the literature (Jeqadeesan et al. 2003; Chan et al. 2009a, b; Mandal et al. 2009; Yamani et al. 2014; Bleiman and Mishael 2010; Das et al. 2013; Gaini et al. 2009). Recently, a series of hierarchical and porous monolithic layered double hydroxide composites with tunable microcages were prepared by modifying the set of cationic species in the layered double hydroxide crystal (Tarutani et al. 2015).

Yamani et al. (2014) demonstrated the utility of chitosan supports for metal oxide adsorbent materials. Nanocrystalline metal oxide impregnated chitosan beads were successfully developed with nanocrystalline aluminum oxide $\left(\mathrm{n}-\mathrm{Al}_{2} \mathrm{O}_{3}\right)$ to form $\mathrm{n}-\mathrm{Al}_{2} \mathrm{O}_{3}$ impregnated chitosan beads. These impregnated beads were able to simultaneously adsorb inorganic aqueous selenite and selenate more effectively than $\mathrm{n}-\mathrm{Al}_{2} \mathrm{O}_{3}$ or chitosan alone.

Verbinnen et al. (2013) reported that a zeolite-supported magnetite was found to be suitable as an adsorbent for the simultaneous adsorption of oxyanions from wastewater. In this study, it was shown that at the ideal $\mathrm{pH}(3-3.5)$, the adsorption capacities for $\mathrm{Mo}, \mathrm{Sb}$ and $\mathrm{Se}$ oxyanions are high $(18-23 \mathrm{mg} / \mathrm{g})$. Anions like sulfate and chloride, which often occur in large amounts in wastewaters, do not really compete for adsorption places on magnetite, but other typical oxyanions largely interfere with each other. The reason for this competition is a similar adsorption mechanism (inner-sphere complex formation) for all studied oxyanions, except for selenate, that forms outersphere complexes, as supported by modeling results.

Li et al. (2015) reported on the preparation of a positively-charged pillared bentonite (Al-bent) that was used as a support for nano-zero valent iron particles for the reductive removal of anionic $\mathrm{Se}(\mathrm{VI})$ from water. A synergistic removal effect for $\mathrm{Se}(\mathrm{VI})$ removal was observed for the supported Al-bent composite, where the removal efficiency was $95.7 \%$. By comparison, this removal exceed that for the sum 
(72\%) of either single component (nano-zero valent iron, 62.1\%) and non-supported Al-bent adsorption $(9.86 \%)$.

Tan et al. (2019a) carried out a study where biochar and activated carbon were both produced from corn straw. The biochar and activated carbon were used as supports for zero valent iron, denoted as biochar-zero valent iron and activated carbonzero valent iron which were then studied as adsorbents for $\mathrm{Se}(\mathrm{IV}) / \mathrm{Se}(\mathrm{VI})$ removal. The adsorption capacity of biochar-zero valent iron for Se(IV) and $\mathrm{Se}(\mathrm{VI})$ was reported at 62.52 and $35.39 \mathrm{mg} / \mathrm{g}$. By comparison, a lower adsorption capacity was observed for activated carbon-zero valent iron, 56.02 and $33.24 \mathrm{mg} / \mathrm{g}$ for $\mathrm{Se}(\mathrm{IV})$ and $\mathrm{Se}$ (VI), respectively. The higher iron content and more positive charges of biocharzero valent iron provided and account for the difference with activated carbon-zero valent iron, in spite of it much lower BET surface area and pore volume of the former. The mechanism of removal of $\mathrm{Se}(\mathrm{IV})$ and $\mathrm{Se}(\mathrm{VI})$ from wastewater in the case of zero valent iron occurs via co-precipitation, reduction, and sorption. Moreover, the use of supported zero valent iron overcomes drawbacks associated with the long-term performance such as oxidization and agglomeration. Huang et al. (2019) reported on the preparation of activated carbon-supported $\mathrm{Fe}$ (II) and nano-zero valent iron were prepared as the permeable reactive barrier media for use in an electrolyzer. In aqueous media at equilibrium conditions, the adsorption results for the activated carbon-supported nano-zero valent iron medium had a higher adsorption capacity over the other adsorbents. The Langmuir adsorption capacity for selenite was reported, as follows: activated carbon, $26.8 \mathrm{mg} / \mathrm{g}$; activated carbon/Fe(II) $33.7 \mathrm{mg} / \mathrm{g}$; activated carbon/nano-zero valent iron, $46.5 \mathrm{mg} / \mathrm{g}$.

Svecova et al. (2011) carried out an adsorption study of selenite and selenate ions onto rutile using batch and column method. In conjunction with X-ray absorption spectroscopy results, evidence of surface complexes, where both inner- and outersphere complexes were proposed. At $\mathrm{pH} 3$, the column method yielded an adsorption capacity of $2.1 \mu \mathrm{mol} / \mathrm{g}$ for selenate and $14.8 \mu \mathrm{mol} / \mathrm{g}$ for selenite onto rutile. Jordan et al. (2014) used X-ray absorption spectroscopy to study the adsorption of selenite onto maghemite and concluded the formation of bidentate inner-sphere complexes. Tridentate complexes were favored for arsenite or antimonite species over selenite due to the incompatible smaller size of selenite.

Mandal et al. (2020) have reported the use of biochar as a support for zero valent iron and polysulfide to immobilize selenium in soil. The soil immobilization showed that the polysulfide-nano-zero valent@biochar (PS-nZVI@BC) is more effective for the control of selenium (selenite) over that of biochar and nZVI@BC. The available selenium content decreased by 77.3\% in PS-nZVI@BC amended soil after 30 days. The ternary material promoted the conversion of more accessible selenium (water-soluble and exchangeable fractions) into the less accessible forms via a range of surface process (precipitation, reduction, complexation and surface adsorption), where the latter three were dominant mechanisms for Se immobilization. Hence, PS-nZVI@BC is a promising and effective material for immobilizing selenium in contaminated soils by lowering its water exchangeable mobile fraction. The hierarchical porous structured polysulfide supported nano-zero valent iron/biochar and efficient immobilization of selenium in the soil. 
The selected examples described above reveal how the use of supports for conventional and unconventional adsorbents can contribute to a wider field of application by improvement in the overall adsorption properties, and materials stabilization toward leaching and oxidation.

\subsubsection{Selenium Rejection with Nanofiltration and Reverse Osmosis Membranes}

From all pressure-driven membrane separation technologies, which includes microfiltration, ultrafiltration, nanofiltration and reverse osmosis, only nanofiltration and reverse osmosis membranes were found to be effective for the treatment of selenium contaminated water (Santos et al. 2015; Stefaniak et al. 2018). Nanofiltration and reverse osmosis membranes offer many advantages, such as minimal impact of water quality variations, no addition of chemicals is required, and a smaller footprint required for the process equipment (Mondal and Wickramasinghe 2008).

Operating Principles of Nanofiltration/Reverse Osmosis Nanofiltration and reverse osmosis are membrane separation processes in which the driving force is the transmembrane pressure applied on a liquid to pass through a so-called semipermeable membrane. The target contaminant size in nanofiltration is in the nanometer range (e.g. multivalent ions and micropollutants), which corresponds to the approximate pore size of the membrane. In osmosis membrane, which is a typical process for seawater desalination, is used for the rejection of monovalent ions. The separation process for inorganics in nanofiltration/reverse osmosis is generally dominated by two principle factors including steric hindrance and electrostatic interaction (Owusu-Agyeman et al. 2017). The high rejection of selenium species, i.e. selenite $\mathrm{Se}(\mathrm{IV})$ and selenate $\mathrm{Se}(\mathrm{VI})$, by nanofiltration/reverse osmosis membranes is predominant by the size exclusion giving the high molecular weight and hydrated radius of both Se species (Chung et al. 2010). Se(IV) has a molecular weight of $126.96 \mathrm{~g} / \mathrm{mol}$ and a hydrated radius of $0.276 \mathrm{~nm}$ as $\mathrm{SeO}_{3}{ }^{2-}$ (Vlaev and Genieva 2004), while Se(VI) has a molecular weight of $142.96 \mathrm{~g} / \mathrm{mol}$ and a hydrated radius $0.384 \mathrm{~nm}$ as $\mathrm{SeO}_{4}{ }^{2-}$ (Nightingale 1959). In nanofiltration, Donnan exclusion mechanism, which represent the electrostatic interactions between the charged membrane surface and ions present in solution, is a further mechanism that contributes to the rejection of selenium species (He et al. 2016a, b). Schematic presentation of the main rejection mechanisms in nanofiltration/reverse osmosis membranes are shown in Fig. 3.6.

Variation of Selenium Rejection with Membrane and Water Type Various nanofiltration/reverse osmosis membranes were investigated for Se rejection from laboratory to full pilot scale and for different water types (Kharaka et al. 1996; He et al. 2016a, b, 2018c; Chung et al. 2010; Richards et al. 2011; Chehayeb and Lienhard 2017; Cingolani et al. 2018; Malhotra et al. 2020). Table 3.4 summarizes the work 


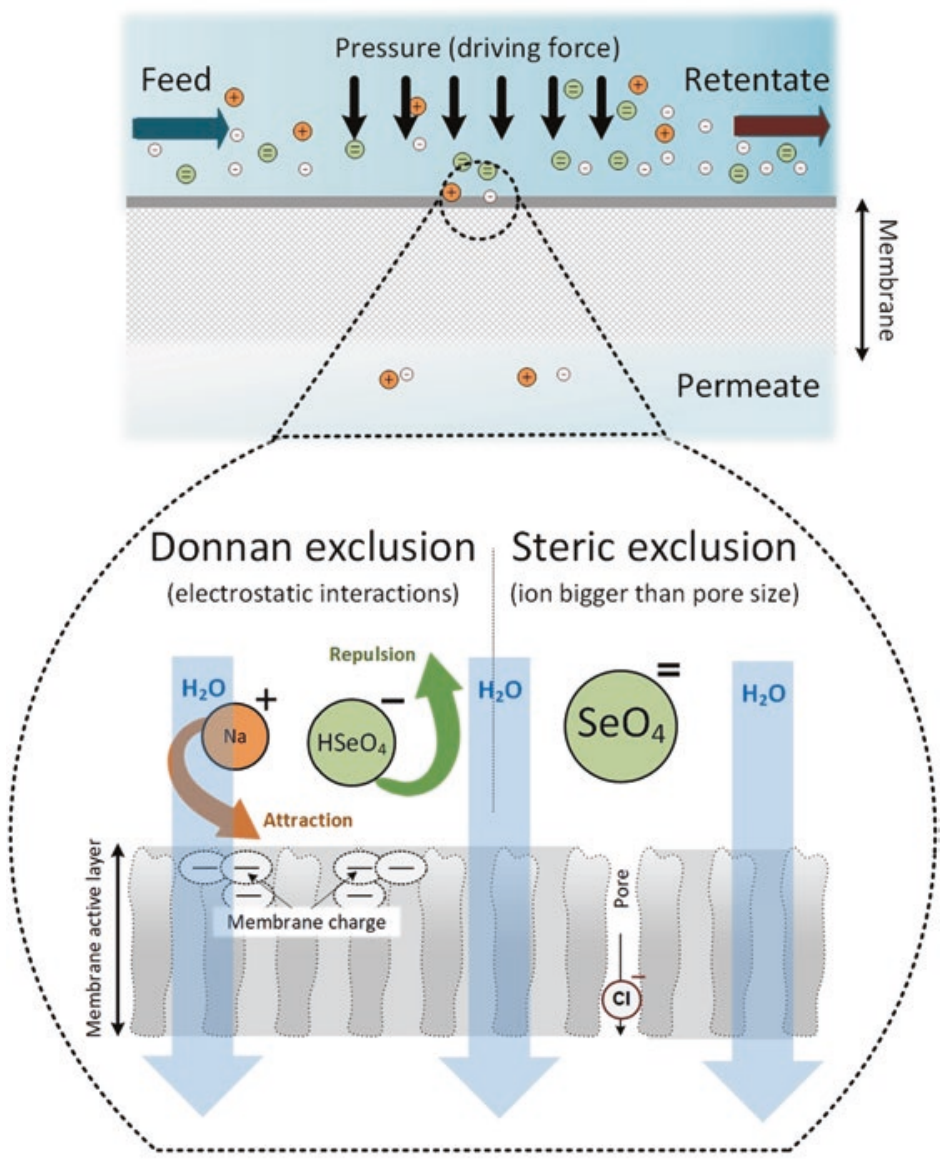

Fig. 3.6 Mechanisms of ion rejection in nanofiltration/reverse osmosis. (Source: Youssef-Amine Boussouga, Eggenstein-Leopoldshafen, Germany)

that has been reported to date on selenium rejection with nanofiltration/reverse osmosis. The rejection of selenium is generally higher with tight membranes (e.g. nanofiltration (NF1 and NF90) and reverse osmosis (BW30)) than with the loose membranes, e.g. NF2 and NF20. This is due to the different molecular weight cutoff and hence the interplay between size exclusion and charge repulsion during the separation (Krieg et al. 2005). Water type (at neutral pH) does not appear to influence the efficiency of the membranes. To further understand the effect of water chemistry on the rejection of selenium with nanofiltration/reverse osmosis, the impact of $\mathrm{pH}$ is discussed in the next section. $\mathrm{pH}$ determines what type of species selenium occurs as in water and given the importance of size exclusion and charge repulsion this may be an important contributing factor in retention. 
Table 3.4 Selenium rejection with different nanofiltration/reverse osmosis membranes. Pressure in bar; flux in $\mathrm{L} / \mathrm{m}^{2} \mathrm{~h}$; selenium rejection in \%

\begin{tabular}{|c|c|c|c|c|c|}
\hline Membrane & Water type & Pressure & Flux & $\begin{array}{l}\text { Selenium } \\
\text { rejection }\end{array}$ & References \\
\hline $\mathrm{NF}-1^{\mathrm{a}}$ & $\begin{array}{l}\text { Groundwater; } 1600 \\
\mu \mathrm{g} / \mathrm{L}, \mathrm{pH} 8\end{array}$ & 15 & 130.0 & $\begin{array}{l}95 \text { for } \mathrm{Se}(\mathrm{VI}) \\
\text { species }\end{array}$ & $\begin{array}{l}\text { Malhotra et al. } \\
(2020)\end{array}$ \\
\hline $\mathrm{NF}-2^{\mathrm{a}}$ & $\begin{array}{l}\text { Groundwater; } 1600 \\
\mu \mathrm{g} / \mathrm{L}, \mathrm{pH} 8\end{array}$ & 15 & 280.0 & $\begin{array}{l}76 \text { for } \mathrm{Se}(\mathrm{VI}) \\
\text { species }\end{array}$ & $\begin{array}{l}\text { Malhotra et al. } \\
(2020)\end{array}$ \\
\hline $\mathrm{NF} 20^{\mathrm{a}}$ & $\begin{array}{l}\text { Groundwater; } 1600 \\
\mu \mathrm{g} / \mathrm{L}, \mathrm{pH} 8\end{array}$ & 15 & 170.0 & $\begin{array}{l}61 \text { for } \mathrm{Se}(\mathrm{VI}) \\
\text { species }\end{array}$ & $\begin{array}{l}\text { Malhotra et al. } \\
(2020)\end{array}$ \\
\hline BW30 & $\begin{array}{l}\text { Brackish groundwater; } \\
15 \mu \mathrm{g} / \mathrm{L}, \mathrm{pH} 8\end{array}$ & 9 & 13.5 & $\geq 93.8^{\mathrm{d}}$ & $\begin{array}{l}\text { Richards et al. } \\
\text { (2011) }\end{array}$ \\
\hline NF90 ${ }^{a}$ & $\begin{array}{l}\text { Brackish groundwater; } \\
15 \mu \mathrm{g} / \mathrm{L}, \mathrm{pH} 8\end{array}$ & 15 & 23.1 & $\geq 92.9^{\mathrm{d}}$ & $\begin{array}{l}\text { Richards et al. } \\
\text { (2011) }\end{array}$ \\
\hline TFC-S ${ }^{a}$ & $\begin{array}{l}\text { Brackish groundwater; } \\
15 \mu \mathrm{g} / \mathrm{L}, \mathrm{pH} 8\end{array}$ & 15 & 24.3 & $90.2^{\mathrm{d}}$ & $\begin{array}{l}\text { Richards et al. } \\
\text { (2011) }\end{array}$ \\
\hline ESPA4 $^{\mathrm{a}}$ & $\begin{array}{l}\text { Brackish groundwater; } \\
15 \mu \mathrm{g} / \mathrm{L}, \mathrm{pH} 8\end{array}$ & 15 & 23.1 & $92.6^{\mathrm{d}}$ & $\begin{array}{l}\text { Richards et al. } \\
\text { (2011) }\end{array}$ \\
\hline FILMTEC NF & $\begin{array}{l}\text { Agricultural drainage } \\
\text { water; }<1000 \mu \mathrm{g} / \mathrm{L}\end{array}$ & - & - & $>95^{\mathrm{d}}$ & $\begin{array}{l}\text { Kharaka et al. } \\
\text { (1996) }\end{array}$ \\
\hline ESPA $^{a}$ & $\begin{array}{l}\text { Wastewater; } 326 \mu \mathrm{g} / \mathrm{L} \text {, } \\
\text { pH } 7.2\end{array}$ & 8 & - & $\begin{array}{l}\text { 99-94 for } \\
\text { Se(IV) species }\end{array}$ & $\begin{array}{l}\text { Chung et al. } \\
(2010)\end{array}$ \\
\hline $\mathrm{ESNA}^{\mathrm{a}}$ & $\begin{array}{l}\text { Wastewater; } 326 \mu \mathrm{g} / \mathrm{L} \text {, } \\
\text { pH } 7.2\end{array}$ & 8 & - & $\begin{array}{l}\text { 93-72 for } \\
\text { Se(IV) species }\end{array}$ & $\begin{array}{l}\text { Chung et al. } \\
(2010)\end{array}$ \\
\hline POSS-PA TFN & $\begin{array}{l}\text { Synthetic solutions; } \\
1000 \mathrm{mg} / \mathrm{L} \text {, pH } 7.5\end{array}$ & 10 & 54.0 & $\begin{array}{l}93.9 \text { for } \\
\mathrm{Se}(\mathrm{VI}) \text { species }\end{array}$ & $\begin{array}{l}\text { He et al. (2016a, } \\
\text { b) }\end{array}$ \\
\hline POSS-PA TFN & $\begin{array}{l}\text { Synthetic solutions; } \\
1000 \mathrm{mg} / \mathrm{L}, \mathrm{pH} 7.5\end{array}$ & 10 & 54.0 & $\begin{array}{l}96.5 \text { for } \\
\text { Se(IV) species }\end{array}$ & $\begin{array}{l}\text { He et al. (2016a, } \\
\text { b) }\end{array}$ \\
\hline TFN-30 & & 10 & 115.0 & $\begin{array}{l}96.5 \text { for } \\
\text { Se(VI) species }\end{array}$ & $\begin{array}{l}\text { Chehayeb and } \\
\text { Lienhard (2017) }\end{array}$ \\
\hline TFN-30 & & 10 & 115.0 & $\begin{array}{l}97.4 \text { for } \\
\text { Se(IV) species }\end{array}$ & $\begin{array}{l}\text { Chehayeb and } \\
\text { Lienhard (2017) }\end{array}$ \\
\hline TFC- $50^{\mathrm{b}}$ & & 10 & 85.0 & $\begin{array}{l}98.2 \text { for } \\
\mathrm{Se}(\mathrm{VI}) \text { species }\end{array}$ & $\begin{array}{l}\text { He et al. (2018a, } \\
\text { b, c) }\end{array}$ \\
\hline TFC- $50^{\mathrm{b}}$ & & 10 & 85.0 & $\begin{array}{l}99.1 \text { for } \\
\text { Se(IV) species }\end{array}$ & $\begin{array}{l}\text { He et al. (2018a, } \\
\text { b, c) }\end{array}$ \\
\hline $\begin{array}{l}\text { DT-RO (Gel } \\
\text { GPT-BW 30) }\end{array}$ & $\begin{array}{l}\text { Landfill leachate; } 63 \\
\mu \mathrm{g} / \mathrm{L}, \mathrm{pH} 7.2\end{array}$ & $60^{c}$ & 32.5 & $>94^{\mathrm{d}}$ & $\begin{array}{l}\text { Cingolani et al. } \\
\text { (2018) }\end{array}$ \\
\hline
\end{tabular}

${ }^{\mathrm{a} C o m m e r c i a l ~ m e m b r a n e ~}$

bLaboratory made membrane

'Data from the third stage of a multistage disc tube reverse osmosis (DT-RO) system

${ }^{\mathrm{d} N o}$ information about the rejected Se species

Effect of Speciation on Selenium Rejection In water, selenium can occur in different oxidation forms (-II, IV, VI) which depends on the redox potential, $\mathrm{pH}$, dissolved organic matter, and microbial activities (Kumar and Riyazuddin 2011). $\mathrm{Se}(\mathrm{IV})$ and $\mathrm{Se}$ (VI) species are the predominant Se forms in water (Chand and Prasad 2009). Se(IV) species are found in moderately oxidizing environment (moderate 
concentration of dissolved $\mathrm{O}_{2}$ as electron acceptor), while $\mathrm{Se}(\mathrm{VI})$ species are mostly present in oxidizing environment of high dissolved $\mathrm{O}_{2}$ concentration (Sharma et al. 2019). For instance, in environment conditions of $\mathrm{pH} 8.1$ and with electron activity (pE) of 12.5, the concentration of $\mathrm{Se}(\mathrm{VI})$ would be estimated to be 10 times higher than Se(IV) concentration (Sharma et al. 2019). In nanofiltration/reverse osmosis, the speciation chemistry of a contaminant affects the rejection mechanisms in both size and charge mechanisms (Richards et al. 2009). The influence of the $\mathrm{pH}$ on the speciation of Se is shown in Fig. 3.7. He et al. (2016a, b) have investigated the effect of the speciation on $\mathrm{Se}(\mathrm{IV})$ and $\mathrm{Se}(\mathrm{VI})$ rejection by varying $\mathrm{pH}$ during the filtration experiments with a laboratory made nanofiltration membrane (see Fig. 3.7). Higher rejection $(>90 \%)$ of $\mathrm{Se}(\mathrm{IV})$ was observed at $\mathrm{pH}>9$, where the divalent $\mathrm{SeO}_{3}{ }^{2-}$

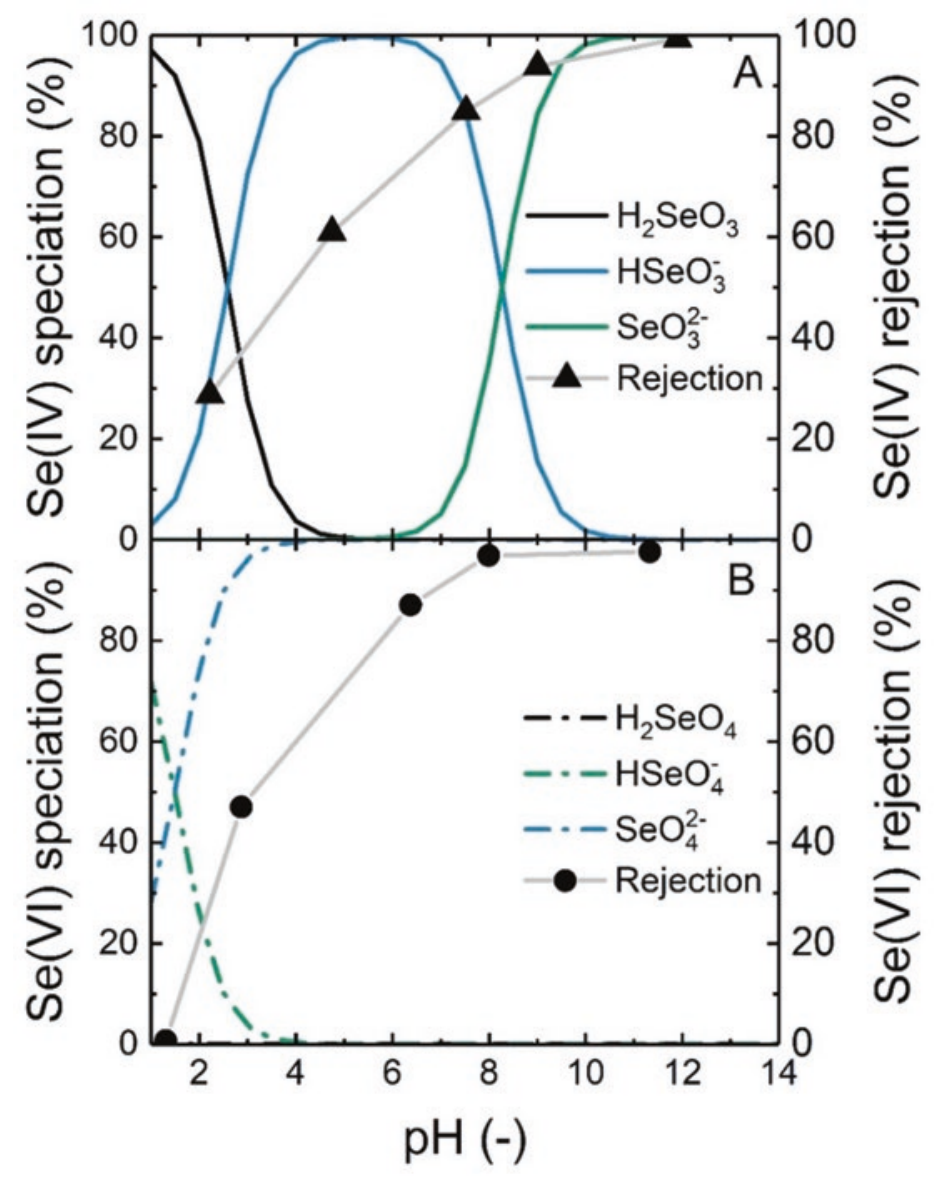

Fig. 3.7 Speciation of selenium (Se) and its rejection with laboratory-made TFN membrane, adapted from $\mathrm{He}$ et al. (2016a, b); speciation of $\mathrm{Se}(\mathrm{IV})$ and $\mathrm{Se}(\mathrm{VI})$ was calculated at $25^{\circ} \mathrm{C}$ and $\mathrm{CO}_{2}$ partial pressure of $3.9 \cdot 10^{-4}$ bar, by using the software MINTEQ v.3.1, KTH, Sweden 
becomes the dominant species as shown in Fig. 3.7a. In the other hand, the rejection of $\mathrm{Se}(\mathrm{VI})$ was higher than in the case of $\mathrm{Se}(\mathrm{IV})$ at all $\mathrm{pH}$ values due to the presence of the divalent $\mathrm{SeO}_{4}{ }^{2-}$ species in water from $\mathrm{pH}>4$ (see Fig. 3.7b). Similar behavior was observed with commercial nanofiltration membranes used to remove $\mathrm{Se}(\mathrm{VI})$ (Malhotra et al. 2020). Further, it is noted that the increase in $\mathrm{Se}(\mathrm{VI})$ rejection with $\mathrm{pH}$ is influenced by the surface charge characteristic of the membrane that becomes more negative with increasing the $\mathrm{pH}$, like most polymeric nanofiltration/reverse osmosis membranes. To sum-up, $\mathrm{pH}$ variation in water and wastewater affect the efficiency of nanofiltration/reverse osmosis process especially when using loose nanofiltration membranes where the dominant separation mechanism is charge exclusion. In addition to water chemistry, the separation efficiency of nanofiltration/ reverse osmosis processes further depend on the operating conditions, such as pressure and recovery that are reviewed in the subsequent section.

Effect of Operating Conditions - Transmembrane Pressure and Recovery In addition to water chemistry, nanofiltration/reverse osmosis performance is also influenced by the operating conditions, such as the applied (transmembrane) pressure and recovery (Ballet et al. 2007; Lee et al. 2015). Transmembrane pressure variations affect the water transport and hence the diluting effect (Verliefde et al. 2013), and determines flux and recovery. Regarding the recovery, which is the ratio of permeate production by feed volume, is also known by its influence on permeate quality and membrane fouling/scaling (Lee et al. 2015). Malhotra et al. (2020) have investigated the effect of transmembrane pressure on the $\mathrm{Se}(\mathrm{VI})$ rejection with loose (NF2) and tight (NF2) nanofiltration membranes, whereas, Chung et al. (2010) have studied the effect of the recovery and $\mathrm{Se}(\mathrm{VI})$ rejection with nanofiltration/reverse osmosis membranes. Results from both studies are shown in Fig. 3.8. Results shows that, the rejection of $\mathrm{Se}(\mathrm{VI})$ increased with the transmembrane pressure and from 15 bar the rejection remained constant for both nanofiltration membranes (Fig. 3.8a). This behavior is explained by solution-diffusion mechanism where the solvent flux increases with the transmembrane pressure resulting in high rejection (Verliefde et al. 2013). On the other hand, the observed decrease in rejection with recovery (see Fig. 3.8b) has been attributed to the increase of $\mathrm{Se}(\mathrm{VI})$ concentration at the membrane surface (concentration polarization) which enhances the solute transport through the membrane (Chung et al. 2010). In addition, at higher recovery, the rejection of $\mathrm{Se}(\mathrm{VI})$ with the nanofiltration was more affected than with the reverse osmosis membrane where the ions transfer is known to be less convective and more diffusive (Pontié et al. 2008). In summary, the rejection of Se with nanofiltration/ reverse osmosis membranes increases with transmembrane pressure whereas it decreases with the recovery. However, further in-depth investigations are still needed to work at high recovery and thus to decrease the retentate quantity without affecting the efficiency of the nanofiltration/reverse osmosis process.

\section{Gaps in Knowledge in Selenium Removal by Nanofiltration/Reverse}

Osmosis Besides the studies on the effect of $\mathrm{pH}$ and ultimately the speciation on the rejection of selenium with nanofiltration/reverse osmosis, future studies that 


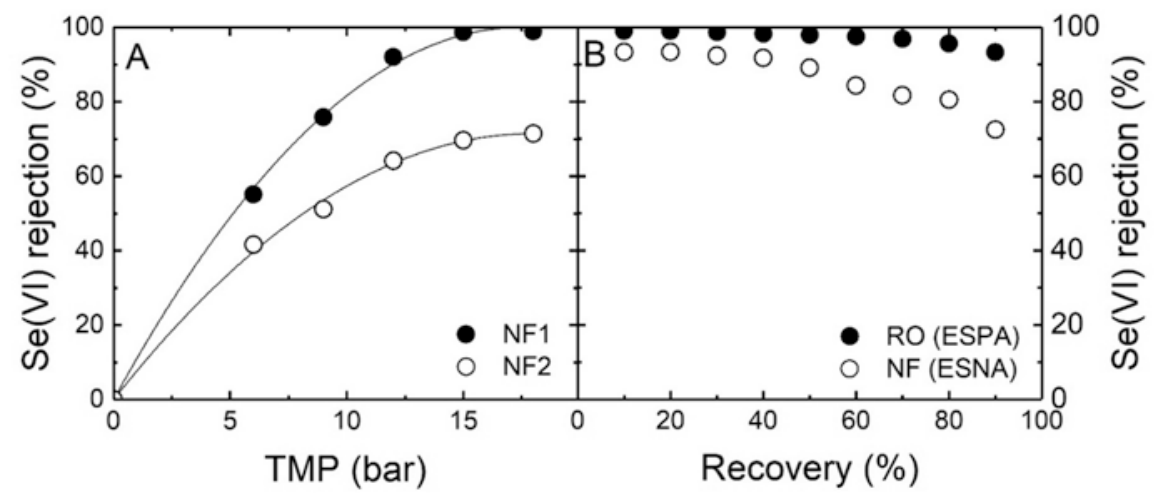

Fig. 3.8 Rejection of Se(VI) with nanofiltration/reverse osmosis membranes as a function (a) the transmembrane pressure (TMP) and (b) the recovery (source: (a) adapted from Malhotra et al. (2020): Se(VI) $1600 \mu \mathrm{g} / \mathrm{L}$ and $\mathrm{pH} 8$; (b) adapted from Chung et al. (2010): S(VI) $326 \mu \mathrm{g} / \mathrm{L}, \mathrm{pH} 7.2$ and pressure 8 bar)

investigate the impact of the solute-solute interactions. The presence of other compounds and how these interact with selenium, such as phosphates (in case of wastewater), hardness and organic matter (in case of natural water) has to date not been investigated. In this context, further research is needed to fully understand, for instance, the solute-solute interactions that can impact the rejection of Se and the complex transport mechanisms through the nanofiltration/reverse osmosis membrane. Regarding the impact of the operating conditions on selenium rejection with nanofiltration/reverse osmosis, futures studies need to focus on the velocity variations (in case of cross flow systems) that effect mass transfer. For the process itself, much more dedicated work focused on system design and the optimization of the operating parameters to achieve zero liquid discharge and eventually lower specific energy consumption.

\subsubsection{Selenium Removal Using Electrodialysis}

Operating Principles of Electrodialysis Electrodialysis is an electro-membrane process, in which the driving force is the electrical potential over the membrane stack that generates a direct electric current. Anions are moved from the cathode to the anode, while cations move in the other direction. While counter-ions can pass through the ion exchange membranes, co-ions are repulsed from similarly charged membranes and cannot be transported across. The target in electrodialysis is to only remove charged ions, therefore electrodialysis is generally incapable of removing non-charged elements from water streams. Figure 3.9 shows the basic concept of an electrodialysis process. Electrodialysis is more energy efficient compared to reverse osmosis for desalinating brackish water. Specifically, in desalinat- 


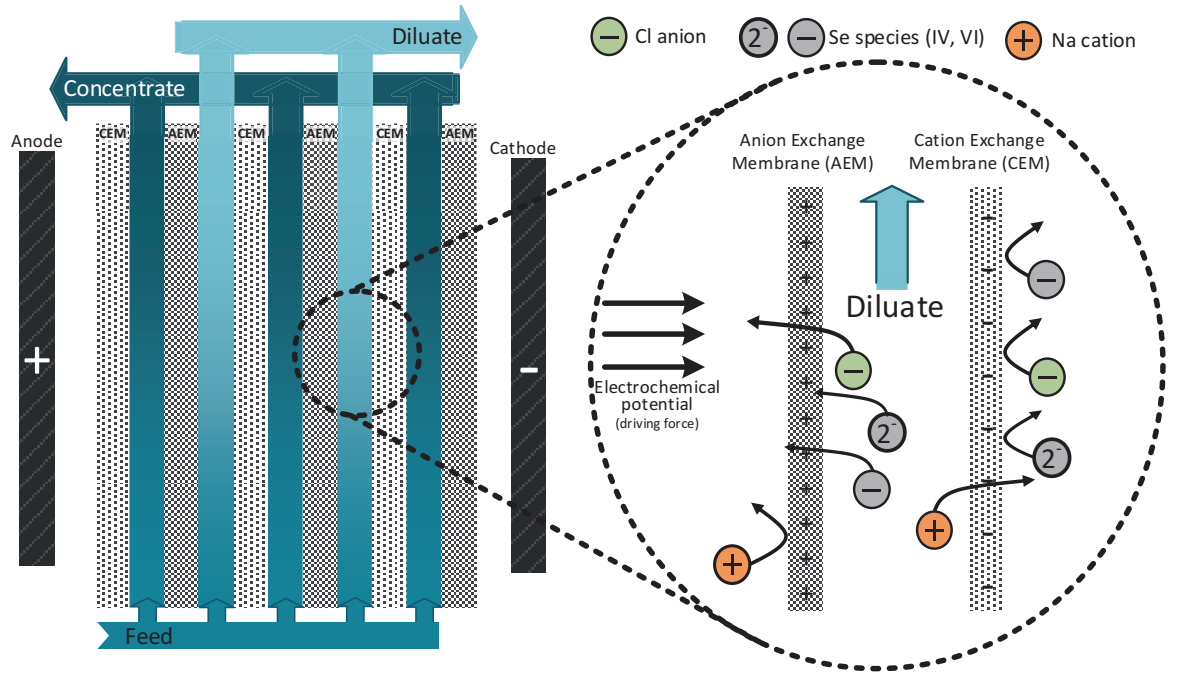

Fig. 3.9 Principle of an electrodialysis process. (Source: Mehran Aliaskari, EggensteinLeopoldshafen, Germany)

ing brackish water with salinity of $4 \mathrm{~g} / \mathrm{L}$ total dissolved solids or less; this higher efficiency also depends on the recovery of the process and extent of salt removal (Karimi et al. 2015; Patel et al. 2021). Both selenium species, selenite (Se(IV)) and selenate $(\mathrm{Se}(\mathrm{VI}))$ are anions in the neutral $\mathrm{pH}$ range. In consequence, electrodialysis can in principle remove common selenium species from water. Electrodialysis can indeed remove different trace inorganic contaminants including fluoride, nitrate and $\operatorname{arsenic}(\mathrm{V})$ from brackish water to some extent (Onorato et al. 2017). However, reports on selenium removal by electrodialysis are to date very sparse.

Effect of Operative Parameters on Selenium Removal by Electrodialysis In the absence of data on selenium removal by electrodialysis, one can consider the removal of similar ions. Kim et al. (2012) have investigated the competitive separation of single- versus double-charged ions by electrodialysis in different flowrates. The results suggest that at higher flowrates, double-charged ions show a somewhat increased transport compared to single charged ions. The higher transport of doublecharged ions in higher flowrates is attributed to the thinner boundary layer, as the limiting factor for ion transport in electrodialysis is this layer, in which diffusivity and mobility of the ions play an important role in transport. Selenate is analogous to sulfate and has similar chemistry and diffusivity in water (see Table 3.5), therefore similar removal by electrodialysis can be expected for them. Sosa-Fernandez et al. (2019) show that an increase in current intensity had little impact on the final sulfate removal, and high sulfate removals up to $97 \%$ can be achieved when diluate solution is depleted of other anions such as chloride. However, Onorato et al. (2017) have investigated the effect of applied electrical potential on selenium removal. By an increase in electrical potential from 12 to $18 \mathrm{v}$, selenium removal is improved from 
Table 3.5 Diffusion coefficient of different anions in water at $25^{\circ} \mathrm{C}$ and $1 \mathrm{~atm}$

\begin{tabular}{l|l|l|l|l|l|l}
\hline Diffusion coefficient & Se $(I V)$ & Se $(V I)$ & Sulfate $^{\mathrm{c}}$ & Chloride $^{\mathrm{c}}$ & Nitrate $^{\mathrm{c}}$ & Fluoride $^{\mathrm{c}}$ \\
\hline Ionic mobility $\left(\times 10^{12} \mathrm{~mol} \mathrm{~s} / \mathrm{kg}\right)$ & 0.36 & 0.38 & 0.43 & 0.82 & 0.77 & 0.59 \\
\hline Diffusivity $\left(\times 10^{9} \mathrm{~m}^{2} / \mathrm{s}\right)$ & 0.89 & 0.94 & 1.06 & 2.03 & 1.90 & 1.47 \\
\hline
\end{tabular}

aida et al. (2011)

bYuan-Hui and Gregory (1974)

'HDR Engineering Inc (2002)

$33 \%$ to $48 \%$. Karimi and Ghassemi (2015) have shown that electric potential has a bigger impact on divalent ions compared to monovalent ions. Figure 3.10 shows the speciation of selenium compounds over a $\mathrm{pH}$ range of 1 to 13 . As the $\mathrm{pH}$ of the sample water tested by Onorato et al. (2017) is reported at 7 to 9, selenium is divalent in this $\mathrm{pH}$.

Effect of Speciation on Selenium Removal with Electrodialysis In a general study with brackish water that contained some Se, Onorato et al. (2017) have also investigated Se removal as a function of $\mathrm{pH}$. The brackish water had an electric conductivity of $8290 \mu \mathrm{S} / \mathrm{cm}(\approx 5.3 \mathrm{~g} / \mathrm{L} \mathrm{NaCl})$. In this, selenate $(\mathrm{Se}(\mathrm{VI}))$ was the dominant Se species at a relatively low concentration of $20 \mu \mathrm{g} / \mathrm{L}$ (WHO guideline: $40 \mu \mathrm{g} / \mathrm{L}$ (WHO 2017)), while no data for selenite Se(IV) was reported. Removal of Se(VI) is shown in Fig. 3.10, along with speciation simulation for both $\mathrm{Se}$ (VI) and $\mathrm{Se}$ (IV) in $\mathrm{pH} 1$ to 13 by Minteq (v3.1, KTH, Sweden). Removal of selenate (Se(VI)) at neutral $\mathrm{pH}$ was about $40 \%$, and indeed relatively low. Unfortunately, no removal data for selenite (Se(IV)) is available. However, Based on the speciation of $\mathrm{Se}(\mathrm{IV})$ in Fig. 3.10, it is expected that Se(IV) removal would be maximum in between $\mathrm{pH}$ 4 to 7 , where selenium is dominantly monovalent. This is expected due to the higher diffusivity and lower hydration number of monovalent species compared to divalent ions (Marcus 1997; Tanaka et al. 2013). The increased removal of Se(VI) in pH 8 to 11 (see Fig. 3.10) was attributed to the presence of calcium, which may have caused a co-precipitation of various ions (i.e. $\left.\mathrm{CaSeO}_{4}\right)($ Onorato et al. 2017). The complexity of the real water used in these experiments makes it difficult to draw meaningful conclusions about selenium removal by electrodialysis from these results. In the case of specific wastewaters that require pretreatment steps before the electrodialysis process, the $\mathrm{pH}$ of the feed must be considered as selenium removal is $\mathrm{pH}$ dependent and hence will be affected strongly by $\mathrm{pH}$ variation. For example, Gingerich et al. (2018) investigated selenium removal from wastewater of coal-fired power plants. After a pretreatment process necessary for removing other contaminants, the $\mathrm{pH}$ of the wastewater is high and therefore the solution $\mathrm{pH}$ may have an impact on selenium removal by electrodialysis based on the very limited observations from Onorato et al. (2017).

Effect of Competing Anions on Selenium Removal by Electrodialysis While electrodialysis can in principle remove trace selenium concentrations, presence of other anions in water may hinder Se removal through competition. While there is no data available for Se, this process is likely from observations with other similar ions. For 


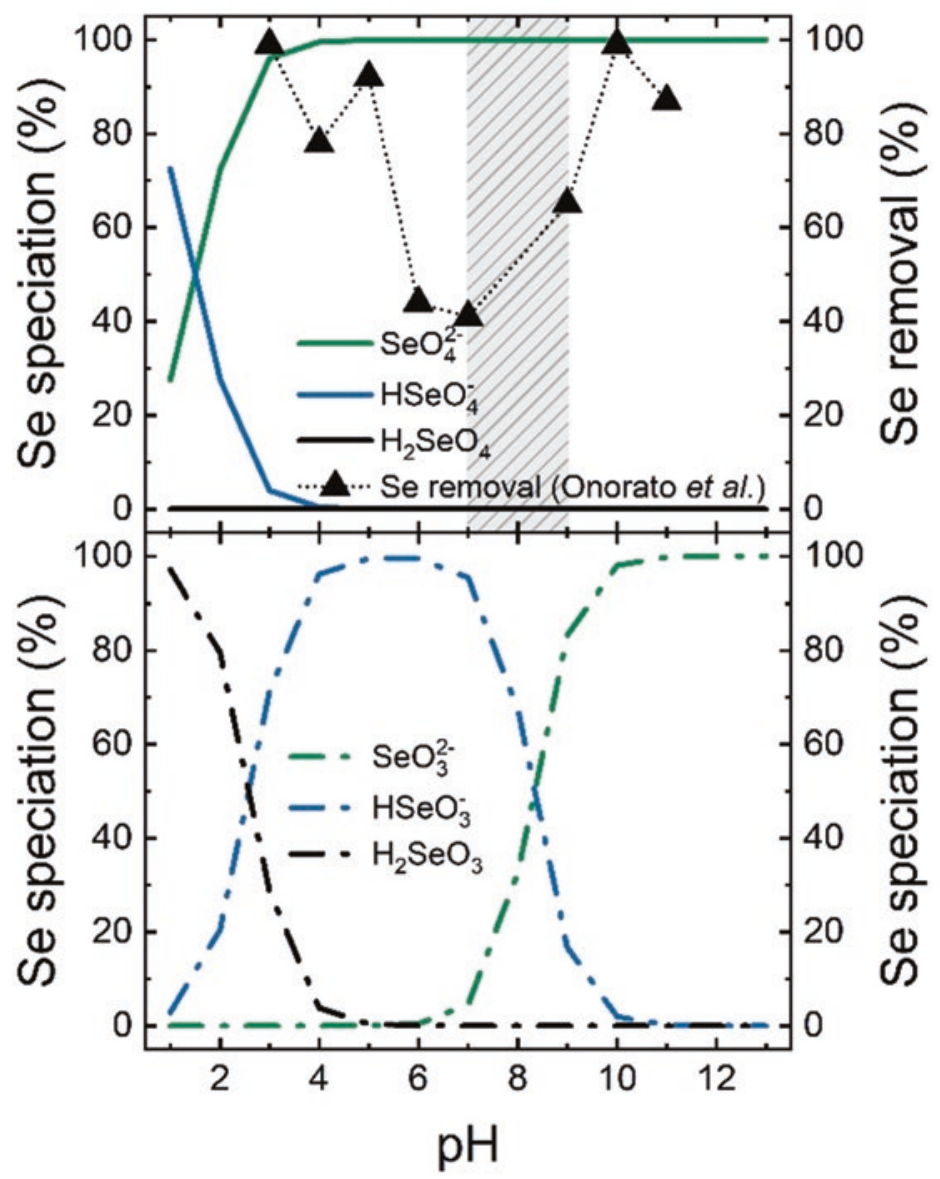

Fig. 3.10 Speciation of selenium VI (top) and IV (bottom) over pH 1 to 13 and removal of selenium VI, adapted from Onorato et al. (2017); electric potential $12 \mathrm{~V}$; feed salinity $5.3 \mathrm{~g} / \mathrm{L}$; membranes Neosepta CMX-SB \& AMX-SB, Tokuyama Soda Ltd., Japan; the highlighted pH range shows the real $\mathrm{pH}$ of sample water used which was then modified by adding $\mathrm{HCl}$ and $\mathrm{NaOH}$ )

example, in experiments removing sulfate from saline water, Sosa-Fernandez et al. (2019) showed that the removal of sulfate was always lower than that of chloride. It is expected that oxoselenium anions removal follow the same trend as sulfate because selenium and sulphur are both in the 15th group of the periodic table and have chemical similarities, e.g. ionic mobility and diffusion coefficient in Table 3.5. Ionic mobility and diffusion coefficient of selenium species and different anions are presented in Table 3.5. Lower mobility and diffusivity of both $\mathrm{Se}(\mathrm{IV})$ and $\mathrm{Se}(\mathrm{VI})$, suggest that an increase in the salinity of the feed water may result in a lower removal of selenium due to the competition of other present anions in water to be transported. 
Gaps in Knowledge in Selenium Removal by Electrodialysis Very few studies on Se removal by electrodialysis have been reported to date. Several handbooks (HDR Engineering Inc 2002) and patents (Wallace 2013a, b) mention electrodialysis as a process to remove selenium from water, in the reviewed documents no references or experimental results other than reports of the charged state of selenium species in water was observed. Moreover, in mentioned patents (Wallace 2013a, b), it is suggested to have a selenium removal process after electrodialysis to ensure complete selenium removal from product water. This implies that no complete removal was expected. Additionally, the complex chemistry of real brackish groundwater in the only published study (Onorato et al. 2017) makes it difficult to conclude the effectiveness of electrodialysis for selenium removal. Presence of other compounds (e.g. hardness, organic matter, multivalent ions and salinity) in water may affect selenium removal by electrodialysis. More systematic experiments are needed to understand the mechanisms and the ability of various electrodialysis membranes and operating parameters to achieve effective Se removal.

\subsubsection{Remediation of Solutions Containing Selenium by Chitosan-Enhanced Ultrafiltration}

Pressure-driven membrane processes such as reverse osmosis and nanofiltration are able to reject species with very low molecular weight such as metal ions. In reverse osmosis, the separation of various species of a mixture is related directly to their relative transport rates within the membrane, which are determined by their diffusivity and solubility in the membrane material. In nanofiltration, the separation of solutes results from a complex mechanism including steric hindrance dependent on the relative sizes of the pores and the solutes (Ferry 1936), Donnan exclusion resulting from the Coulomb interaction between charged solutes and the membrane fixed charge (Donnan 1995), dielectric exclusion in terms of both Born dielectric effect, resulting from the solvation energy barrier due to the decrease of the dielectric constant of the solution inside the membrane pores (Bowen et al. 1997; Déon et al. 2012) and image charge effects due to the interaction between the ions and the polarization charges, induced by the ions, at the interface between the membrane matrix and the solution inside the pores (Yaroshchuk 2000; Szymczyk et al. 2005). Reverse osmosis is generally used when a total retention of ions is desired whereas nanofiltration is rather dedicated to partial demineralization of waters. However, even if reverse osmosis and nanofiltration processes are capable of rejecting ions, unfortunately, they produce relatively low permeation fluxes and requires high transmembrane pressures to obtain significant flux (Table 3.6), which result in a high energy cost. Oppositely, ultrafiltration requires lower applied pressures while providing higher permeation fluxes, but the small solute removal performances are much lower due to larger pores. 
Table 3.6 Comparison of different pressure-driven membrane processes

\begin{tabular}{l|l|l|l|l}
\hline & $\begin{array}{l}\text { Reverse } \\
\text { osmosis }\end{array}$ & Nanofiltration & Ultrafiltration & References \\
\hline $\begin{array}{l}\text { Molecular weight } \\
\text { cut-off (kDa) }\end{array}$ & $<0.1$ & $0.1-1$ & $1-300$ & \\
\hline Pore diameters (nm) & $<0.5$ & $0.5-2$ & $2-100$ & \\
\hline $\begin{array}{l}\text { Transmembrane } \\
\text { pressure (bar) }\end{array}$ & $80-30$ & $40-10$ & $5-1$ & $\begin{array}{l}\text { Aimar et al. } \\
(2010)\end{array}$ \\
\hline $\begin{array}{l}\text { Permeation flux (L/ } \\
\mathbf{h m}^{2} \text { ) }\end{array}$ & $10-60$ & $50-100$ & $50-500$ & $\begin{array}{l}\text { Aimar et al. } \\
(2010)\end{array}$ \\
\hline $\begin{array}{l}\text { Exclusion } \\
\text { mechanisms }\end{array}$ & $\begin{array}{l}\text { Solution- } \\
\text { diffusion }\end{array}$ & $\begin{array}{l}\text { Steric, electric and } \\
\text { dielectric effects }\end{array}$ & $\begin{array}{l}\text { Steric and } \\
\text { electric effects }\end{array}$ & \\
\hline
\end{tabular}

(a)
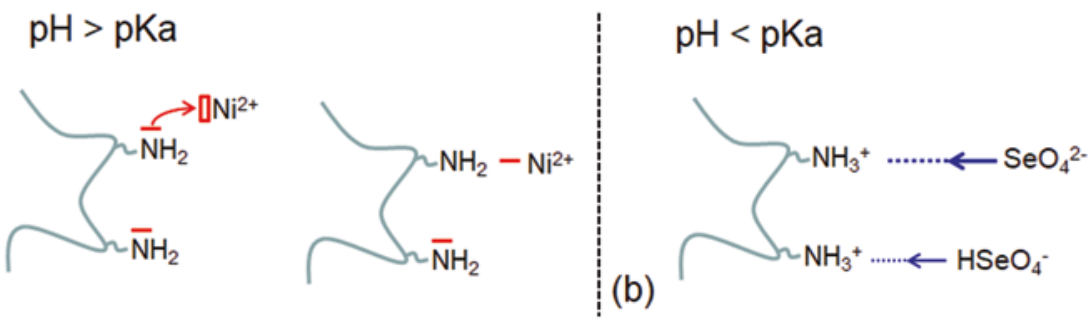

Fig. 3.11 (a) Complexation mechanism with metal ions, and (b) electrostatic attraction with oxyanions of $\mathrm{Se}(\mathrm{VI})$ by amine groups of polymers

However, the range of use of ultrafiltration can be enlarged towards solutes smaller than membrane pores by means of pretreatments such as micellization (Kryvoruchko et al. 2002; Witek et al. 2005; Chhatre et al. 2008) or complexation (Rumeau et al. 1992; Kryvoruchko et al. 2002; Mimoune et al. 2007). This preliminary treatment aims at increasing the effective size of ions for improving their rejection due to steric effects. This step is implemented by complexation of metal ions with either synthetic polymers, such as polyethylenimine (Molinari et al. 2004) poly(acrylic acid) (Cojocaru et al. 2007) and macrocycle and macromolecular compounds (Walkowiak et al. 2009) or natural polymers, such as alginate (Fatin-Rouge et al. 2006) and chitosan (Crini et al. 2017) as chelating agent. Due to their many potential donor sites, these polymers have shown very interesting trends for complexation of various metal cations such as copper, lead, nickel, and cobalt by coordinate bonds with lone pairs of ligand. This mechanism of metal complexation is well-known (Rivas et al. 2003) (Fig. 3.11a) and has been investigated many times (Lam et al. 2018).

Polymers can also be used for the removal of anionic pollutants. In this case, physicochemical mechanisms leading to links between ions and polymers are different, and attractive electrostatic interactions can be used. In the case of selenium removal, a polymer with positively charged groups such as protonated amine groups $\left(-\mathrm{NH}_{3}{ }^{+}\right)$must be chosen to induce attractive electrostatic interaction with oxyanions of selenium, as it is depicted in Fig. 3.11b. 


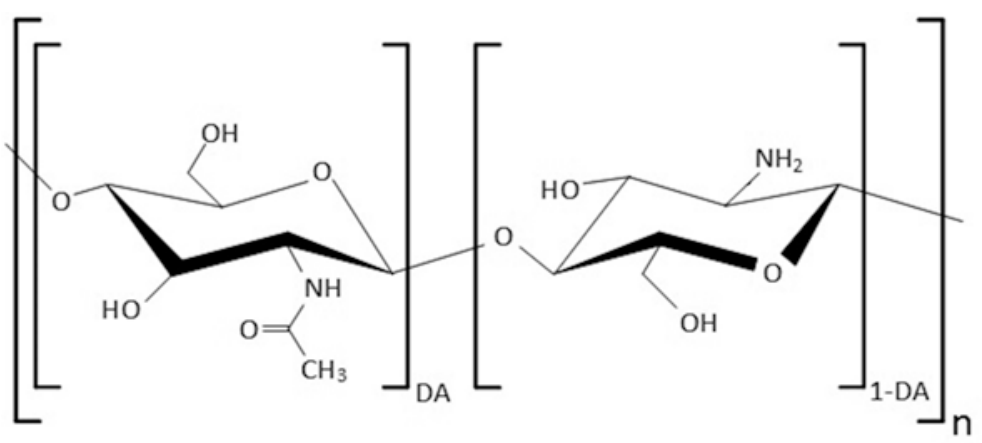

Fig. 3.12 Chitosan molecule. DA: degree of acetylation

The rejection of oxyanions forms of Se(IV) and (VI) by chitosan-enhanced ultrafiltration was investigated under various experimental conditions by Déon et al. (2017). Chitosan was chosen because its structure contains amino $\left(-\mathrm{NH}_{2}\right)$ groups as well as numerous hydroxyl groups conferring a strong hydrophilic character. In this study, polymer-enhanced ultrafiltration of oxyanions was implemented under acid conditions $\left(\mathrm{pH}<\mathrm{pK}_{\mathrm{a} \text { chitosan }}=6.3\right)$ for which amine groups $\left(-\mathrm{NH}_{2}\right)$ of the deacetylated part (1-DA in Fig. 3.12) were protonated. Polymer then behaved like a positively charged polyelectrolyte.

In order to better understand the rejection of Se(IV) and Se(VI), it is also worthwhile to keep in mind that the latter can be present in different forms depending on $\mathrm{pH}$ value. As shown by Fig. 3.13, for acid $\mathrm{pH}, \mathrm{Se}$ (IV) can be in neutral form (selenious acid) and/or monovalent anion form (hydrogen selenite) whereas it can be in monovalent anion form (hydrogen selenite) and/or in divalent anion form (selenite ions) at basic $\mathrm{pH}$ values. As to $\mathrm{Se}(\mathrm{VI})$, it is mainly in divalent anion form (selenite ion) for $\mathrm{pH}$ above 3.5 .

The impact of chitosan addition on rejection of Se(IV) and (VI) by a ultrafiltration membrane can be observed in Figs. 3.14a and b, respectively. It clearly appears that chitosan addition before filtration contributes substantially to increasing rejection of selenium, the form of which is monovalent $\left(\mathrm{HSeO}_{3}{ }^{-}\right)$or divalent $\left(\mathrm{SeO}_{4}{ }^{2-}\right)$ at the $\mathrm{pH}$ of the solution $(\mathrm{pH}=4)$. In this $\mathrm{pH}$ condition, electrostatic attraction between the positive $-\mathrm{NH}_{3}{ }^{+}$groups of chitosan and the negative charge of oxyanions allows a notable increase of selenium rejection, although complexation does not occur. The addition of $120 \mathrm{~mol}$ of monomer units per mol of Se(VI) even makes it possible to obtain rejection rate close to $95 \%$ (Fig. 3.14b). In the absence of polymer, it should be noted that $\mathrm{Se}(\mathrm{VI})$ is more rejected than $\mathrm{Se}(\mathrm{IV})$ in the same conditions, due to stronger repulsive interactions between the negatively charged membrane and divalent anions $\left(\mathrm{SeO}_{4}{ }^{2-}\right)$ as compared with monovalent anion $\left(\mathrm{HSeO}_{3}{ }^{-}\right)$. Figures 3.14a and $\mathrm{b}$ also show that the permeation flux notably decreases when concentration of chitosan increases due to the increase in viscosity of solutions and accumulation of polymer/ion at the membrane surface. However, these flux values are still much 

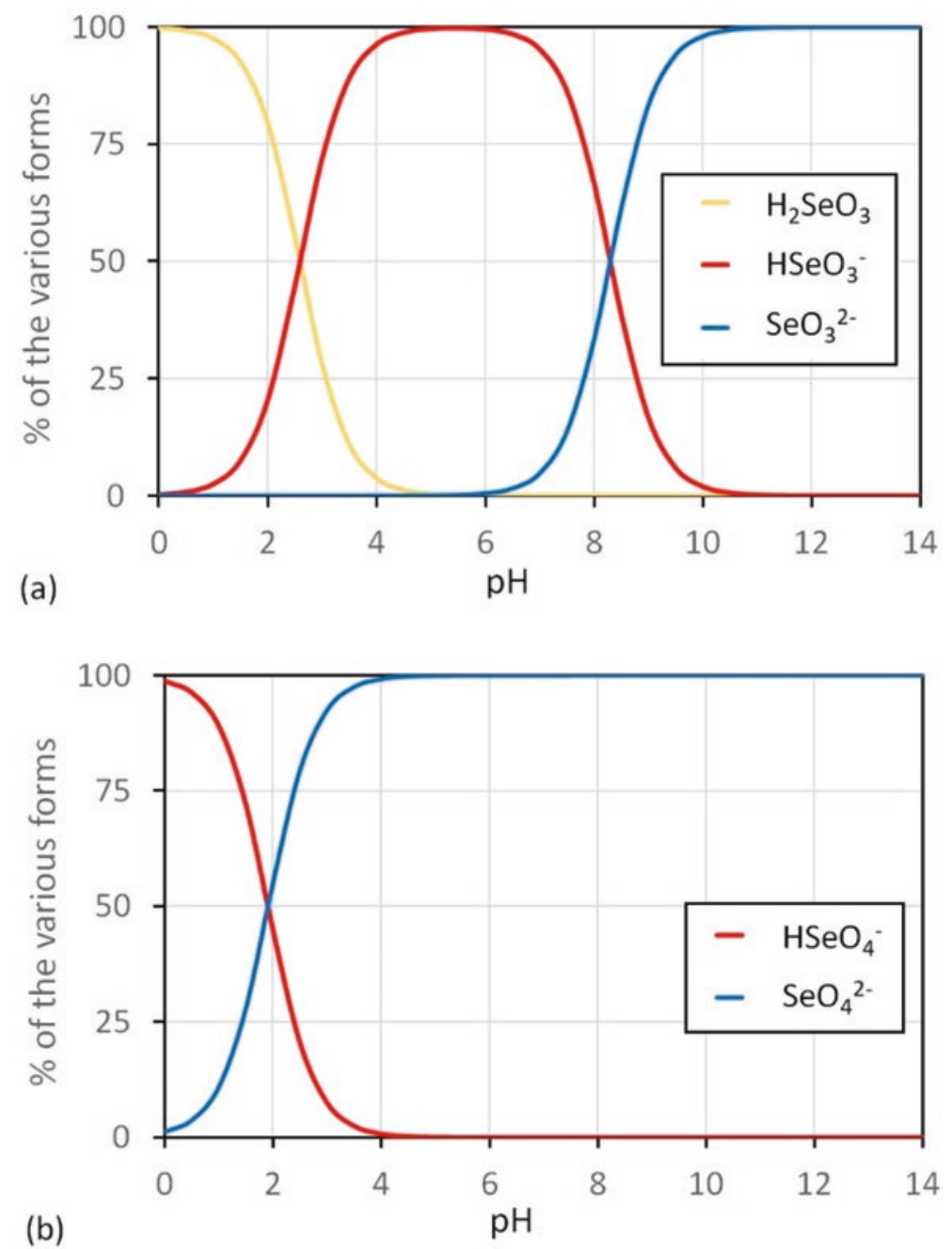

Fig. 3.13 Distribution diagrams of the various forms of a) $\mathrm{Se}(\mathrm{IV})$ and b) $\mathrm{Se}(\mathrm{VI})$

higher than those produced by nanofiltration (and reverse osmosis) membranes at the same applied pressures.

These results have, therefore, shown that polymer addition in selenium solutions before ultrafiltration, can have a positive effect on selenium rejection on condition that polymer and selenium species have opposite charges and the ionic strength is sufficiently low in order not to screen the electrostatic interactions between oxyanions and polymer. Polymer-enhanced ultrafiltration appears as a potential option to remove anionic pollutants from wastewaters. 

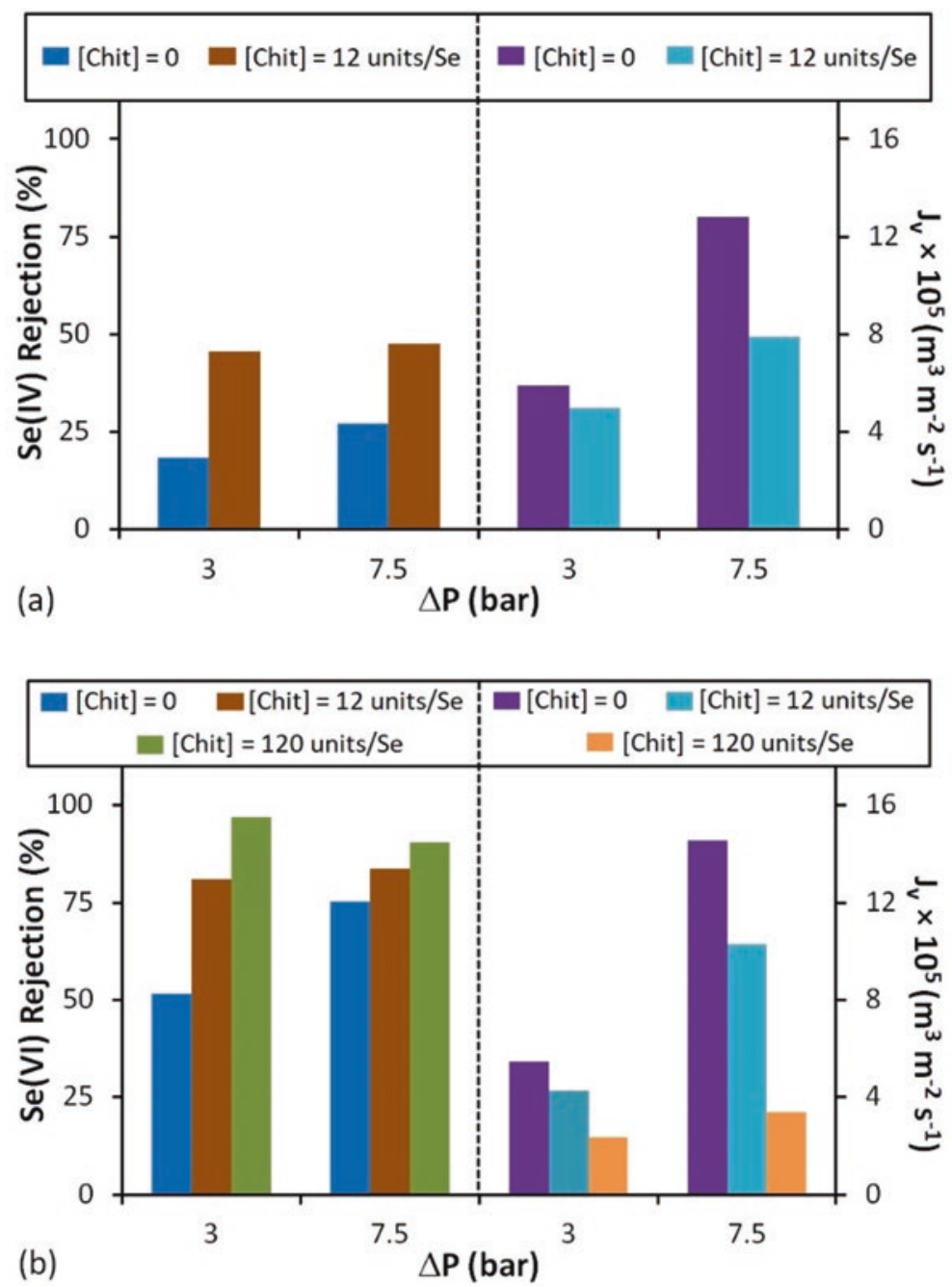

Fig. 3.14 Rejection and permeation flux obtained by ultrafiltration (CERAM 60 membrane, molecular weight cut off: $8 \mathrm{kDa}$ ) of solutions containing $1.7 \mathrm{mmol} / \mathrm{L}$ of (a) $\mathrm{Se}(\mathrm{IV})$ and (b) $\mathrm{Se}(\mathrm{VI})$ with and without chitosan at $\mathrm{pH}=4$

\subsubsection{Biological Removal of Selenate by Activated Sludge}

Microbial metabolism can reduce selenate into solid selenium (elemental Se) via selenite, and selenite can be reductively transformed into volatile selenium, e.g. dimethyl selenide. These processes enable elimination of soluble Se from the water phase to the solid or gas phase and can be utilized to develop cost-effective and ecofriendly technologies for the treatment of Se-containing water/wastewater (Fig. 3.15). Such microbial Se metabolisms are mediated by different types of 


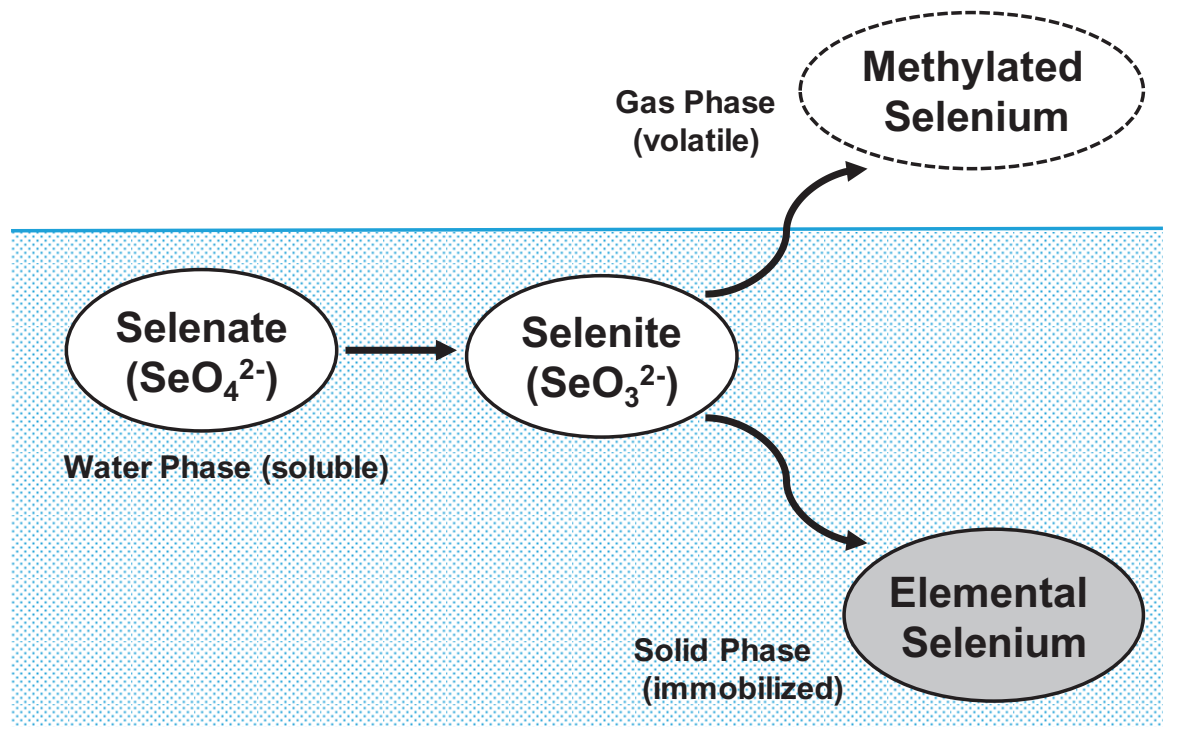

Fig. 3.15 Microbial selenium metabolism enabling the removal of soluble Se as selenate and selenite from the water phase. Selenate reduction into selenite proceeds mainly under anoxic conditions; selenite volatilization occurs mostly under aerobic conditions, while selenite reduction into elemental Se proceeds under both aerobic and anoxic conditions

microbes and are known to proceed under both aerobic and anaerobic conditions. Since various kinds of aerobic and anaerobic microbes exist in activated sludge, it possesses a considerable potential for the biological treatment of seleniumcontaining wastewater under alternating anoxic/oxic conditions. This section describes a trial to utilize activated sludge for the treatment of selenate.

The activated sludge taken from a coke-oven wastewater treatment facility in a steel plant was used to remove selenate from artificial wastewater in a model sequencing batch reactor under alternating anoxic/oxic conditions (Zhang et al. 2019a). The synthetic wastewater was composed of 1 or $5 \mathrm{mM}$ selenate, $44 \mathrm{mM}$ sodium lactate as the carbon source, $30 \mathrm{~g} / \mathrm{L} \mathrm{NaCl}$, and other minerals, simulating high-salinity selenium refinery industrial wastewater. The model sequencing batch reactor was constructed in a $200-\mathrm{mL}$ Erlenmeyer flask with a working volume of $160 \mathrm{~mL}$, and operated at a constant temperature of $28^{\circ} \mathrm{C}$.

At the beginning, the sequencing batch reactor was operated under anoxic conditions with a 7-day cycle duration to specifically enrich bacteria that reduce selenate as a terminal electron acceptor of anaerobic respiration because they are considered the main contributors to selenate reduction (startup period; phases I and II). After almost complete removal of soluble Se was achieved, treatment with the 3-day cycle duration was started (phases III to VI). In phase III, the sequencing batch reactor was operated under the same anoxic conditions, and an aeration step was added in the following phases. In those alternating anoxic/oxic conditions, the aeration 
period was prolonged stepwise from 3 to $7 \mathrm{~h}$, from phases IV to VI to evaluate the influence of aeration on the Se removal.

The selenium treatment performance of the sequencing batch reactor is shown in Fig. 3.16. In all treatment phases, selenate concentration in the effluent was maintained below the detection limit, and soluble Se was almost completely removed (>97\%) without significant accumulation of selenite, independent of the length of the aeration step. However, a considerable amount of solid Se was found in the effluent as suspended solid-Se, and consequently removal of total Se was much lower than that of soluble Se. The suspended solid-Se concentration was maintained at relatively low levels, and the average total Se removal during the anoxic operation (phase III) was $88 \%$. On the other hand, during alternating anoxic/oxic conditions (phases IV to VI), total Se removal was not stable, varying from $39 \%$ to $81 \%$, and the suspended solid-Se concentration in the effluent tended to be higher than that observed during the anoxic operation. The shear force generated by aeration seemed to disperse the solid Se particles in the sequencing batch reactor and make them remain in the effluent.

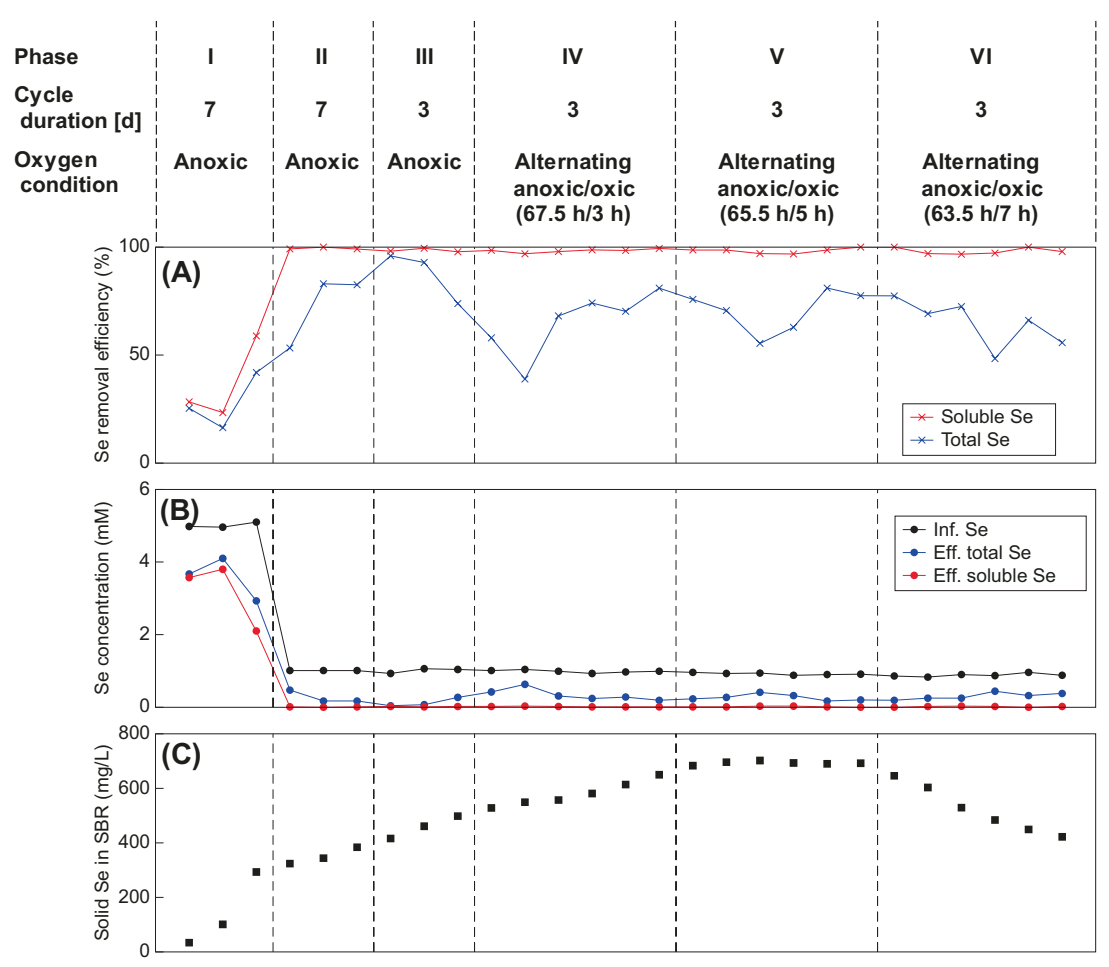

Fig. 3.16 Se removal performance of the sequencing batch reactor: (a) Se removal efficiencies; (b) Se concentrations in the influent and effluent; and (c) solid Se in the reactor. (Adapted from Zhang et al. 2019a) 
During the series of treatments, the amount of solid Se in the sequencing batch reactor gradually increased from the startup to phase IV, indicating that selenium removed from the water phase accumulated in the sequencing batch reactor as solid Se, most likely elemental Se (bioimmobilization/bioprecipitation). The extension of the aeration period in phases V and VI clearly changed the fate of Se in the sequencing batch reactor; specifically, the amount of Se in the sequencing batch reactor was kept constant during phase $\mathrm{V}$, and the amount of Se decreased during phase VI. Based on the selenium mass balance calculation, the disappearance of Se from the sequencing batch reactor in phase VI was found to be due to the generation of volatile selenium, such as dimethyl selenide, dimethyl diselenide, and dimethyl selenyl sulfide (biovolatilization).

Through the above-mentioned trial, it was confirmed that activated sludge has a promising potential to treat wastewater containing selenate, which is difficult to efficiently remove by typical physicochemical technologies. Soluble Se could be completely removed by activated sludge; however, a considerable amount of suspended solid-Se remained in the effluent, especially in alternating anoxic/oxic conditions. Therefore, post-treatment, such as high-speed centrifugation, filtration, chemical coagulation (Staicu et al. 2015a), and electrocoagulation (Staicu et al. 2015c), which are described in detail in other sections, is necessary to remove suspended solid-Se in the effluent to improve the removal efficiency of total Se. Further, activated sludge can convert selenate to both solid Se and volatile Se, depending on the duration of the aeration period. Under anoxic conditions, selenate was reduced into elemental Se, which should be removed and disposed of as waste sludge, while biovolatilization of Se became efficient under prolonged oxic conditions and Se was removed into the gas phase. The use of activated sludge under anoxic conditions enables the establishment of energy-saving treatment processes. On the other hand, alternating anoxic/oxic conditions with longer aeration periods allow the feasibility of recovering selenium with few impurities with the treatment process by trapping volatile selenium using an off-gas trap (Kagami et al. 2013).

\subsection{Conclusion}

During the Renaissance, the Swiss physician and alchemist Paracelsus wrote: "All things are poison, and nothing is without poison; only the dose determines what is not a poison". In other words, substances considered beneficial at low doses can be toxic in too large quantities. This is the case of selenium, which is considered an important trace element and at the same time a potentially dangerous emerging substance. At low doses, selenium is an essential nutrient for animal and human life. However, at high doses, it becomes toxic. Selenium is naturally present in the environment but it also has an anthropogenic origin (coal combustion, mining activities, phosphate fertilizer production, etc.). We can be exposed to selenium through its presence in soil, (drinking) water, air and food. One of the main sources of selenium exposure is tap water. In Europe, the maximum level to be respected at the 
consumer's tap has been set at $10 \mu / \mathrm{L}$, a threshold that is exceeded in many countries, including France. In general, it is drilling water from seleniferous areas that poses treatment problems. Selenium is currently the subject of much research both in terms of its chemistry (speciation), impact and toxicity, and also its elimination. However, in the field of water treatment, the problem is not simple. Indeed, when Se is present at trace levels, below $50 \mu \mathrm{g} / \mathrm{L}$, in complex waters due to the presence of other substances, Se is a chemical substance very difficult to eliminate.

There are several treatment methods, each with its advantages and disadvantages, such as chemical precipitation, adsorption on conventional materials (metal oxides, alumina, coal), coagulation, electrocoagulation, ion exchange, membrane filtration (reverse osmosis, nanofiltration) or biological pathways (microbial reduction, phytoremediation, etc.). In France, for selenium removal to produce drinking water, adsorption treatment technologies are now preferred because of their efficiency, simplicity, residence times of less than a few minutes, and low-cost for point-of-use applications. For the treatment of industrial wastewaters, a combination of several processes is often necessary for reasons related to the different nature of the pollutants (including selenium) to be treated and especially to economic problems. Indeed, there is no single, low-cost process that can effectively and selectively remove selenium. At industrial scale, the coupling between coprecipitation and coagulation-flocculation process is used to remove selenium present in polycontaminated effluents. However, the scientific community remains interested in the development of new technologies for the elimination of selenium. The development of new processing methods is a topical issue, as evidenced by the many publications published in recent years. Among the new processes proposed, biosorption on nonconventional materials such as chitosan seems to be a promising way forward because this agri-food industry co-product is cheap and effective in eliminating trace forms of selenium.

Selenium will undoubtedly be one of the next priority substances to be addressed in the coming years, from a chemical, biological, ecotoxicological, health, economic and industrial point of view!

Acknowledgements Nadia Morin-Crini and Grégorio Crini (Besançon, France) thanks the FEDER (Fonds Européen de Développment Régional) for its financial support (NIRHOFEX Program: "Innovative materials for wastewater treatment") and the Université de Franche-Comté for the research grant awarded to Guest Professor C. Bradu.

\section{References}

Adadi P, Barakova NV, Muravyov KY, Krivoshapkina EF (2019) Designing selenium functional foods and beverages: a review. Food Res Int 120:708-725. https://doi.org/10.1016/j. foodres.2018.11.029

AFSSA (2007) Évaluation des risques sanitaires liés aux situations de dépassement des limites et références de qualité des eaux destinées à la consommation humaine (in French). ISBN 978-2-11-095843-3 
Aimar P, Bacchin P, Maurel A (2010) Filtration membranaire (OI, NF, UF, MFT) - Aspects théoriques: mécanismes de transfert (in French). Techniques de l'Ingénieur

Amiard JC (2011) Les risques chimiques environnementaux (in French). Lavoisier Tec\&Doc. isbn:978-2-7430-2234-1

ANSES (2012) Avis relatif sur l'évaluation des risques sanitaires liés aux dépassements de la limite de qualité du sélénium dans les eaux destinées à la consommation humaine (in French). $\mathrm{N}^{\circ}$ 2011-SA-0220

AWWA (1999) Electrodialysis and electrodialysis reversal. American Water Works Association, AWWA Manual M38:13p

Azaizeh H, Salhani N, Sebesvari Z, Shardendu S, Emons H (2006) Phytoremediation of selenium using subsurface-flow constructed wetland. Int J Phytoremediation 8:187-198. https://doi. org/10.1080/15226510600846723

Baek K, Kasem N, Ciblak A, Vesper D, Padilla I, Alshawabkeh AN (2013) Electrochemical removal of selenate from aqueous solutions. Chem Eng J 215-216:678-684. https://doi.org/10.1016/j. cej.2012.09.135

Bakather OY, Fard AK, Ihsanullah, Khraisheh M, Nasser MS, Atieh MA (2017) Enhanced adsorption of selenium ions from aqueous solution using iron oxide impregnated carbon nanotubes. Biorg Chem Applications. https://doi.org/10.1155/2017/4323619

Balistrieri LS, Chao TT (1987) Selenium adsorption by goethite. Soil Sci Soc Am J 51:1145-1151. https://doi.org/10.2136/sssaj1987.03615995005100050009x

Balistrieri LS, Chao TT (1990) Adsorption of selenium by amorphous iron oxyhydroxide and manganese dioxide. Geochim Cosmochim Acta 54:739-751. https://doi. org/10.1016/0016-7037(90)90369-V

Ballet GT, Hafiane A, Dhahbi M (2007) Influence of operating conditions on the retention of phosphate in water by nanofiltration. J Membr Sci 290:164-172. https://doi.org/10.1016/j. memsci.2006.12.046

Bandara PC, Perez JVD, Nadres ET, Nannapaneni RG, Krakowiak KJ, Rodrigues DF (2019) Graphene oxide nanocomposite hydrogel beads for removal of selenium in contaminated water. ACS Appl Polymer Mater 1:2668-2679. https://doi.org/10.1021/acsapm.9b00612

Bañuelos GC, Lin ZQ, Xuebin Y (2014) Selenium in the environment and human health. Proceedings of the 3rd international conference on selenium in the environment and human health, Hefei, China, 10-14 November 2013. CRC Press, Taylor \& Francis Group. ISBN: 978-1-138-00017-9

Bar Yosef B, Meek D (1987) Selenium sorption by kaolinite and montmorillonite. Soil Sci 144:11-19

Benjamin MM, Bloom NS (1981) Effects of strong binding of anionic adsorbates on adsorption of trace metals on amorphous iron oxyhydroxide. In: Tewari PH (ed) adsorption from aqueous solutions. Plenum Press, New York, pp 41-60. https://doi.org/10.1007/978-1-4613-3264-0_3

Benjamin MM, Hayes KF, Leckie JO (1982) Removal of toxic metals from power generation waste streams by adsorption and coprecipitation. Water Pollut Control Federation 54:1472-1481. https://www.jstor.org/stable/25041739

Bleiman N, Mishael YG (2010) Selenium removal from drinking water by adsorption to chitosanclay composites and oxides: batch and column tests. J Hazard Mater 183:590-595. https://doi. org/10.1016/j.jhazmat.2010.07.065

Bowen WR, Mohammad AW, Hilal N (1997) Characterisation of nanofiltration membranes for predictive purposes - use of salts, uncharged solutes and atomic force microscopy. J Membr Sci 126:91-105. https://doi.org/10.1016/S0376-7388(96)00276-1

BRGM (2011) Panorama 2010 du marché du sélénium. Labbé JF and Christmann P (Eds.). Report: RP-60202, August 2011, 90p

Cai ZL, Zhang JZ, Li HJ (2019) Selenium, aging and aging-related diseases. Aging Clin Exp Res 31:1035-1047. https://doi.org/10.1007/s40520-018-1086-7

Calix EM, Tan LC, Rene ER, Nanchariah YV, van Hullebusch ED, Lens PNL (2019) Simultaneous removal of sulfate and selenate from wastewater by process integration of an ion exchange col- 
umn and upflow anaerobic sludge blanket bioreactor. Sep Sci Technol 54:1387-1399. https:// doi.org/10.1080/01496395.2018.1533562

Cantafio AW, Hagen KD, Lewis GE, Bledsoe TL, Nunan KM, Macy JM (1996) Pilot-scale selenium bioremediation of San Joaquin drainage water with Thauera selenatis. Appl Environ Microbiol 62:3298-3303. https://doi.org/10.13140/2.1.4914.8489

Carvalho KM, Martin DF (2001) Removal of aqueous selenium by four aquatic plants. J Aqua Plant Manag 39:33-36

Catalano JG, Zhang Z, Fenter P, Bedzyk MJ (2006) Inner-sphere adsorption geometry of Se(IV) at the hematite (100)-water interface. J Colloid Interface Sci 297:665-671

Chan YT, Kuan WH, Chen TY, Wang MK (2009a) Adsorption mechanism of selenate and selenite on the binary oxide systems. Water Res 43:4412-4420. https://doi.org/10.1016/j. watres.2009.06.056

Chan YT, Kuan WH, Chen TY, Wang MK (2009b) Adsorption mechanism of selenate and selenite on the binary oxide systems. Water Res 43:4412-4420. https://doi.org/10.1016/j. watres.2009.06.056

Chand V, Prasad S (2009) Trace determination and chemical speciation of selenium in environmental water samples using catalytic kinetic spectrophotometric method. J Hazard Mater 165:780-788. https://doi.org/10.1016/j.jhazmat.2008.10.076

Chapman PM (1999) Invited debate/commentary: selenium - a potential time bomb or just another contaminant? Human Ecological Risk Assess 5:1123-1138

Chapman PM, Adams WJ, Brooks MJ, Delos CG, Luoma SN, Maher WA, Ohlendorf HM, Presser TS, Shaw DP (2010) Ecological assessment of selenium in the aquatic environment. CRC Press, Taylor \& Francis Group, Boca Raton. ISBN-13: 978-1-4398-2678-2

Chauhan R, Awasthi S, Srivastava S, Dwivedi S, Pilon-Smits EAH, Dhankher OP, Tripathi RD (2019) Understanding selenium metabolism in plants and its role as a beneficial element. Crit Rev Environ Sci Technol 49:1937-1958. https://doi.org/10.1080/10643389.2019.1598240

Chehayeb KM, Lienhard JH (2017) Entropy generation analysis of electrodialysis. Des 413:184-198. https://doi.org/10.1016/j.desal.2017.03.001

Chhatre AJ, Marathe KV (2008) Modeling and performance study of MEUF of divalent metal ions in aqueous streams. Sep Sci Technol 43:3286-3304. https://doi. org/10.1080/01496390802212641

Chubar N (2014) EXAFS and FTIR studies of selenite and selenite sorption by alkoxide-free solgel generated $\mathrm{Mg}-\mathrm{Al}-\mathrm{CO}_{3}$ layered double hydroxide with very labile interlayer anions. J Mater Chem A 2014(2):15995. https://doi.org/10.1039/c4ta03463e

Chung J, Nerenberg R, Rittmann BE (2006) Bioreduction of selenate using a hydrogen-based membrane biofilm reactor. Environ Sci Technol 40:1664-1671. https://doi.org/10.1021/es051251g

Chung J, Rittmann BE, Her N, Lee SH, Yoon Y (2010) Integration of $\mathrm{H}_{2}$-based membrane biofilm reactor with RO and NF membranes for removal of chromate and selenate. Water Air Soil Pollut 207:29-37. https://doi.org/10.1007/s11270-009-0116-7

Cingolani D, Fatone F, Frison N, Spinelli M, Eusebi AL (2018) Pilot-scale multi-stage reverse osmosis (DT-RO) for water recovery from landfill leachate. Waste Manag 76:566-574. https:// doi.org/10.1016/j.wasman.2018.03.014

Cojocaru C, Zakrzewska-Trznadel G (2007) Response surface modeling and optimization of copper removal from aqua solutions using polymer assisted ultrafiltration. J Membr Sci 298:56-70. https://doi.org/10.1016/j.memsci.2007.04.001

Combs GF (1988) Selenium in foods. Adv Food Res 32:84-113. https://doi.org/10.1016/ S0065-2628(08)60286-4

Combs GF, Combs SB (1986) The role of selenium in nutrition. Academic Press Inc., New York. ISBN: 0121834956

Conley JM, Funk DH, Buchwalter DB (2009) Selenium bioaccumulation and maternal transfer in the mayfly centroptilum triangulifer in a life-cycle, periphyton-biofilm trophic assay. Environ Sci Technol 43:7952-7957. https://doi.org/10.1021/es9016377 
Cornell RM, Schwertmann U (2000) Iron oxides in the laboratory: preparation and characterization, 2nd edn. Wiley-VCH, NJ, Hoboken. https://doi.org/10.1002/9783527613229

Crini G (2017) Le sélénium dans les eaux: une nouvelle substance dangereuse pour demain ? (in French). In: eaux industrielles contaminées. Besançon: Presses Universitaires de FrancheComté, France. Chapter 15, pp. 447-466. ISBN 978-2-84867-589-3

Crini G, Badot PM (2007) Traitement et épuration des eaux industrielles polluées. Presses Universitaires de Franche-Comté, France, Besançon. ISBN 978-2-84867-197-0

Crini G, Badot PM (2010) Sorption processes and pollution. Presses Universitaires de FrancheComté, France, Besançon. ISBN 978-2-84867-304-2

Crini G, Lichtfouse E (2018) Wastewater treatment: an overview. In: Crini G, Lichtfouse E (eds) Green adsorbents for pollutant removal. Springer Nature, Switzerland. Chapter 1, Cham, pp 1-21. https://doi.org/10.1007/978-3-319-92111-2_1

Crini G, Morin-Crini N, Fatin-Rouge N, Déon S, Fievet P (2017) Metal removal from aqueous media by polymer-assisted ultrafiltration with chitosan. Arab J Chem 10:S3826-S3839. https:// doi.org/10.1016/j.arabjc.2014.05.020

Cristiano E, Hu YJ, Siegfried M, Kaplan D, Nitsche H (2011) A comparison of point of zero charge measurement methodology. Clays Clay Miner 59:107-115. https://doi.org/10.1346/ CCMN.2011.0590201

Das S, Hendry MJ, Essilfie-Dughan J (2013) Adsorption of selenate onto ferrihydrite, goethite, and lepidocrocite under neutral $\mathrm{pH}$ conditions. Appl Geochem 28:185-193. https://doi. org/10.1016/j.apgeochem.2012.10.026

Das S, Lindsay MBJ, Essilfie-Dughan J, Hendry MJ (2017) Dissolved Se(VI) removal by zerovalent iron under oxic conditions: influence of sulfate and nitrate. ACS Omega 2:1513-1522. https://doi.org/10.1021/acsomega.6b00382

Das S, Lindsay MBJ, Hendry MJ (2019) Selenate removal by zero-valent iron under anoxic conditions: effects of nitrate and sulfate. Environ Earth Sci 78:528. https://doi.org/10.1007/ s12665-019-8538-z

Davis JA, Leckie JO (1980) Surface ionization and complexation at the oxide/water interface. 3. Adsorption of anions. J Colloid Interface Sci 74:32-43. https://doi. org/10.1016/0021-9797(80)90168-X

DeForest DK, Gilron G, Armstrong SA, Robertson EL (2012) Species sensitivity distribution evaluation for selenium in fish eggs: considerations for development of a Canadian tissue-based guideline, integrated environ. Integr Environ Assess Manag 8:6-12. https://doi.org/10.1002/ ieam. 245

Déon S, Escoda A, Fievet P, Dutournié P, Bourseau P (2012) How to use a multi-ionic transport model to fully predict rejection of mineral salts by nanofiltration membranes. Chem Eng $\mathrm{J}$ 189-190:24-31. https://doi.org/10.1016/j.cej.2012.02.014

Déon S, Deher J, Lam B, Crini N, Crini G, Fievet P (2017) Remediation of solutions containing oxyanions of selenium by ultrafiltration: study of rejection performances with and without chitosan addition. Ind Eng Chem Res 56:10461-10471. https://doi.org/10.1021/acs.iecr.7b02615

Dessì P, Jain R, Singh S, Seder-Colomina M, van Hullebusch ED, Rene ER, Ahammad SZ, Carucci A, Lens PNL (2016) Effect of temperature on selenium removal from wastewater by UASB reactors. Water Res 94:146-154. https://doi.org/10.1016/j.watres.2016.02.007

Dhillon KS, Bañuelos GS (2017) Overview and prospects of selenium phytoremediation approaches. In: Selenium plants. Pilon-Smits E, Winkel L and Lin ZQ (Eds.). Plant ecophysiology, volume 11, pp. 277-321. doi:https://doi.org/10.1007/978-3-319-56249-0_16

Di Marzio A, Lambertucci SA, Fernandez AJG, Martinez-Lopez E (2019) From Mexico to the Beagle Channel: a review of metal and metalloid pollution studies on wildlife species in Latin America. Environ Res 176:108462. https://doi.org/10.1016/j.envres.2019.04.029

Dinh QT, Cui Z, Tran TAT, Wang D, Yang WX, Zhou F, Wang M, Yu D, Liang D (2018) Selenium distribution in the Chinese environment and its relationship with human health: a review. Environ Pollut 112:294-309. https://doi.org/10.1016/j.envint.2017.12.035 
Dobrowolski R, Otto M (2013) Preparation and evaluation of Fe-loaded activated carbon for enrichment of selenium for analytical and environmental purposes. Chemosphere 90:683-690. https://doi.org/10.1016/j.chemosphere.2012.09.049

Dong H, Chen Y, Sheng G, Li J, Cao J, Li Z, Li Y (2016) The roles of a pillared bentonite on enhancing $\mathrm{Se}(\mathrm{VI})$ removal by ZVI and the influence of co-existing solutes in groundwater. J Hazard Mater 304:306-312. https://doi.org/10.1016/j.jhazmat.2015.10.072

Donnan FG (1995) Theory of membrane equilibria and membrane potentials in the presence of non-dialysing electrolytes. A contribution to physical-chemical physiology. J Membr Sci $100: 45-55$

Donner MW, Cuss CW, Poesch M, Sinnatamby RN, Shotyk W, Siddique T (2018) Selenium in surface waters of the lower Athabasca River watershed: chemical speciation and implications for aquatic life. Environ Pollut 243:1343-1351. https://doi.org/10.1016/j.envpol.2018.09.067

Duc M, Lefèvre G, Fédoroff M (2006) Sorption of selenite ions on hematite. J Colloid Interface Sci 298:556-563

Dzombak DA, Morel FM (1990) Surface complexation modeling: hydrous ferric oxide. Wiley, New York

Dzul Erosa MS, Höll WH, Horst J (2009) Sorption of selenium species onto weakly basic anion exchangers: I. Equilibrium studies. React Funct Polym 69:576-585. https://doi.org/10.1016/j. reactfunctpolym.2009.03.013

Eklund L, Persson I (2014) Structure and hydrogen bonding of the hydrated selenite and selenate ions in aqueous solution. Dalton Trans 43:6315-6321. https://doi.org/10.1039/c3dt53468e

El-Shafey EI (2007a) Removal of Se (IV) from aqueous solution using sulphuric acid-treated peanut shell. J Environ Manage 84:620-267

El-Shafey EI (2007b) Sorption of Cd(II) and Se(IV) from aqueous solution using modified rice husk. J Hazard Mater 147:546-555. https://doi.org/10.1016/j.jhazmat.2007.01.051

Espinosa-Ortiz EJ, Rene ER, van Hullebusch ED, Lens PNL (2015) Removal of selenite from wastewater in a Phanerochaete chrysosporium pellet based fungal bioreactor. Int Biodeter Biodegr 102:361-369. https://doi.org/10.1016/j.ibiod.2015.04.014

Etteieb S, Magdouli S, Zolfaghari M, Brar SK (2020) Monitoring and analysis of selenium as an emerging contaminant in mining industry: a critical review. Sci Total Environ 698:134339. https://doi.org/10.1016/j.scitotenv.2019.134339

EU (1998) Council Directive 98/83/EC of 3 November 1998 on the quality of water intended for human consumption. Off. J. L 330, European Union, pp. 32-54

Evans SF, Ivancevic MR, Yan JQ, Naskar AK, Levine AM, Lee RJ, Tsouris C, Paranthaman MP (2019) Magnetic adsorbents for selective removal of selenite from contaminated water. Sep Sci Technol 54:2138-2146. https://doi.org/10.1080/01496395.2019.1617742

Ezzatahmadi N, Ayoko GA, Millar GJ, Speight R, Yan C, Li J, Li S, Zhu J, Xi Y (2017) Claysupported nanoscale zero-valent iron composite for the remediation of contaminated aqueous solutions: a review. Chem Eng Sci 312:336-350. https://doi.org/10.1016/j.cej.2016.11.154

Fatin-Rouge N, Dupont A, Vidonne A, Dejeu J, Fievet P, Foissy A (2006) Removal of some divalent cations from water by membrane-filtration assisted with alginate. Water Res 40:1303-1309. https://doi.org/10.1016/j.watres.2006.01.026

Fernández-Martínez A, Charlet L (2009) Selenium environmental cycling and bioavailability: a structural chemist point of view. Rev Environ Sci Biotechnol 8:81-110. https://doi.org/10.1007/ s11157-009-9145-3

Ferry JD (1936) Ultrafilter membranes and ultrafiltration. Chem Rev 18:373-455

Fordyce F (2007) Selenium geochemistry and health. Ambio 36:94-97. https://doi.org/10.157 9/0044-7447(2007)36[94:sgah]2.0.co;2

Fordyce FM (2013) Selenium deficiency and toxicity in the environment. In: Selenius O (ed) Essentials of medical geology. Springer, Dordrecht, pp 375-416. https://doi. org/10.1007/978-94-007-4375-5_16

Frankenberger WT, Benson S (1994) Selenium in the environment. Marcel Dekker, Inc., Basel. ISBN: 0-8247-8993-8 
Frankenberger WT, Engberg RA (1998) Environmental chemistry of selenium. Marcel Dekker, Inc., Basel. ISBN: 0-8247-0136-4

Fujita M, Ike M, Kashiwa M, Hashimoto R, Soda S (2002) Laboratory-scale continuous reactor for soluble selenium removal using selenate-reducing bacterium, Bacillus sp. SF1. Biotechnol Bioeng 80:755-761

Fukushi K, Sverjensky DA (2007) A surface complexation model for sulfate and selenate on iron oxides consistent with spectroscopic and theoretical molecular evidence. Geochim Cosmochim Acta 71:1-24. https://doi.org/10.1016/j.gca.2006.08.048

Gaini L, Lakraimi M, Sebbar E, Meghea A, Bakasse M (2009) Removal of indigo carmine dye from water to Mg-Al- $\mathrm{CO}_{3}$-calcined layered double hydroxides. J. Hazard Mater 161:627-632. https://doi.org/10.1016/j.jhazmat.2008.04.089

Gandin V, Khalkar P, Braude J, Fernandes AP (2018) Organic selenium compounds as potential chemotherapeutic agents for improved cancer treatment. Free Radic Biol Med 127:80-97. https://doi.org/10.1016/j.freeradbiomed.2018.05.001

Gao S, Tanji KK, Lin ZQ, Terry N, Peters DW (2003) Selenium removal and mass balance in a constructed flow-through wetland system. J Environ Qual 32:1557-1570. https://doi.org/10.2134/ jeq2003.1557

Gao S, Tanji KK, Dahlgren RA, Ryu J, Herbel MJ, Higashi RM (2007) Chemical status of selenium in evaporation basins for disposal of agricultural drainage. Chemosphere 69:585-594

Garduño-Zepeda AM, Márquez-Quiroz C (2018) Use of selenium in crop production. Review. ITEA Informacion Technica Econimica Agraria 114:327-343. https://doi.org/10.12706/ itea.2018.019

Gebreeyessus GD, Zewge F (2019) A review on environmental selenium issues. SN Appl Sci 1:55. https://doi.org/10.1007/s42452-018-0032-9

Genin JM, Bourrie G, Trolard F, Abdelmoula M, Jaffrezic A, Refait P, Maitre V, Humbert B, Herbillon A (1998) Thermodynamic equilibria in aqueous suspensions of synthetic and natural Fe(II)-Fe(III) green rusts: occurrences of the mineral in hydromorphic soils. Environ Sci Technol 32:1058-1068. https://doi.org/10.1021/es970547m

Geoffroy N, Demopoulos GP (2011) The elimination of selenium(IV) from aqueous solution by precipitation with sodium sulfide. J Hazard Mater 185:148-154. https://doi.org/10.1016/j. jhazmat.2010.09.009

Gibson BD, Blowes DW, Lindsay MBJ, Ptacek CJ (2012) Mechanistic investigations of Se(VI) treatment in anoxic groundwater using granular iron and organic carbon. J Hazard Mater 241-242:92-100. https://doi.org/10.1016/j.jhazmat.2012.09.015

Gingerich DB, Grol E, Mauter MS (2018) Fundamental challenges and engineering opportunities in flue gas desulfurization wastewater treatment at coal fired power plants. Envrion Sci Water Res 4:909-925. https://doi.org/10.1039/c8ew00264a

Glasauer S, Doner HE, Gehring AU (1995) Adsorption of selenite to goethite in a flow through reaction chamber. Eur J Soil Sci 46:47-52

Goldberg S (1985) Chemical modeling of anion competition on goethite using the constant capacitance model. Soil Sci Soc Am J 49:851-856

Goldberg S (2014) Modeling selenate adsorption behavior on oxides, clay minerals, and soils using triple layer model. Soil Sci 179:568-576

GOLDER (2009) Literature review of treatment technologies to remove selenium from mining influenced water. Golder Associates Inc., 40p

Gonzalez CM, Hernandez J, Peralta-Videa JR, Botez CE, Parsons JG, Gardea-Torresdey JL (2012) Sorption kinetic study of selenite and selenate onto a high and low pressure aged iron oxide nanomaterial. J Hazard Mater 211-212:138-145. https://doi.org/10.1016/j.jhazmat.2011.08.023

González-Acevedo ZI, Olguín MT, Rodríguez-Martínez CE, Frías-Palos H (2012) Sorption and desorption processes of selenium (VI) using non-living biomasses of aquatic weeds in horizontal flow. Water Air Soil Pollut 223:4119-4128. https://doi.org/10.1007/s11270-012-1178-5 
Gu XX, Tang TY, Liu XT, Hou YL (2019) Rechargeable metal batteries based on selenium cathodes: progress, challenges and perspectives. J Mater Chem A 7:11566-11583. https://doi. org/10.1039/c8ta12537f

Gunawardana B, Singhal N, Swedlund P (2012) Dechlorination of pentachlorophenol by zero valent iron and bimetals: effect of surface characteristics and bimetal preparation procedure. Proc Ann Int Confer Soils, Sediments, Water \& Energy 17:68-81

Gupta J, Fatima MT, Islam Z, Khan RH, Uversky VN, Salahuddin P (2019) Nanoparticle formulations in the diagnosis and therapy of Alzheimer's disease. Int J Biol Macromol 130:515-526. https://doi.org/10.1016/j.ijbiomac.2019.02.156

Hansen HK, Pena SF, Gutierrez C, Lazo A, Lazo P, Ottosen LM (2019) Selenium removal from petroleum refinery wastewater using an electrocoagulation technique. J Hazard Mater 364:78-81. https://doi.org/10.1016/j.jhazmat.2018.09.090

Harvey P, Campanella B, Castro P, Harms H, Lichtfouse E, Schaeffner A, Smrcek S, WerckReichhart D (2002) Phytoremediation of polyaromatic hydrocarbons, anilines and phenols. Environ Sci Pollut Res 9:29-47. https://doi.org/10.1007/BF02987315

Hasan SH, Ranjan D, Talat M (2010) Agro-industrial waste "wheat bran" for the biosorptive remediation of selenium through continuous up-flow fixed-bed column. J Hazard Mater 181:1134-1142. https://doi.org/10.1016/j.jhazmat.2010.05.133

Hassanvand A, Wei K, Talebi S, Chen GQ, Kentish SE (2017) The role of ion exchange in membranes capacitive deionization. Membranes 7:54. https://doi.org/10.3390/membranes7030054

Hatfield DL (2001) Selenium: its molecular biology and role in human health. Kluwer Academic Publishers, Dordrecht. ISBN: 0-7923-7335-9

Hayes KF (1987) Equilibrium, spectroscopic, and kinetic studies of ion adsorption at the oxide/ aqueous interface. Ph.D. thesis, Stanford University, Stanford, California, USA

Hayes KF, Roe AL, Brown GE Jr, Hodgson KO, Leckie JO, Parks GA (1987) In situ x-ray absorption study of surface complexes: selenium oxyanions on $\alpha-\mathrm{FeOOH}$. Science 238:783-786

Hayes KF, Charalambos P, Leckie JO (1988) Modeling ionic strength effects on anion adsorption at hydrous oxide/solution interface. J Colloid Interface Sci 125:717-726. https://doi. org/10.1016/0021-9797(88)90039-2

Haygarth PM (1994) Global importance and global cycling of selenium. In: Frankenberger WT, Benson S (eds) Selenium in the environment. Marcel Dekker, New York, pp 1-28

HDR Engineering Inc (2002) Handbook of public water systems Second edition. John Wiley \& Sons, Inc. ISBN: 978-0-471-15083-1

He YG, Tang YP, Chung TS (2016a) Concurrent removal of selenium and arsenic from water using polyhedral oligomeric silsesquioxane (POSS)-polyamide thin-film nanocomposite nanofiltration membrane. Ind Eng Chem Res 55:12929-12938. https://doi.org/10.1021/acs.iecr.6b04272

He Y, Tang YP, Chung TS (2016b) Concurrent removal of selenium and arsenic from water uUsing polyhedral oligomeric silsesquioxane (POSS)-polyamide thin-film nanocomposite nanofiltration. Membranes Ind Eng Chem Res 55:12929-12938. https://doi.org/10.1021/acs. iecr.6b04272

He YR, Zhao DL, Chung TS (2018a) $\mathrm{Na}^{+}$functionalized carbon quantum dot incorporated thinfilm nanocomposite membranes for selenium and arsenic removal. J Membr Sci 564:483-491. https://doi.org/10.1016/j.memsci.2018.07.031

He YZ, Xiang YJ, Zhou YY, Yang Y, Zhang JC, Huang HL, Shang C, Luo L, Gao J, Tang L (2018b) Selenium contamination, consequences and remediation techniques in water and soils: a review. Environ Res 164:288-301. https://doi.org/10.1016/j.envres.2018.02.037

He Y, Liu J, Han G, Chung TS (2018c) Novel thin-film composite nanofiltration membranes consisting of a zwitterionic co-polymer for selenium and arsenic removal. J Membr Sci 555:299-306. https://doi.org/10.1016/j.memsci.2018.03.055

Health Canada (2014) Recommandations pour la qualité de l'eau potable au Canada - Le sélénium (in French). Santé Canada, Ottawa, $\mathrm{N}^{\circ}$ de publication 130476 (www.santecanada.gc.ca), ISBN 978-0-660-21552-5 
Hejna M, Gottardo D, Baldi A, Dell'Orto V, Cheli F, Zaninelli M, Rossi L (2018) Review: nutritional ecology of heavy metals. Animal 12:2156-2170. https://doi.org/10.1017/S175173111700355X

Henderson AD, Demond AH (2007) Long-term performance of zero-valent iron permeable reactive barriers: a critical review. Environ Eng Sci 24:401-423. https://doi.org/10.1089/ees.2006.0071

Hiemstra T, Van Riemsdijk WH (1999) Surface structural ion adsorption modeling of competitive binding of oxyanions by metal(hydr)oxides. J Colloid Interface Sci 210:182-193. https://doi. org/10.1006/jcis.1998.5904

Hingston FJ, Posner AM, Quirk JP (1971) Competitive adsorption of negatively charged ligands on oxide surfaces. Discuss Faraday Soc 52:334-342. https://doi.org/10.1039/DF9715200334

Hockin SL, Gadd GM (2007) Bioremediation of metals and metalloids by precipitation and cellular binding. In: Barton LL, Hamilton WA (eds) Sulphate-reducing bacteria. Environmental and Engineered systems. Cambridge University Press. Chapter 14, pp. 405-434. https://doi. org/10.1017/CBO9780511541490.015

Hu CZ, Chen QX, Chen GX, Liu HJ, Qu JH (2015) Removal of Se(IV) and Se(VI) from drinking water by coagulation. Sep Purif Technol 142:65-70. https://doi.org/10.1016/j. seppur.2014.12.028

Huang JC, Passeport E, Terry N (2012) Development of a constructed wetland water treatment system for selenium removal: use of mesocosms to evaluate design parameters. Environ Sci Technol 46:12021-12029. https://doi.org/10.1021/es301829r

Huang T, Liu L, Zhang S, Xu J (2019) Evaluation of electrokinetics coupled with a reactive barrier of activated carbon loaded with a nanoscale zero-valent iron for selenite removal from contaminated soils. J Hazard Mater 368:104-114. https://doi.org/10.1016/j.jhazmat.2019.01.036

Hunter WJ, Manter DK (2009) Reduction of selenite to elemental red selenium by Pseudomonas sp. strain CA5. Curr Microbiol 58:493-498. https://doi.org/10.1007/s00284-009-9358-2

Ibrahim SAZ, Kerkadi A, Agouni A (2019) Selenium and health: an update on the situation in the Middle East and North Africa. Nutrients 11:1457. https://doi.org/10.3390/nu11071457

Ihnat M (1989) Occurrence and distribution of selenium. CRC Press, Boca Raton

Iida Y, Yamaguchi T, Tanaka T (2011) Experimental and modeling study on diffusion of selenium under variable bentonite content and porewater salinity. J Nuclear Sci Technol 48:1170-1183

INERIS (2011) Sélénium et composés. Fiche de données toxicologiques et environnementales des substances chimiques (in French) - DRC-08-83451-01269B, $\mathrm{n}^{\circ}$ 2.2, Septembre 2011

INRS (2011) Fiche toxicologique - Sélénium et composés, Santé et sécurité au travail (in French), $\mathrm{n}^{\circ} 150$

Ivanenko NV (2018) The role of microorganisms in transformation of selenium in marine waters. Russian J Marine Biol 44:87-93. https://doi.org/10.1134/S1063074018020049

Jadhav RA, Agnihotri R, Gupta H, Fan LS (2000) Mechanism of selenium sorption by activated carbon. Canadian J Chem Eng 78:168-174. https://doi.org/10.1002/cjce.5450780122

Jelas Haron MD, Wan Yunus WMZ, Zakaria MP, Margona MK, Silong S, Tokunaga S (2001) Removal of selenium from aqueous solution using complexes of iron(III)- and copper(II)-chelating resins. Malaysian J Anal Sci 7:457-461

Jeqadeesan G, Mondal K, Lalvani SB (2003) Comparative study of selenite adsorption on carbon based adsorbents and activated alumina. Environ Technol 24:1049-1059

Ji Y, Li L, Wang YT (2019) Selenium removal by activated alumina in batch and continuous-flow reactors. Water Environ Res. https://doi.org/10.1002/wer.1159

Johansson CL, Paul NA, de Nys R, Roberts DA (2015) The complexity of biosorption treatments for oxyanions in a multi-element mine effluent. J Environ Manage 151:386-392. https://doi. org/10.1016/j.jenvman.2014.11.031

Johnson PI, Gersberg RM, Rigby M, Roy S (2009) The fate of selenium in the Imperial and Brawley constructed wetlands in the Imperial Valley (California). Ecol Eng 35:908-913. https://doi.org/10.1016/j.ecoleng.2008.12.020

Jordan N, Ritter A, Scheinost AC, Weiss S, Schild D, Hubner R (2014) Selenium(IV) uptake by maghemite $\left(\gamma-\mathrm{Fe}_{2} \mathrm{O}_{3}\right)$. Environ Sci Technol 48:1665-1674. https://doi.org/10.1021/es4045852 
Kadlec RH, Wallace S (2009) Treatment wetlands. CRC Press, Taylor \& Francis Group, Boca Raton. ISBN 978-1-56670-526-4

Kagami T, Narita T, Kuroda M, Notaguchi E, Yamashita M, Sei K, Soda S, Ike M (2013) Effective selenium volatilization under aerobic conditions and recovery from aqueous phase by Pseudomonas stutzeri NT-I. Water Res 47:1361-1368. https://doi.org/10.1016/j. watres.2012.12.001

Kalaitzidou K, Nikoletopoulos AA, Tsiftsakis N, Pinakidou F, Mitrakas M (2019) Adsorption of $\mathrm{Se}(\mathrm{IV})$ and $\mathrm{Se}(\mathrm{VI})$ species by iron oxy-hydroxides: effect of positive surface charge density. Sci Total Environ 687:1197-1206. https://doi.org/10.1016/j.scitotenv.2019.06.174

Kang Y, Inoue N, Rashid MM, Sakurai K (2002) Fixation of soluble selenium in contaminated soil by amorphous iron (hydr)oxide. Environ Sci 15:173-182

Kapoor A, Tanjore S, Viraraghavan T (1995) Removal of selenium from water and wastewater. Int J Environ Studies 49:137-147. https://doi.org/10.1080/00207239508711016

Karimi L, Ghassemi A (2015) Effects of operating conditions on ion removal from brackish water using a pilot-scale electrodialysis reversal system. Des Water Treatment 57:8657-8669. https:// doi.org/10.1080/19443994.2015.1024748

Karimi L, Abkar L, Aghajani M, Ghassemi A (2015) Technical feasibility comparison of off-grid PV-EDR and PV-RO desalination systems via their energy consumption. Sep Purif Technol 151:82-94. https://doi.org/10.1016/j.seppur.2015.07.023

Kashiwagi Y, Kokufuta E (2000) Selective determination of selenite and selenate in wastewater by graphite furnace AAS after iron(III) hydroxide coprecipitation and reductive coprecipitation on palladium collector using hydrazinium sulfate. Anal Sci 16:1215-1219

Kawamoto D, Yamanishi Y, Ohashi H, Yonezu K, Honma T, Sugiyama T, Kobayashi Y, Okaue Y, Miyazaki A, Yokoyama T (2019) A new and practical Se(IV) removal method for $\mathrm{Fe}^{3+}$ type cation exchange resin? J Hazard Mater 378:120593. https://doi.org/10.1016/j.jhazmat.2019.04.076

Kazeem TS, Labaran BA, Ahmed HUR, Mohammed T, Essa MH, Al-Suwaiyan MS, Vohra MS (2019) Treatment of aqueous selenocyanate anions using electrocoagulation. Int J Electrochem Sci 14:10538-10564. https://doi.org/10.20964/2019.11.51

Khakpour H, Younesi H, Mohammadhosseini M (2014) Two-stage biosorption of selenium from aqueous solution using dried biomass of the baker's yeast Saccharomyces cerevisiae. J Environ Chem Eng 2:532-542. https://doi.org/10.1016/j.jece.2013.10.010

Kharaka YK, Ambats G, Presser TS, Davis RA (1996) Removal of selenium from contaminated agricultural drainage water by nanofiltration membranes. Appl Geochem 11:797-802. https:// doi.org/10.1016/S0883-2927(96)00044-3

Kidgell JT, de Nys R, Hu Y, Paul NA, Roberts DA (2014) Bioremediation of a complex industrial effluent by biosorbents derived from freshwater macroalgae. Plos One 9:e94706. https://doi. org/10.1371/journal.pone.0094706

Kieliszek M (2019) Selenium - Fascinating microelement, properties and sources in food. Molecules 24:1298. https://doi.org/10.3390/molecules24071298

Kieliszek M, Błażejak S, Gientka I, Bzducha-Wróbel A (2015) Accumulation and metabolism of selenium by yeast cells. Appl Microbiol Biotechnol 99:5373-5382. https://doi.org/10.1007/ s00253-015-6650-x

Kim Y, Walker WS, Lawler DF (2012) Competitive separation of di- vs. mono-valent cations in electrodialysis: effects of the boundary layer properties. Water Res 46:2042-2056. https://doi. org/10.1016/j.watres.2012.01.004

Kong D, Wilson LD (2017) Synthesis and characterization of cellulose-goethite composites and their adsorption properties with roxarsone. Carbohydr Polym 169:282-294. https://doi. org/10.1016/j.carbpol.2017.04.019

Koren DW, Gould WD, Lortie L (1992) Selenium removal from waste water. In: water processing recycling in mining and metallurgical industries. CIM, Edmonton, Alberta, pp 171-182

Kosmulski M (2001) Chemical properties of material surfaces. Marcel Dekker, Inc, New York 
Krieg HM, Modise SJ, Keizer K, Neomagus HWJP (2005) Salt rejection in nanofiltration for single and binary salt mixtures in view of sulphate removal. Desalination 171:205-215. https:// doi.org/10.1016/j.desal.2004.05.005

Kryvoruchko A, Yurlova L, Kornilovich B (2002) Purification of water containing heavy metals by chelating-enhanced ultrafiltration. Des 144:243-248. https://doi.org/10.1016/ S0011-9164(02)00319-3

Kuan WH, Lo SL, Wang MK, Lin CF (1998) Removal of Se(IV) and Se(VI) from water by aluminum oxide coated sand. Water Res 32:915-923. https://doi.org/10.1016/ S0043-1354(97)00228-5

Kumar AR, Riyazuddin P (2011) Speciation of selenium in groundwater: seasonal variations and redox transformations. J Hazard Mater 192:263-269. https://doi.org/10.1016/j. jhazmat.2011.05.013

Kumar ASK, Jiang SJ, Warchoł JK (2017) Synthesis and characterization of two-dimensional transition metal dichalcogenide magnetic $\mathrm{MoS}_{2} @ \mathrm{Fe}_{3} \mathrm{O}_{4}$ nanoparticles for adsorption of $\mathrm{Cr}(\mathrm{VI}) /$ Cr(III). ACS Omega 2:6187-6200. https://doi.org/10.1021/acsomega.7b00757

Kumkrong P, LeBlanc KL, Mercier PHJ, Mester Z (2018) Selenium analysis in waters. Part 1: regulations and standard methods. Sci Total Environ 640:1611-1634. https://doi.org/10.1016/j. scitotenv.2018.05.392

Kwon JH, Wilson LD, Sammynaiken RS (2014) Sorptive uptake studies of an arylarsenical with iron oxide composites on an activated carbon support. Dent Mater 7:1880-1898. https://doi. org/10.3390/ma7031880

Kwon JA, Wilson LD, Sammynaiken R (2015) Sorptive uptake of selenium with magnetite and its supported materials onto activated carbon. J Colloid Interface Sci 457:388-397. https://doi. org/10.1016/j.jcis.2015.07.013

Labaran BA, Vohra MS (2014) Photocatalytic removal of selenite and selenate species: effect of EDTA and other process variables. Environ Technol 35:1091-1100. https://doi.org/10.108 0/09593330.2013.861857

Lam B, Déon S, Morin-Crini N, Crini G, Fievet P (2018) Polymer-enhanced ultrafiltration for heavy metal removal: influence of chitosan and carboxymethyl cellulose on filtration performances. J Clean Prod 171:927-933. https://doi.org/10.1016/j.jclepro.2017.10.090

LeBlanc KL, Kumkrong P, Mercier PHJ, Mester Z (2018) Selenium analysis in waters. Part 2: Speciation methods. Sci Total Environ 640:1635-1651. https://doi.org/10.1016/j. scitotenv.2018.05.394

Leckie JO, Benjamin MM, Hayes K, Kaufman G, Altman S (1980) Adsorption/coprecipitation of trace elements from water with iron oxyhydroxide. Technical Report, EPRI RP-910-1, Electric Power Research Institute, Paolo Alto, California

Lee JJ, Woo YC, Kim HS (2015) Effect of driving pressure and recovery rate on the performance of nanofiltration and reverse osmosis membranes for the treatment of the effluent from MBR. Des Water Treat 54:3589-3595. https://doi.org/10.1080/19443994.2014.923196

Lemly AD (2002) Selenium assessment in aquatic ecosystems: a guide for hazard evaluation and water quality criteria. Springer-Verlag, New York. ISBN: 978-1-4612-6549-8

Lemly AD (2004) Aquatic selenium pollution is a global environmental safety issue. Ecotoxicol Environ Saf 59:44-56

Lenz M, Gmerek A, Lens PNL (2006) Selenium speciation in anaerobic granular sludge. Int J Environ Anal Chem 86:615-627. https://doi.org/10.1080/03067310600585902

Li XQ, Zhang WX (2006) Iron nanoparticles: the core-shell structure and unique properties for $\mathrm{Ni}(\mathrm{II})$ sequestration. Langmuir 22:4638-4642. https://doi.org/10.1021/la060057k

Li Z, Li H, Yang X, Zhang H, Liu C, Cao (2013) Characterization of Se(IV) removal from aqueous solution by Aspergillus sp. J2. Chem Eng J 220:67-71. https://doi.org/10.1016/j. cej.2012.11.136

Li Y, Cheng W, Sheng G, Li J, Dong H (2015) Synergetic effect of a pillared bentonite support on $\mathrm{Se}(\mathrm{VI})$ removal by nanoscale zero valent iron. Appl Catal B 174-175:329-335. https://doi. org/10.1016/j.apcatb.2015.03.025 
Liang L, Yang W, Guan X, Li J, Xu Z, Wu J, Huang Y, Zhang X (2013) Kinetics and mechanisms of $\mathrm{pH}$-dependent selenite removal by zero valent iron. Water Res 47:5846-5855. https://doi. org/10.1016/j.watres.2013.07.011

Liang L, Guan X, Shi Z, Li J, Wu Y, Tratnyek PG (2014a) Coupled effects of aging and weak magnetic fields on sequestration of selenite by zero-valent iron. Environ Sci Technol 48:6326-6334. https://doi.org/10.1021/es500958b

Liang L, Sun W, Guan X, Huang Y, Choi W, Bao H, Li J, Jiang Z (2014b) Weak magnetic field significantly enhances selenite removal kinetics by zero valent iron. Water Res 49:371-380. https://doi.org/10.1016/j.watres.2013.10.026

Liang L, Guan X, Huang Y, Ma J, Sun X, Qiao J, Zhou G (2015) Efficient selenate removal by zero-valent iron in the presence of weak magnetic field. Sep Purif Technol 156:1064-1072. https://doi.org/10.1016/j.seppur.2015.09.062

Lide DR (2009) Hanbook of chemistry and physics, 90th edn. Chemical Rubber Company, CRC Press, Boca Raton, 2804p

Lin ZQ, Terry N (2003) Selenium removal by constructed wetlands: quantitative importance of biological volatilization in the treatment of selenium-laden agricultural drainage water. Envrion Sci Technol 37:606-615

Ling L, Pan BC, Zhang WX (2015) Removal of selenium from water with nanoscale zero-valent iron: mechanisms of intraparticle reduction of Se(IV). Water Res 71:274-281. https://doi. org/10.1016/j.watres.2015.01.002

Liu Y, Wang J (2019) Reduction of nitrate by zero valent iron (ZVI)-based materials: a review. Sci Total Environ 671:388-403. https://doi.org/10.1016/j.scitotenv.2019.03.317

Liu A, Liu J, Han J, Zhang WX (2017) Evolution of nanoscale zero-valent iron (nZVI) in water: microscopic and spectroscopic evidence on the formation of nano- and micro-structured iron oxides. J Hazard Mater 322:129-135. https://doi.org/10.1016/j.jhazmat.2015.12.070

Liu F, Huang JC, Zhou CQ, Gao WQ, Xia SF, He SB, Zhou WL (2019) Development of an algal treatment system for selenium removal: Effects of environmental factors and post-treatment processing of Se-laden algae. J Hazard Mater 365:546-554. https://doi.org/10.1016/j. jhazmat.2018.11.017

Lo SL, Chen TZ (1997) Adsorption of Se(IV) and Se(VI) on an iron-coated sand from water. Chemosphere 35:919-930. https://doi.org/10.1016/S0045-6535(97)00190-2

Lundquist TJ, Gerhardt MB, Green FB, Blake Tresan R, Newman RD, Oswald WJ (1994) The algal-bacterial selenium removal system: mechanisms and field study. In: Frankenberger WT, Benson S (eds) Selenium in the environment. Marcel Dekker, Inc., Chapter 11, Basel, pp 251-278

Mal J, Nancharaiah YV, van Hullebusch ED, Lens PNL (2017) Biological removal of selenate and ammonium by activated sludge in a sequencing batch reactor. Bioresour Technol 229:11-19. https://doi.org/10.1016/j.biortech.2016.12.112

Malhotra M, Pal M, Pal P (2020) A response surface optimized nanofiltration-based system for efficient removal of selenium from drinking water. J Water Process Eng 33:101007. https://doi. org/10.1016/j.jwpe.2019.101007

Manceau A, Charlet L (1994) The mechanism of selenate adsorption on goethite and hydrous ferric oxide. J Colloid Interface Sci 168:87-93. https://doi.org/10.1006/jcis.1994.1396

Mandal S, Mayadevi S, Kulkarni BD (2009) Adsorption of aqueous selenite [Se(IV)] species on synthetic layered double hydroxide materials. Ind Eng Chem Res 48:7893-7898

Mandal S, Pu S, Wang X, Ma H, Bai Y (2020) Hierarchical porous structured polysulfide supported nZVI/biochar and efficient immobilization of selenium in the soil. Sci Total Environ 708:134831. https://doi.org/10.1016/j.scitotenv.2019.134831

Mane P, Bhosle A, Jangam C, Vishwakarma C (2011) Bioadsorption of selenium by pretreated algal biomass. Adv Appl Sci Res 2:202-207

Marcus Y (1997) Ion properties. Marcel Dekker, New York

Marinas BJ, Selleck RE (1987) Desalination of agricultural drainage return water. Part II: analysis of the performance of a 13,000 GDP RO unit. Des 61:263-274 
Marinas BJ, Selleck RE (1992) Reverse osmosis treatment of multicomponent electrolyte solutions. J Membr Sci 72:211-229. https://doi.org/10.1016/0376-7388(92)85050-S

Martinez M, Gimenez J, de Pablo J, Rovira M, Duro L (2006) Sorption of selenium(IV) and selenium(VI) onto magnetite. Appl Surf Sci 252:3767-3773. https://doi.org/10.1016/j. apsusc.2005.05.067

Matulova M, Urik M, Bujdos M, Duborska E, Cesnek M, Miglierini MB (2019) Selenite sorption onto goethite: isotherm and ion-competitive studies, and effect of $\mathrm{pH}$ on sorption kinetics. Chem Papers 73:2975-2985. https://doi.org/10.1007/s11696-019-00847-1

Mavrov V, Stamenov S, Todorova E, Chmiel H, Erwe T (2006) New hybrid electrocoagulation membrane process for removing selenium from industrial wastewater. Des 201:290-296. https://doi.org/10.1016/j.desal.2006.06.005

Mayland HF (1994) Selenium in plant and animal nutrition. In: Frankenberger WT, Benson S (eds) Selenium in the environment. Marcel Dekker, Inc., Chapter 2, Basel, pp 29-46

McCloskey J, Twidwell L, Park B, Fallon M (2008) Removal of selenium oxyanions from industrial scrubber waters utilizing elemental iron. Proceeding of the Sixth International Symposium on Hydrometallurgy, pp. 140-148

McGrath SP, Zhao J, Lombi E (2002) Phytoremediation of metals, metalloids, and radionuclides. Adv Agron 75:1-56. https://doi.org/10.1016/S0065-2113(02)75002-5

Mechora S (2019) Selenium as a protective agent against pests: a review. Plan Theory 8:262. https://doi.org/10.3390/plants8080262

Merrill DT, Manzione MA, Parker DS, Petersen JJ, Chow W, Hobbs AO (1986) Field evaluation of arsenic and selenium removal by iron coprecipitation. J Water Poll Control Federation $58: 18-26$

Merrill DT, Manzione MA, Parker DS, Petersen JJ, Chow W, Hobbs AO (1987) Field evaluation of arsenic and selenium removal by iron coprecipitation. Environ Prog Sustain Energy 6:82-90. https://doi.org/10.1002/ep.670060209

Mimoune S, Belazzougui RE, Amrani F (2007) Purification of aqueous solutions of metal ions by ultrafiltration. Desalination 217:251-259. https://doi.org/10.1016/j.desal.2007.01.016

Minzatu V, Davidescu CM, Ciopec M, Negrea P, Duteanu N, Negrea A, Motoc M, Manea A (2019) Eco-materials for arsenium and selenium removal from aqueous solutions. Revista Chimie 70:1586-1591

Mohapatra DP, Kirpalani DM (2019) Selenium in wastewater: fast analysis method development and advanced oxidation treatment applications. Water Sci Technol 79:842-849. https://doi. org/10.2166/wst.2019.010

Molinari R, Gallo S, Argurio P (2004) Metal ions removal from wastewater or washing water from contaminated soil by ultrafiltration-complexation. Water Res 38:593-600. https://doi. org/10.1016/j.watres.2003.10.024

Mollah MYA, Morkovsky P, Gomes JAG, Kesmez M, Parga J, Cocke DI (2004) Fundamentals, present and future perspectives of electrocoagulation. J Hazard Mater 114:199-210. https://doi. org/10.1016/j.jhazmat.2004.08.009

Mondal S, Wickramasinghe SR (2008) Produced water treatment by nanofiltration and reverse osmosis membranes. J Membr Sci 322:162-170. https://doi.org/10.1016/j.memsci.2008.05.039

Moore L, Mahmoudkhani A (2011) Methods for removing selenium from aqueous systems. In: Proceedings tailings and mine waste. Vancouver BC, Canada, pp. 6-9

MSE (2001) Selenium treatment/removal alternatives demonstration project. MSE Technology Applications, Inc., Butte, Montana. Final Report, US EPA

Muecke R, Micke O, Schomburg L, Buentzel J, Kisters K, Adamietz IA (2018) Selenium in radiation oncology-15 years of experiences in Germany. Nutrients 10:483. https://doi.org/10.3390/ nu10040483

Murphy AP (1988) Removal of selenate from water by chemical reduction. Ind Eng Chem Res 27:187-191. https://doi.org/10.1021/ie00073a033

Nettem K, Almusallam AS (2013) Equilibrium, kinetic, and thermodynamic studies on the biosorption of selenium(IV) ions onto Ganoderma lucidum biomass. Sep Sci Technol 48:2293-2301 
Nightingale ER (1959) Phenomenological theory of ion solvation. Effective radii of hydrated ions. J Phys Chem 63:1381-1387. https://doi.org/10.1021/j150579a011

OEHHA (2010) Office of Environmental Health Hazard Assessment. Public health goals for chemicals in drinking-water, Selenium

Olegario JT, Yee N, Miller M (2010) Reduction of Se(VI) to Se(-II) by zerovalent iron nanoparticle suspensions. J Nanopart Res 12:2057-2068. https://doi.org/10.1007/s11051-009-9764-1

OMS (2011) Selenium in drinking-water. WHO/HSE/WSH/10.01/14. Geneva, Switzerland

Onorato C, Banasiak LJ, Schäfer AI (2017) Inorganic trace contaminant removal from real brackish groundwater using electrodialysis. Sep Purif Technol 187:426-435. https://doi.org/10.1016/j. seppur.2017.06.016

Owusu-Agyeman I, Jeihanipour A, Luxbacher T, Schäfer AI (2017) Implications of humic acid, inorganic carbon and speciation on fluoride retention mechanisms in nanofiltration and reverse osmosis. J Membr Sci 528:82-94. https://doi.org/10.1016/j.memsci.2016.12.043

Pal R, Rai J (2010) The phytoextraction potential of water hyacinth (Eichchornia crassipes): removal of selenium and copper. Chem Ecol 26:163-172

Parker DR, Page AL (1994) Vegetation management strategies for remediation of seleniumcontaminated soils. In: Frankenberger WT, Benson S (eds) Selenium in the environment. Marcel Dekker, Inc., Chapter 13, Basel, pp 327-342

Patel SK, Biesheuvel PM, Elimelech M (2021) Energy consumption of brackish water desalination: identifying the sweet spots for electrodialysis and reverse osmosis. ACS ES\&T Engineering. https://doi.org/10.1021/acsestengg.0c00192

Paul T, Saha NC (2019) Environmental arsenic and selenium contamination and approaches towards its bioremediation through the exploration of microbial adaptations: a review. Pedosphere 29:554-568. https://doi.org/10.1016/S1002-0160(19)60829-5

Peak D, Sparks DL (2002) Mechanisms of selenate adsorption on iron oxides and hydroxides. Environ Sci Technol 36:1460-1466. https://doi.org/10.1021/es0156643

Petr M, Šišková K, Machala L, Kašlík J, Šafářová K, Zbořil R (2012) Laser-induced transformations of zero-valent iron particles. AIP Conference Proceedings 47-5. doi:https://doi. org/10.1063/1.4759473

Pettine M, McDonald TJ, Sohn M, Anquandah GAK, Zboril R, Sharma VK (2015) A critical review of selenium analysis in natural water samples. Trends Environ Anal Chem 5:1-7. https://doi.org/10.1016/j.teac.2015.01.001

Phillips DH, Gu B, Watson DB, Roh Y (2003) Impact of sample preparation on mineralogical analysis of zero-valent iron reactive barrier materials. J Environ Qual 32:1299-1305

Pilon-Smits EAH, LeDuc DL (2009) Phytoremediation of selenium using transgenic plants. Curr Opin Biotechnol 20:207-212. https://doi.org/10.1016/j.copbio.2009.02.001

Plant JA, Kinniburgh DG, Smedely PL, Fordyce FM, Klinck B (2003) Arsenic and selenium. Elsevier Ltd 9:17-66. https://doi.org/10.1016/B0-08-043751-6/09047-2

Plotnikov VI (1960) Coprecipitation of selenium and tellurium with metal hydroxides. Russian J Inorg Chem 5:3451-3354

Pontié M, Dach H, Leparc J, Hafsi M, Lhassani A (2008) Novel approach combining physicochemical characterizations and mass transfer modelling of nanofiltration and low pressure reverse osmosis membranes for brackish water desalination intensification. Desalination 221:174-191. https://doi.org/10.1016/j.desal.2007.01.075

Preedy VR (2015) Selenium. Chemistry, analysis, function and effects. Royal Society of Chemistry. ISBN 978-1-84973-891-0

Ramola S, Mishra T, Rana G, Srivastava RK (2014) Characterization and pollutant removal efficiency of biochar derived from bagasse, bamboo and tyre. Environ Monit Assess 186:9023-9039. https://doi.org/10.1007/s10661-014-4062-5

Reilly C (2002) Metal contamination of food. Its Significance for food quality and human health. Blackwell Science, third edition. ISBN 0-632-05927-3

Reilly C (2006) Selenium in food and Health. Springer, second edition. ISBN 0-387-33243-X 
Reinsch BC, Forsberg B, Penn RL, Kim CS, Lowry GV (2010) Chemical transformations during aging of zerovalent iron nanoparticles in the presence of common groundwater dissolved constituents. Environ Sci Technol 44:3455-3461. https://doi.org/10.1021/es902924h

Rene ER, Shu L, Jegatheesan V (2019) Environmentally friendly (bio)technologies for the removal of emerging organic and inorganic pollutants from water. IWA Publishing, London. ISBN 9781789061017

Richards LA, Richards BS, Rossiter HMA, Schäfer AI (2009) Impact of speciation on fluoride, arsenic and magnesium retention by nanofiltration/reverse osmosis in remote Australian communities. Desalination 248:177-183. https://doi.org/10.1016/j.desal.2008.05.054

Richards LA, Richards BS, Schäfer AI (2011) Renewable energy powered membrane technology: salt and inorganic contaminant removal by nanofiltration/reverse osmosis. J Membr Sci 369:188-195. https://doi.org/10.1016/j.memsci.2010.11.069

Rietra RPJJ, Hiemstra T, Van Riemsdijk WH (2001) Comparison of selenate and sulfate adsorption on goethite. J Colloid Interface Sci 240:384-390. https://doi.org/10.1006/jcis.2001.7650

Rittmann BE (2007) The membrane biofilm reactor is a versatile platform for water and wastewater treatment. Environ Eng Res 12:8-11

Rivas BL, Pereira ED, Moreno-Villoslada I (2003) Water-soluble polymer-metal ion interactions. Prog Polym Sci 28:173-208

Roberson MJ (1999) Removal of selenate from irrigation drainage water using zero-valent iron. $\mathrm{Ph} . \mathrm{D}$. thesis. University of California, Riverside

Roberts DA, Paul NA, Dworjanyn SA, Hu Y, Bird MI, de Nys R (2015) Gracilaria waste biomass (sampah rumput laut) as a bioresource for selenium biosorption. J Appl Phycology 27:611-620. https://doi.org/10.1007/s10811-014-0346-y

Rosenfeld I, Beath OA (1964) Selenium: geobotany, biochemistry, toxicity and nutrition. Academic Press Inc., New York, 411p

Rovira M, Giménez J, Martínez M, Martínez-Lladó X, Pablo J, Martí V, Duro L (2008) Sorption of selenium(IV) and selenium(VI) onto natural iron oxides: goethite and hematite. J Hazard Mater 150:279-284. https://doi.org/10.1016/j.jhazmat.2007.04.098

Rumeau M, Persin F, Sciers V, Persin M, Sarrazin J (1992) Separation by coupling ultrafiltration and complexation of metallic species with industrial water soluble polymers. Application for removal or concentration of metallic cations. J Membr Sci 73:313-322

Sandy T, DiSante C (2010) Review of available technologies for the removal of selenium from water. CH2M Hill: Englewood CO. Final report prepared for the North American Metals Council, USA. Technical Report 2010:2-223

Santos S, Ungureanu G, Boaventura R, Botelho C (2015) Selenium contaminated waters: an overview of analytical methods, treatment options and recent advances in sorption methods. Sci Total Environ 521-522:246-260. https://doi.org/10.1016/j.scitotenv.2015.03.107

Sayehmiri K, Azami M, Mohammadi Y, Soleymani A, Tardeh Z (2018) The association between selenium and prostate cancer: a systematic review and meta-analysis. Asian Pac J Cancer Prev 19:1431-1437

Shamas J, Wagner C, Cooke T (2009) Technologies and strategies for the treatment of selenium as a microconstituent in industrial wastewater. WEF Microconstituents and industrial water quality specialty conference, Baltimore

Shao LX, Yi YM, Lu JM, Jiang XF (2019) Recent progress in selenium-catalyzed organic reactions. Org Chem Frontiers 6:2999-3041. https://doi.org/10.1039/c9qo00620f

Shardendu SN, Boulyga SF, Stengel E (2003) Phytoremediation of selenium by two helophyte species in subsurface flow constructed wetland. Chemosphere 50:967-973. https://doi. org/10.1016/S0045-6535(02)00607-0

Sharma VK, McDonald TJ, Sohn M, Anquandah GAK, Pettine M, Zboril R (2015) Biogeochemistry of selenium. A review. Environ Chem Lett 13:49-58. https://doi.org/10.1007/ s10311-014-0487-x

Sharma VK, Sohn M, McDonald TJ (2019) Remediation of selenium in water. A review. In: Ahuja $\mathrm{S}$ (ed) Advances in water purification techniques. Elsevier. Chapter 8, Amsterdam, pp 203-218 
Sharrad MOM, Liu HJ, Fan MH (2012) Evaluation of FeOOH performance on selenium reduction. Sep Purif Technol 84:29-34. https://doi.org/10.1016/j.seppur.2011.07.011

Shi KL, Wang XF, Guo ZJ, Wang SG, Wu WS (2009) Se(IV) sorption on $\mathrm{TiO}_{2}$ : Sorption kinetics and surface complexation modeling. Colloids Surf A Physicochem Eng Aspects 349:90-95. https://doi.org/10.1016/j.colsurfa.2009.07.057

Shrift A (1964) A selenium cycle in nature. Nature 201:1304-1305

Shrimpton HK, Blowes DW, Ptacek CJ (2015) Fractionation of selenium during selenite reduction by granular zerovalent iron. Environ Sci Technol 49:11688-11696. https://doi.org/10.1021/ acs.est. 5 b01074

Simeonidis K, Mourdikoudis S, Kaprara E, Mitrakas M, Polavarapu L (2016) Inorganic engineered nanoparticles in drinking water treatment: a critical review. Environ Sci Water Res Technol 2:43-70. https://doi.org/10.1039/c5ew00152h

Simonoff M, Simonoff G (1991) Le sélénium et la vie. Masson, Paris, 280p

Sinharoy A, Saikia S, Pakshirajan (2019) Biological removal of selenite rom wastewater and recovery as selenium nanoparticles using inverse fluidized bed reactor. J Water Process Eng 32:100988. https://doi.org/10.1016/j.jwpe.2019.100988

Sorg TJ, Logsdon GS (1978) Treatment technology to meet the interim primary drinking water regulations for inorganics. Part 2. J Am Water Works Ass 70:379-393. https://doi. org/10.1002/j.1551-8833.1978.tb04198.x

Sosa-Fernandez PA, Post JW, Leermakers FAM, Rijnaarts HHM, Bruning H (2019) Removal of divalent ions from viscous polymer-flooding produced water and seawater via electrodialysis. J Membr Sci 589:117251. https://doi.org/10.1016/j.memsci.2019.117251

Sposito G (1984) The surface chemistry of soils. Oxford University Press, New York, p 234p. ISBN: 9780195034219

Staicu LC, van Hullebusch ED, Oturan MA, Ackerson CJ, Lens PNL (2015a) Removal of colloidal biogenic selenium from wastewater. Chemosphere 125:130-138. https://doi.org/10.1016/j. chemosphere.2014.12.018

Staicu LC, van Hullebusch ED, Lens PNL (2015b) Production, recovery and reuse of biogenic elemental selenium. Environ Chem Lett 13:89-96. https://doi.org/10.1007/s10311-015-0492-8

Staicu LC, van Hullebusch ED, Lens PNL, Pilon-Smits EAH, Oturan MA (2015c) Electrocoagulation of colloidal biogenic selenium. Environ Sci Pollut Res Int 22:3127-3137. https://doi.org/10.1007/s11356-014-3592-2

Staicu LC, Morin-Crini N, Crini G (2017) Desulfurization: critical step towards enhanced selenium removal from industrial effluents. Chemosphere 172:111-119. https://doi.org/10.1016/j. chemosphere.2016.12.132

Stefaniak J, Dutta A, Verbinnen B, Shakya M, Rene ER (2018) Selenium removal from mining and process wastewater: a systematic review of available technologies. J Wat Supply Res Technol AQUA 67:903-918. https://doi.org/10.2166/aqua.2018.109

Strathmann H (2004) Ion-exchange membrane separation processes, vol 9. 360p. e-ISBN 9780080509402. https://www.elsevier.com/books/ion-exchange-membrane-separationprocesses/strathmann/978-0-444-50236-0

Stumm W, Huang CP, Jenkins SR (1970) Specific chemical interaction affecting the stability of dispersed systems. Croatica Chem Acta 42:223-245

Su C, Suarez DL (2000) Selenate and selenite sorption on iron oxides: an infrared and electrophoretic study. Soil Sci Soc Am 64:101-111

Su TZ, Guan XH, Gu GW, Wang JM (2008) Adsorption characteristics of As(V), Se(IV), and V(V) onto activated alumina: effects of $\mathrm{pH}$, surface loading, and ionic strength. J Colloid Interface Sci 326:347-353

Su TZ, Guan XH, Tang YL, Gu GW, Wang JM (2010) Predicting competitive adsorption behavior of major toxic anionic elements onto activated alumina: a speciation-based approach. J Hazard Mater 176:466-472. https://doi.org/10.1016/j.jhazmat.2009.11.052

Surai PF, Taylor-Pickard JA (2008) Current advances in selenium research and applications, vol 1. Wageningen Academic Publishers. ISBN: 978-90-8686-073-9 
Suzuki TM, Tanaka DAP, Tanco MAL, Kanesato M, Yokoyama T (2000) Adsorption and removal of oxyanions of arsenic and selenium on the zirconium(IV) loaded polymer resin functionalized with diethylenetriamine N,N,N',N'-polyacetic acid. J Environ Monit 2:550-555. https:// doi.org/10.1039/B006738P

Svecova L, Dosso M, Cremel S, Simonnot MO, Sardin M, Humbert B, Den Auwer C, Michot LJ (2011) Sorption of selenium oxyanions on $\mathrm{TiO}_{2}$ (rutile) studied by batch or column experiments and spectroscopic methods. J Hazard Mater 189:764-772. https://doi.org/10.1016/j. jhazmat.2011.02.090

Szymczyk A, Fievet P (2005) Investigating transport properties of nanofiltration membranes by means of a steric, electric and dielectric exclusion model. J Membr Sci 252:77-88

Tabelin CB, Igarashi T, Villacorte-Tabelin M, Park I, Opiso EM, Ito M, Hiroyoshi N (2018) Arsenic, selenium, boron, lead, cadmium, copper, and zinc in naturally contaminated rocks: a review of their sources, modes of enrichment, mechanisms of release, and mitigation strategies. Sci Total Environ 645:1522-1553. https://doi.org/10.1016/j.scitotenv.2018.07.103

Tan LC, Nancharaiah YV, van Hullebusch ED, Lens PNL (2016) Selenium: environmental significance, pollution, and biological treatment technologies. Biotechnol Adv 34:886-907. https:// doi.org/10.1016/j.biotechadv.2016.05.005

Tan LC, Papirio S, Luongo V, Nancharaiah YV, Cennamo P, Esposito G, van Hullebusch ED, Lens PNL (2018) Comparative performance of anaerobic attached biofilm and granular sludge reactors for the treatment of model mine drainage wastewater containing selenate, sulfate and nickel. Chem Eng J 345:545-555. https://doi.org/10.1016/j.cej.2018.03.177

Tan GC, Mao Y, Wang HY, Junaid M, Xu N (2019a) Comparison of biochar- and activated carbonsupported zero-valent iron for the removal of $\mathrm{Se}(\mathrm{IV})$ and $\mathrm{Se}(\mathrm{VI})$ : influence of $\mathrm{pH}$, ionic strength, and natural organic matter. Environ Sci Pollut Res 26:21609-21618. https://doi.org/10.1007/ s11356-019-05497-0

Tan HW, Mo HY, Lau ATY, Xu YM (2019b) Selenium species: current status and potentials in cancer prevention and therapy. Int J Mol Sci 20:75. https://doi.org/10.3390/ijms20010075

Tanaka H, Nakayama N, Chikuma M, Tanaka T, Ittoh K, Sakurei H (1983) Selective collection of selenium(IV) from environmental water by functionalized ion exchange resin. In: Pawlowski L, Verdier AJ, Lacy WJ (eds) Chemistry for the protection of the environment, vol 23. Elsevier, New York, pp 365-372

Tanaka M, Takahashi Y, Yamaguchi N, Kim KW, Zheng G, Sakamitsu M (2013) The difference of diffusion coefficients in water for arsenic compounds at various $\mathrm{pH}$ and its dominant factors implied by molecular simulations. Geochim Cosmochim Acta 105:360-371. https://doi. org/10.1016/j.gca.2012.12.004

Tang C, Huang YH, Zeng H, Zhang Z (2014a) Reductive removal of selenate by zero-valent iron: the roles of aqueous $\mathrm{Fe}^{2+}$ and corrosion products, and selenate removal mechanism. Water Res 67:166-174. https://doi.org/10.1016/j.watres.2014.09.016

Tang C, Huang YH, Zeng H, Zhang Z (2014b) Promotion effect of $\mathrm{Mn}^{2+}$ and $\mathrm{Co}^{2+}$ on selenate reduction by zero-valent iron. Chem Eng J 244:97-104. https://doi.org/10.1016/j.cej.2014.01.059

Tarutani N, Tokudome Y, Fukui M, Nakanishi K, Takahashi M (2015) Fabrication of hierarchically porous monolithic layered double hydroxide composites with tunable microcages for effective oxyanion adsorption. RSC Adv 5:57187. https://doi.org/10.1039/c5ra05942a

Terry N (2016) Phytoremediation of selenium-contaminated soil and water. In: Banuelos GS, Lin ZQ, MF DM, LRG G, AR DR (eds) Global advances in selenium research from theory to application. 4th international conference on selenium in the environment and human health, Sao Paulo, October 18-21, 2015, pp 197-198

Tuzen M, Sari A (2010) Biosorption of selenium from aqueous solution by green algae (Cladophora hutchinsiae) biomass: equilibrium, thermodynamic and kinetic studies. Chem Eng J 158:200-206. https://doi.org/10.1016/j.cej.2009.12.041

Twidwell L, McCloskey J, Miranda P, Gale M (1999) Technologies and potential technologies for removing selenium from process and mine wastewater. In: Proceedings of the recycling, waste, treatment and clean technology (REWAS). San Sebastian, Spain (5-9 September 1999), pp. $1645-1656$ 
Twidwell L, McCloskey J, Joyce H, Dahlgren E, Hadden A (2005) Removal of selenium oxyanions from mine waters utilizing elemental iron and galvanically coupled metals. In: Proceedings of the Jan D. Mill symposium. Innovations in natural resource. Salt Lake City, UT, USA (28 February - 2 March 2005), pp. 299-313

Ullah H, Liu G, Yousaf B, Ali MU, Abbas Q, Munir MAM, Mian MM (2018) Developmental selenium exposure and health risk in daily foodstuffs: a systematic review and meta-analysis. Ecotoxicol Environ Saf 149:291-306. https://doi.org/10.1016/j.ecoenv.2017.11.056

Ullah H, Liu GJ, Yousaf B, Ali MU, Irshad S, Abbas Q, Ahmad R (2019) A comprehensive review on environmental transformation of selenium: recent advances and research perspectives. Environ Geochem Health 41:1003-1035. https://doi.org/10.1007/s10653-018-0195-8

USEPA (2004) Draft aquatic life water quality criteria for selenium - 2004. Office of Science and Technology, Office of Water. U.S. EPA-822-D-04-001

USEPA (2016) Aquatic life ambient water quality criterion for selenium - Freshwater 2016. Office of Science and Technology, Office of Water. U.S. EPA-822-R-16-006

van Hullebusch ED (2017) Bioremediation of selenium contaminated wastewater. Cham, Springer, Switzerland. ISBN 978-3-319-57830-9

Varlamova EG, Maltseva VN (2019) Uniqueness of the microelement selenium and its key functions. Biophysics 4:646-660. https://doi.org/10.1134/S0006302919040021

Verbinnen B, Block C, Lievens P, van Brecht A, Vandecasteele C (2013) Simultaneous removal of molybdenum, antimony and selenium oxyanions from wastewater by adsorption on supported magnetite. Waste Biomass Valorization 4:635-645. https://doi.org/10.1007/s12649-013-9200-8

Verliefde ARD, Van der Meeren P, Van der Bruggen B (2013) Solution-dffusion processes. In: Tarabara VV, Hoek EMV (eds) Encyclopedia of membrane science and technology. Wiley and Sons, Hoboken/New York, pp 1-26

Vilaginès R (2010) Eau, environnement et santé publique. Introduction à l'hydrologie, Lavoisier

Vinceti M, Filippini T, Cilloni S, Bargellini A, Vergoni AV, Tsatsakis A, Ferrante M (2017) Health risk assessment of environmental selenium: emerging evidence and challenges (review). Mol Med Rep 15:3323-3335

Vinceti M, Filippini T, Del Giovane C, Dennert G, Zwahlen M, Brinkman M, Zeegers MPA, Horneber M, D'Amico R, Crespi CM (2018a) Selenium for preventing cancer. Cochrane Database Syst Rev 1:CD005195. https://doi.org/10.1002/14651858.CD005195.pub4

Vinceti M, Filippini T, Wise LA (2018b) Environmental selenium and human health: an update. Current Environ Health Rep 5:464-485. https://doi.org/10.1007/s40572-018-0213-0

Vlaev LT, Genieva SD (2004) Electron transport properties of ions in aqueous solutions of sodium selenite. J Structural Chem 45:825-831. https://doi.org/10.1007/s10947-005-0064-z

Vriens B, Lenz M, Charlet L, Berg M, Winkel LHE (2014) Natural wetland emissions of methylated trace elements. Nat Commun 5:3035

Walkowiak W, Kozlowski CA (2009) Macrocycle carriers for separation of metal ions in liquid membrane processes - a review. Desalination 240:186-197. https://doi.org/10.1016/j. desal.2007.12.041

Wallace PS (2013a) System for rinsing electrodialysis electrodes. US patent 20140042029A1

Wallace PS (2013b) System for removing selenium from a feed stream. US patent 9259703B2

Wang H, Wu T, Chen J, Zheng Q, He C, Zhao Y (2015) Sorption of Se(IV) on Fe- and Al-modified bentonite. J Radioanal Nucl Chem 303:107-113. https://doi.org/10.1007/s10967-014-3422-5

Wen HJ, Carignan J (2007) Reviews on atmospheric selenium: emissions, speciation and fate. Atmos Environ 41:7151-7165. https://doi.org/10.1016/j.atmosenv.2007.07.035

White AF, Dubrovsky NM (1994) Chemical oxidation-reduction controls on selenium mobility in groundwater systems. In: Frankenberger WT, Benson S (eds) Selenium in the environment. Marcel Dekker, Inc., Chapter 8, Basel, pp 185-222

WHO (2017) Guidelines for drinking-water quality. www.who.int

Wijnja H, Schulthess CP (2000) Vibrational spectroscopy study of selenate and sulfate adsorption mechanisms on Fe and Al (Hydr)oxide surfaces. J Colloid Interface Sci 229:286-297. https:// doi.org/10.1006/jcis.2000.6960 
Witek A, Koltuniewicz A (2005) A micellar-enhanced ultrafiltration for simultaneous removal of $\mathrm{Cu}^{2+}$ and phenols. W Membrane News 69:30-33

Woollins JD, Laitinen RS (2011) Selenium and tellurium chemistry: from small molecules to biomolecules and materials. Springer-Verlag, Berlin. ISBN 978-3-642-20698-6

Wu L (2004) Review of 15 years of research on ecotoxicology and remediation of land contaminated by agricultural drainage sediment rich in selenium. Ecotoxicol Environ Saf 57:257-269. https://doi.org/10.1016/S0147-651(03)00064-2

Wu D, Sun SP (2016) Speciation analysis of As, Sb and Se. Trends Environ Anal Chem 11:9-22. https://doi.org/10.1016/j.teac.2016.05.001

Wu Z, Bañuelos GS, Lin ZQ, Liu Y, Yuan L, Yin X, Li M (2015) Biofortification and phytoremediation of selenium in China. Front Plant Sci 6:136. https://doi.org/10.3389/fpls.2015.00136

Yamani JS, Lounsbury AW, Zimmerman JB (2014) Adsorption of selenite and selenate by nanocrystalline aluminum oxide, neat and impregnated in chitosan beads. Water Res 50:373-381. https://doi.org/10.1016/j.watres.2013.10.054

Yaroshchuk AE (2000) Dielectric exclusion of ions from membranes. Adv Colloid Interface Sci 85:193-230

Yee N, Ma J, Dalia A, Boonfueng T, Kobayashi DY (2007) Se(VI) reduction and precipitation of $\mathrm{Se}(0)$ by the facultative bacterium Enterobacter cloacae SLD1a-1 are regulated by FNR. Appl Environ Microbiol 73:1914-1920. https://doi.org/10.1128/AEM.02542-06

Yoon IH, Kim KW, Bang S, Kim MG (2011) Reduction and adsorption mechanisms of selenite by zero-valent iron and related corrosion. Appl Catal B 104:185-192. https://doi.org/10.1016/j. apcatb.2011.02.014

Yoon IH, Bang S, Kim KW, Kim MG, Park SY, Choi WK (2016) Selenate removal by zero-valent iron in oxic condition: the role of $\mathrm{Fe}(\mathrm{II})$ and selenate removal mechanism. Environ Sci Pollut Res 23:1081-1090. https://doi.org/10.1007/s11356-015-4578-4

Yuan-Hui L, Gregory S (1974) Diffusion of ions in sea water and in deep-sea sediments. Geochim Cosmochim Acta 38:703-714. https://doi.org/10.1016/0016-7037(74)90145-8

Zeng TT, Rene ER, Zhang SQ, Lens PNL (2019) Removal of selenate and cadmium by anaerobic granular sludge: EPS characterization and microbial community analysis. Proc Safety Environ Protection 126:150-159. https://doi.org/10.1016/j.psep.2019.03.039

Zhang P, Sparks DL (1990) Kinetics of selenate and selenite adsorption/desorption at the goethite/ water interface. Environ Sci Technol 24:1848-1856. https://doi.org/10.1021/es00082a010

Zhang Y, Wang J, Amrhein C, Frankenberger WT Jr (2005) Removal of selenate from water by zerovalent iron. J Environ Qual 34:487-495

Zhang N, Lin LS, Gang DC (2008) Adsorptive selenite removal from water using iron-coated GAC adsorbents. Water Res 42:3809-3816. https://doi.org/10.1016/j.watres.2008.07.025

Zhang L, Liu N, Yang L, Lin Q (2009) Sorption behavior of nano- $\mathrm{TiO}_{2}$ for the removal of selenium ions from aqueous solution. J Hazard Mater 170:1197-1203. https://doi.org/10.1016/j. jhazmat.2009.05.098

Zhang YY, Kuroda M, Arai S, Kato F, Inoue D, Ike M (2019a) Biological removal of selenate in saline wastewater by activated sludge under alternating anoxic/oxic conditions. Front Environ Sci Eng 13:68. https://doi.org/10.1007/s11783-019-1154-z

Zhang X, Li XY, Zhang F, Peng SH, Tumrani SH, Ji XD (2019b) Adsorption of Se(IV) in aqueous solution by zeolites synthesized from fly ashes with different compositions. J Water Reuse Des 9:506-519. https://doi.org/10.2166/wrd.2019.036

Zhu YG, Pilon-Smits EAH, Zhao FJ, Williams PN, Meharg AA (2009) Selenium in higher plants: understanding mechanisms for biofortification and phytoremediation. Trends Plant Sci 14:436-442. https://doi.org/10.1016/j.tplants.2009.06.006

Zhu MH, Niu GD, Tang J (2019) Elemental Se: fundamentals and its optoelectronic applications. J Mater Chem C 7:2199-2206. https://doi.org/10.1039/c8tc05873c

Zingaro RA, Dufner DC, Murphy AP, Moody CD (1997) Reduction of oxoselenium anions by iron (II) hydroxide. Environ Int 23:299-304. https://doi.org/10.1016/S0160-4120(97)00032-9 